\title{
1 Mitotic R-loops direct Aurora B kinase to maintain 2 centromeric cohesion
}

3 Erin C. Moran ${ }^{1}$, Limin Liu $^{1}$, Ewelina Zasadzinska ${ }^{1}$, Courtney A. Kestner ${ }^{1}$, Ali Sarkeshik ${ }^{2}$, Henry

4 DeHoyos ${ }^{1}$, John R. Yates III ${ }^{2}$, Daniel Foltz ${ }^{3}$, P. Todd Stukenberg ${ }^{1, *}$

$6{ }^{1}$ Department of Biochemistry and Molecular Genetics, University of Virginia, School of Medicine, 7 Charlottesville VA 22903

$8 \quad{ }^{2}$ Department of Molecular Medicine, The Scripps Research Institute, La Jolla CA 92037

9 'Department of Biochemistry and Molecular Genetics, Feinberg School of Medicine, 10 Northwestern University, Chicago IL 60611

$11 *$ Corresponding Author

\section{Abstract}

15 Recent work has shown that R-loops exist at mitotic centromeres, but the function of these R-loops 16 is not well understood. Here, we report that mitotic R-loops arise in distinct locations from those 17 formed during interphase. They accumulate on chromosome arms in prophase, where they are

18 quickly resolved and continue to be produced at repetitive sequences including centromeres during 19 a mitotic stall. Aurora B kinase activity is required to resolve R-loops during prophase and R-loops 20 promote the localization of the Chromosome Passenger Complex (CPC) to the inner centromere. 21 CPC purified from mitotic chromosomes interacts with thirty-two proteins involved with R-loop 22 biology. One of these, the RNA regulator RBMX, controls Aurora B localization and activity in 23 vivo. Perturbations in R-loop homeostasis or RBMX cause defects in the maintenance of 24 centromeric cohesion due to the mislocalization of the CPC. We conclude that R-loops are 25 generated by mitotic processes in repetitive DNA sequences, they play important roles in mitotic 26 fidelity, and we have identified a set of mitotic R-loop regulators including the CPC and RBMX 27 that will enable future studies of mitotic R-loops. 


\section{Introduction}

Mitosis is characterized by a reorganization of chromatin structure as most transcription is silenced and terminated (Gottesfeld and Forbes, 1997; Jiang et al., 2004; Taylor, 1960), the higher order structure of chromatin such as topologically associating domains (TADs) are removed (Naumova et al., 2013), and chromatin is condensed. R-loops are three stranded structures in which a strand of RNA is annealed to a denatured double-stranded DNA. R-loops have distinct roles in interphase cells such as transcriptional initiation and termination (Ginno et al., 2012, 2013; Skourti-Stathaki et al., 2014), chromatin compaction (Castellano-Pozo et al., 2013a; Nakama et al., 2012), and both as a source of DNA damage (Bhatia et al., 2014; Costantino and Koshland, 2018; Gan et al., 2011; Wahba et al., 2011) and DNA damage repair (Ohle et al., 2016; Yasuhara et al., 2018). In mitotically arrested cells, R-loops localize to centromeres, are associated with a centromeric DNA damage response (Kabeche et al., 2018) and form the basis of centromeric chromatin loops in maize cells (Liu et al., 2020). However, the function of R-loops at the centromere is poorly understood, and there are major unanswered questions including: whether Rloops arise during an unperturbed mitosis, if they arise only in centromeric sequences, if R-loops are resolved as mitosis progresses, and what is the consequence of not generating mitotic R-loops to mitotic cells.

Aurora B kinase-dependent H3S10 phosphorylation increases in S. cerevisiae strains that accumulate R-loops (Castellano-Pozo et al., 2013a), however it is not clear if Aurora kinases play an active role in regulation of R-loops. It was recently reported that mitotic R-loops are required to activate Aurora B kinase, a major regulator of mitotic events, and this signal is downstream of ATR and CHK1 signaling in the DNA damage response (Kabeche et al., 2018). Aurora B kinase is directly phosphorylated by CHK1 to regulate kinase activity (Petsalaki et al., 2011). Aurora B kinase regulates multiple important steps in mitosis, such as the spindle assembly checkpoint (Biggins and Murray, 2001; Hauf et al., 2003; Kallio et al., 2002; Sacristan and Kops, 2015;

59 Santaguida et al., 2011; Stukenberg and Burke, 2015), sister chromatid cohesion (Dai et al., 2006;

60 Resnick et al., 2006; Tanno et al., 2010), and kinetochore-microtubule attachment regulation

61 (Cimini et al., 2006; Knowlton et al., 2006; Liu et al., 2009; Meppelink et al., 2015; Salimian et 
al., 2011; Welburn et al., 2010). Aurora B kinase associates with three other proteins to form the

63 Chromosome Passenger Complex (CPC). The CPC has a very dynamic localization during

64 prophase; it is initially localized throughout condensing chromosomes, transitions to the axis

65 between sister chromatids, then to the inner centromere (Carmena et al., 2012; Hindriksen et al.,

66 2017; Hirota et al., 2005; Jeyaprakash et al., 2007; Klein et al., 2006; Nozawa et al., 2010). One

67 function of Aurora B on chromosome arms is to remove most interphase cohesin, which is likely

68 the pool at the base of TADs (Losada et al., 2005; Naumova et al., 2013). Paradoxically, sister

69 chromatid cohesion is maintained at inner centromeres, where Aurora B is highest during late

70 prophase until anaphase onset. This is due to a Sgo1-dependent mechanism, whereby Sgo1 recruits

71 the B56-PP2A phosphatase complex in order to maintain cohesion (Kang et al., 2011; Kitajima et

72 al., 2006; Meppelink et al., 2015; Tang et al., 2006). Centromeric CPC is required to maintain

73 sister chromatid cohesion at the centromere(Dai et al., 2006; Resnick et al., 2006), but the

74 mechanism of this activity is less clear.

There is growing evidence that transcripts are made from centromeres in multiple species, but the functions of these transcripts are poorly understood. The human centromere is made up of alpha satellite DNA, forming $\underline{\text { Higher }}$ Order Repeat (HOR) structures (Willard, 1985). HORs are flanked by pericentric heterochromatin, which is formed by alpha satellite monomers and other satellite sequences such as beta and gamma satellites, as well as Human Satellite I and II sequences. The alpha satellite HOR sequences are transcribed in G2/M cells (Hall et al., 2014; Ideue et al., 2014; Liu et al., 2015). Active RNA Polymerase II has been detected at human centromeres in multiple circumstances (Chan et al., 2012; Liu et al., 2015; McNulty et al., 2017); this transcription is well conserved across species. These RNAs are known to be spliced in some organisms (Grenfell et al., 2016; Liu et al., 2020), and in Xenopus laevis these spliced transcripts are known to interact with the CPC, which is required to localize the CPC (Blower, 2016; Grenfell et al., 2016; Jambhekar et al., 2014). Recent efforts to identify RNAs associated with chromatin has also shown that RNA made from human centromeres associate with the chromatin in cis (McNulty et al., 2017) and have long half-lives (Hall et al., 2014; McNulty et al., 2017) suggesting they are stabilized in some way. Multiple components of the human spliceosome have now been found to be important

90 for cohesion (Huen et al., 2010; Karamysheva et al., 2015; van der Lelij et al., 2014; Nishimura et

91 al., 2019; Sundaramoorthy et al., 2014), but the mechanism of how these proteins regulate cohesion

92 is unclear. Recent efforts to identify proteins associated with R-loops (Cristini et al., 2018) have 
93 also identified many splicing proteins, suggesting that the mechanism of activity for these proteins

94 involves R-loop homeostasis during mitosis.

95 We present evidence that R-loops accumulate on chromosomes during prophase, that they 96 are resolved during mitosis and this resolution requires the CPC. In addition, R-loops are required

97 to promote $\mathrm{CPC}$ localization to the inner centromere. We purified the CPC from mitotic 98 chromosomes and identified 32 proteins that interact with R-loops, including the cohesion 99 regulator RBMX. We show that R-loops and RBMX are required to localize the CPC to inner 100 centromeres and this promotes localization of Sgo1 to protect centromeric cohesion. This work 101 provides a function for mitotic R-loops that is distinct from interphase roles and provides a new 102 function for the pool of chromatin-based Aurora B kinase in resolving R-loops in mitosis.

104 Results

$105 R$-loops are found at repetitive regions in mitotic cells.

106 We investigated the genomic loci on mitotic chromosomes that contain R-loops and further 107 tested whether there is a population of R-loops that are regulated by Aurora B kinase (Castellano108 Pozo et al., 2013). Specifically, we performed DNA-RNA IP using S9.6 monoclonal antibody, 109 which recognizes RNA-DNA hybrids (Boguslawski et al., 1986), followed by high throughput 110 sequencing (DRIP-seq) on cells stalled in mitosis for 24 hours with colcemid and then treated with 111 either DMSO, or two different Aurora B inhibitors AZD1152/Barasertib (AZD) or ZM447439 112 (ZM) for the last hour. Each sample had a paired RNaseH1 treated sample to show specificity of 113 the IP. The DNA sequence reads were mapped to the human genome (hg38) and peaks were called 114 by MACS2 (Feng et al., 2012; Zhang et al., 2008). We validated that the peaks were at R-loops 115 by comparing an average line profile of the peaks in each treatment to the average line profile in 116 the RNaseH treated control IPs. An example peak profile is shown in Figure 1A, where the called 117 compiled peaks ( 90,000 peaks per treatment) were approximately ten-fold enriched relative to 118 their respective RNaseH1-treated sample.

119 We first asked if R-loops are in the same locations as in interphase cells or whether new 120 R-loops are formed during mitosis. We compared the called peaks of our mitotic DRIP-seq 121 samples to publicly available data from asynchronous cells that were prepared using a similar IP 122 protocol, sequenced to a similar depth and in cells with a similar karyotype as the cells used in our 123 experiment (Nadel et al., 2015). Significantly more R-loops were found on repeat elements in 
124 mitotic cells compared to interphase cells. In addition, there was a decrease in peaks in promoters 125 and genes in mitotic cells (Figure 1B), which included a drastic loss of R-loop accumulation across 126 gene bodies and transcriptional termination sites in the mitotic samples (Figure 1C, D). The 127 repression of DRIP signal within mitotic cells is consistent with the silencing of transcription 128 during mitosis (Parsons and Spencer, 1997; Prescott and Bender, 1962; Taylor, 1960). These data 129 suggest that mitotic R-loops are distinct from interphase R-loops, which is a consequence of the 130 general termination of transcription that happens as cells enter mitosis and an accumulation of new 131 R-loops at repetitive regions in the genome.

132 We next determined if peaks were regulated by Aurora B. Peaks that existed in mitotic 133 control samples were more enriched after treatment with Aurora inhibitors (Figure 1E, left) and 134 new peaks also appeared (Figure 1E, right). A larger percentage of the R-loops were found at 135 repetitive elements after the addition of Aurora inhibitors for 1 hour (Figure 1B). There was not a 136 dramatic change of R-loops in gene bodies or transcriptional start sites after Aurora B inhibition 137 (Figure 1C, D) however, there was an increase in the number of R-loops at transcription 138 termination sites. This is consistent with the recently identified role of Aurora B as a driver of the 139 mitotic termination of transcription by its ability to remove cohesin from chromatin (Perea-Resa 140 et al., 2020).

141 We focused on the enrichment of R-loops at repetitive elements in mitotic cells, since there 142 was both a drastic increase in peaks called within repetitive elements in the mitotic samples and 143 these further increased upon treatment with Aurora B inhibitors (Figure 1E). We devised a pipeline 144 to identify the repetitive elements that were enriched in our DRIP-seq samples. The input samples 145 were run through a De Bruijn graph algorithm to build a de novo database of repeat elements from 146 DLD1 cells (Novák et al., 2010, 2013). We then aligned our DRIP-seq samples to this database 147 and calculated enrichment values for each repetitive element. The repetitive elements were 148 defined using the Dfam database (Hubley et al., 2016), and classified as subtype Transposable 149 elements (Figure 1F, blue scale), subtype Satellite (green scale) or neither (black). R-loops 150 accumulated (greater than 2-fold) at alpha-satellite repeats (ALR), scaffold attachment repeats 151 (SAR), and Human satellite II repeats (HSATII) in mitosis and these further accumulated after 152 Aurora B inhibition (Figure 1F). Our pipeline identified three distinct alpha-satellite clusters that 153 represent slightly different sequences. All three were enriched in mitosis and further enriched after 154 Aurora B inhibition with both AZD and ZM (treated as duplicates, averaged in Figure 1F, and 
shown in $1 \mathrm{G}, \mathrm{p}<0.001)$. We determined the relative frequency of a set of published HOR-specific 24-base k-mers (Miga, 2017) in asynchronous, DMSO treated mitotic and Aurora B inhibited mitotic samples to test this enrichment in a complimentary manner. Almost all of the alpha-satellite k-mers were enriched greater than 2-fold in mitosis and these were further enriched after treatment with Aurora B inhibitors (Figure 1H, I, p $<0.0001$ for each pair in I). This enrichment is not apparent in samples treated with $\mathrm{RNaseH}$, demonstrating specificity of the alpha-satellite enrichment. We conclude that R-loops accumulate in repetitive elements including alpha-satellite sequences during mitosis, and that Aurora B activity is required to deplete these R-loops.

\section{Dynamics of mitotic R-loops}

We localized R-loops by immunofluorescence using the S9.6 monoclonal antibody on randomly cycling RPE1-T-REx cells to measure the dynamics of mitotic R-loops in a non-arrested cell population (Figure 2A). Cells were co-stained using Anti-Centromere Antibody (ACA) and the DNA-specific dye 4',6-diamidino-2-phenylindole (DAPI). We quantified the R-loop signal intensity at centromeres and chromatin, using a 3D mask containing ACA signal to specify centromeres and a 3D mask created by DAPI staining as a chromatin signal. We then extrapolated the chromosome arm signal by subtraction of the centromere area from the chromatin mask. Rloop signals at both locations are highest in prophase cells, followed by a gradual decline in Rloop signal through the course of mitosis. The differences in centromeric R-loop intensities were

174 significant in each of the distinct stages of mitosis, and the levels of centromeric R-loops had returned to interphase levels by anaphase (Figure 2B and Supplemental figure 1). Chromosome arm R-loops were also highest in prophase, but declined rapidly, to the point where they were statistically indistinguishable from interphase by metaphase (Figure 2C and Supplemental figure 1). This suggests that R-loops form during chromosome condensation across chromosomes but are restricted to centromeres after prophase. Centromeric R-loops persist longer but are resolved by anaphase onset.

We analyzed the intra-nuclear location of prophase R-loops more precisely using confocal

182 microscopy. Prophase R-loops were not observed uniformly across all chromosomes, and some 183 chromosomes were depleted of R-loop foci. The most striking feature was that R-loops form along 184 nuclear rims, which are classically associated with heterochromatin in interphase cells (Figure 2D, 185 line scan in Figure 2E, right; additional prophase nuclei available in Supplemental figure 1). We 
noticed that R-loop foci localized to areas with low DAPI staining within the nuclei of prophase cells, suggesting they form before chromosomes are fully condensed. We quantified the brightest point of R-loop foci within the nuclei of cells. High R-loop foci were constrained to regions of relatively low DAPI intensity in each cell cycle state (Figure 2F, dark red points). Cells were continuously condensing chromatin over the cell cycle points measured. We noted that there was a gradual increase in DAPI intensity of the R-loop staining foci points as cells progress from interphase to prometaphase (Figure 2G). However, in each of the states, the high R-loop staining was always in low to moderate range of DAPI staining intensities (Figure 2F). This suggests that R-loops form on condensing chromatin and potentially represent an intermediate of chromatin condensation. Our data suggests that R-loops are most highly associated with condensing chromatin in early mitosis and associated with heterochromatin at the nuclear periphery.

\section{Aurora B kinase activity removes mitotic $R$-loops in randomly cycling cells}

We performed immunofluorescence using S9.6 and anti-ACA antibodies in addition to DAPI on asynchronous RPE1-TREX cells, as in figure 2, treated with Aurora B kinase inhibitors ZM447439 (ZM) or AZD1152 (AZD) for 1 hour. AZD generated minimal increases in R-loop levels in interphase DNA and centromeres when normalized to ACA $(\mathrm{p}<0.01$ and $\mathrm{p}<0.001$ respectively), although this difference was not seen after $\mathrm{ZM}$ treatment ( $\mathrm{p}=0.5$ and $\mathrm{p}>0.9$; Figure 3A-C). In contrast, both Aurora B inhibitors increased the levels of R-loops on mitotic chromosomes and centromeres $(\mathrm{p}<0.01$ and $\mathrm{p}<0.001$ AZD-DAPI and AZD-ACA; $\mathrm{p}<0.001$ and p<0.001 ZM-DAPI and ZM-ACA respectively; Figure 3A-C). There was no significant difference in ACA levels after treatment with either Aurora B inhibitors, validating its use as a normalization parameter (Figure 3D, ANOVA p-0.24). Thus, we were able to confirm that Aurora B has a role in removing R-loops from mitotic cells using both DRIP-Seq and immunofluorescence.

We confirmed that Aurora B regulates centromeric R-loops as suggested by our DRIP-seq by performing DNA-RNA immunoprecipitation (IP) followed by quantitative PCR (DRIP-qPCR) utilizing primers to the X chromosome Higher Order Repeat of alpha-satellite (DXZ1 HOR) and to ribosomal DNA repeats (rDNA) in mitotically arrested cells. We found that treatment with either AZD or ZM for the last hour in cells stalled for 24 hours in colcemid caused at least a twofold increase in R-loop accumulation at the DXZ1 HOR (Figure 3E-F). There is specificity for alpha-satellite sequences because Aurora B inhibitors had little effect on the accumulated R-loops 
217 at the rDNA locus. We conclude that Aurora B regulates R-loops repetitive regions during mitosis, 218 particularly at centromeric alpha-satellites.

To determine the functions of R-loops during mitosis we created cells that express mCherry tagged E. coli RNaseH1 under a Tet-inducible promoter in HeLa-T-REx cells to generate an inducible system to deplete R-loops. We used clonal lines that expressed detectable levels of

224 RNaseH1 within 8 hours of doxycycline-induced expression (Supplemental figure 2). Previous studies demonstrated that centromeric R-loops are required to activate the centromere pool of Aurora B but did not report a change to the amount of CPC (Kabeche et al., 2018). We localized the Aurora B kinase by immunofluorescence in order to determine if localization of Aurora B kinase is dependent upon R-loops. Induced RNaseH1 significantly depleted Aurora B intensity in mitotic cells compared to the same population of cells without RNaseH1 induction (Figure 4A and B) and compared with cells with induced expression of catalytically dead RNaseH1-2R mutant

231 (Britton et al., 2014, Figure 4A and B). We stained chromosome spreads for S9.6 to observe R232 loops and confirm that expression of RNaseH1-2R mutant does not deplete R-loops. Cells 233 expressing the RNaseH1-2R mutant have R-loop staining throughout the chromosome 234 (Supplemental figure 2).

235 We used a lentivirus to overexpress RNaseH1-EGFP in RPE1-TREx cells and then 236 assessed intensity of Aurora B T-loop phosphorylation (pT232), as well as the signals that localize 237 the CPC to the inner centromere, H3 pT3 and H2A pT120, in order to understand how R-loops 238 control Aurora B activation and localization. Aurora B pT232 staining indicated a loss of auto239 phosphorylated Aurora B in these cells after RNaseH1 overexpression (Supplemental figure 2) 240 confirming that R-loops are involved in activation of the centromere pool of Aurora B (Kabeche 241 et al., 2018) in addition to the pool on chromosome arms. We also observed a decrease in H2A 242 pT120, one of the histone marks that serves as a localization signal (Figure 4C and 4D). We 243 observed an increase in H3 pT3 throughout the chromosome, which explains the spread of Aurora 244 B signal (Supplemental figure 2). This indicates that R-loops are required to reduce the H3 pT3 245 signal, and potentially Haspin kinase on chromosome arms. Together our data suggest that R-loops 246 affect both histone marks that localize the CPC to drive the movements from arm chromatin to the 247 inner centromere. 
The CPC interacts with $R$-loop regulators including RBMX on mitotic chromosomes.

Aurora B has many functions in mitosis so it could have direct or indirect roles in resolving R-loops. We hypothesized that if the CPC had a direct role in R-loop resolution it should be bound to chromatin with other proteins that resolve R-loops. We developed an approach to rapidly purify the CPC bound to chromatin liberated from mitotic chromosomes based on the LAP dual affinity tag (Cheeseman and Desai, 2005). We established four HeLa cells lines expressing LAP-AuroraB, LAP-Borealin, LAP-Survivin or LAP only (Supplemental figure 3). The LAP-Survivin, and LAP-Borealin proteins localized to centromeres in mitosis (Supplemental figure 3). We rapidly isolated mitotic chromatin by a clarification centrifugation followed by pelleting mitotic 258 chromatin. Chromatin was liberated by micrococcal nuclease treatment producing ladders that ranged from mononucleosomes to hexameric nucleosomes. The CPC from mitotic chromatin was tandem-affinity purified and the bound proteins were analyzed by MudPIT (Supplemental Table 1, Supplemental figure 3), which identified a total of 111 proteins (Figure 5A). All three CPC complex members purified at least one other CPC member and no CPC proteins were identified in the LAP control preps. We identified Topo II $\alpha$, Kif20a/MKLP2 and HP1 $\beta$ which have been previously shown to interact with the CPC (Coelho et al., 2008; Gruneberg et al., 2004; Kang et al., 2011; Morrison et al., 2002). The top three GO keywords for proteins identified were Phosphoproteins, Ribonucleoproteins, and RNA-binding, consistent with the fact that RNA has a major role in CPC activity (Figure 5B, Blower, 2016; Jambhekar et al., 2014). The majority (75\%) of the RNA binding proteins that interact with the CPC were also purified in a S9.6 IP (the R-loop interactome, Figure 5B, Cristini et al., 2018). 35\% of these proteins (11 proteins) were also identified as Aurora kinase substrates in phosphoproteomic screens. The fact that the CPC interacts with and phosphorylates R-loop proteins strongly suggests that the $\mathrm{CPC}$ has a direct role in controlling R-loops and all of these proteins are potential regulators of mitotic R-loops.

We initially focused on RBMX because it was identified in the R-loop interactome and is required for centromeric cohesion (Matsunaga et al., 2012). We confirmed that RBMX interacts with the CPC by co-IP (Figure 5C, D). The bulk of RBMX is cytoplasmic in mitosis (Matsunaga 276 et al., 2012), but after extracting soluble proteins in RPE1-T-REx cells the majority of the 277 remaining RBMX colocalized with ACA (Figure 5E) and this localization is dependent upon R278 loops (Figure 5F and F'). We generated a cell line expressing LAP-RBMX to confirm whether 
RBMX is enriched on centromeres. LAP-RBMX is greatly enriched at centromeres as measured 280 by Chromatin Immunopreciptitation (ChIP) using primers against $\alpha$-satellite DNA (Figure 5G).

281 We confirmed the localization by Proximity Ligation Assay (PLA), which measures the proximity 282 of the GFP of the LAP tag to the CPC subunit Survivin in LAP-RBMX expressing cells. Cells were co-stained with antibodies to Borealin and tubulin to generate fiducial marks on inner centromeres and the spindle. PLA signals were found adjacent to Borealin at centromeres of metaphase cells (Figure 5H) and there was little signal if the Survivin antibody was not added to the reaction as a negative control. We conclude that RBMX is recruited to centromeres by R-loops where it interacts with the CPC.

We tested whether RBMX has a function in mitotic R-loop biology. We depleted RBMX by shRNA and co-stained the cells with anti-Aurora-B, ACA, and S9.6 antibodies to determine whether RBMX regulates Aurora-B and R-loops. RBMX protein levels were reduced as evaluated by western blot but the levels of Aurora-B, Survivin, and a set of cohesion regulators were 292 unaffected by depletion of RBMX, suggesting RBMX does not interfere with transcription or 293 protein stability of the CPC (Supplemental figure 4). Depleting RBMX affects Aurora B 294 localization to centromeres as the amount of Aurora-B at inner centromeres of prometaphase cells 295 was significantly reduced (Figure 6A-D). R-loop levels were significantly increased across 296 chromatin in prometaphase cells, consistent with a loss of Aurora B activity (Figure 6A-B, Figure 297 3). We also saw reduction in the levels of the Borealin subunit of the CPC and T-loop 298 phosphorylation of Aurora B kinase (Supplemental figure 4). The reduction of CPC was seen with 299 a second shRNA that reduced RBMX protein levels (Supplemental figure 4), in two cell types 300 (RPE-T-REx cells and HeLa-T-REx cells, Figure 6A-D) and expression of shRNA resistant LAP301 RBMX restored centromeric Aurora-B levels to cells treated with shRNA against RBMX (Figure $3026 \mathrm{C}, \mathrm{D})$. Thus, RBMX is required for centromeric accumulation of Aurora B and mislocalizing 303 Aurora B is not an off-target effect of shRNA expression. RBMX is required for the histone marks 304 that target the CPC to the centromere, but these marks can be restored by forced targeting Aurora 305 B kinase activity to centromeres (Supplemental figure 5), demonstrating that RBMX is not 306 required to generate the histone marks, but they are reduced in cells that are depleted of RBMX 307 because Aurora B is missing. In conclusion, these data suggest that the RNA binding protein, 308 RBMX, is recruited to centromeres by R-loops, where it recruits Aurora B to resolve R-loops. 
$R$-loops and $R B M X$ are required to maintain centromeric cohesion and the role of $R B M X$ in centromeric cohesion is to recruit Aurora B and Sgol

We have shown that RBMX is localized by R-loops (Figure 5) and it has been previously

313 published that RBMX is required for centromeric cohesion (Matsunaga et al., 2012) To identify

314 the function of mitotic R-loops, we tested whether loss of R-loops affects cohesion. We expressed

315 RNaseH1 and RNaseH1-2R in HeLa-T-REx cells and performed mitotic spreads and quantified

316 premature chromatid separation (PCS, Figure 7A). Centromeric cohesion was lost in cells

317 overexpressing RNaseH1 but not in cells expressing RNaseH1-2R (Figure 7B). To test whether

318 RBMX targets the CPC to generate centromeric cohesion, we depleted RBMX and induced CENP-

319 B-INCENP (CB-INCENP) fusion protein expression to forcibly target the CPC to the centromere

320 via CENP-B binding. RBMX depleted cells showed a PCS phenotype, however PCS was

321 dramatically decreased when these cells were induced to express the CB-INCENP (Figure 7C).

322 The loss of centromeric cohesion was restored by targeting the Aurora B to centromeric chromatin.

323 We conclude that R-loops are required to maintain centromeric cohesion by RBMX-dependent 324 recruitment of the CPC.

325 Sgol is a key regulator of centromeric cohesion, and Aurora B activity is required to

326 localize Sgol to inner centromeres (Dai et al., 2006; van der Waal et al., 2012). We explored the

327 relationship of the R-loops with the localization of Sgo1 to determine the mechanism by which

328 RBMX and R-loops maintain centromeric cohesion. Expressing RNaseH1 reduced the

329 centromeric levels of Sgo1 significantly ( $<<0.0001$, Figure 7D, E). Depletion of RBMX similarly

330 reduced centromeric levels of Sgol, and this could be recovered by forced targeting of the CPC

331 by CB-INCENP (Figure 7F, G). We conclude that RBMX targets the CPC to recruit Sgo1.

The pool of the CPC recruited by RBMX protects cohesion by recruiting Sgol

334 Our finding that targeting the CPC to centromeres can reverse the PCS that was induced 335 by RBMX depletion suggested that this pool of the CPC is involved in protecting centromeric 336 cohesion. It is difficult to assay a role for the CPC in centromeric cohesion because the CPC is 337 required to remove cohesin from non-centromeric regions during prophase (Giménez-Abián et al., 338 2004; Losada et al., 2002; Nishiyama et al., 2013). Thus, even if cells depleted of Aurora-B lost 339 centromeric cohesion the chromatids would remain cohesive through the chromosome arms. Arm 340 cohesion is removed but centromeric cohesion is still preserved when human cells are arrested 
341 with microtubule poisons for 2-3 hours (Giménez-Abián et al., 2004). We therefore modified an 342 assay that previously showed that the CPC is required to maintain centromeric cohesion (Tanno et 343 al., 2010). We generated a population of mitotic cells by initially synchronizing cells in S-phase 344 by double thymidine block and then ten hours after release from thymidine we treated cells with 345 colcemid for 3 hours to allow the cells to arrest in mitosis and lose arm cohesion. We then treated 346 the cells with Aurora-B inhibitors for an additional two hours and measured PCS by mitotic 347 spreads (Figure 7A). Forty percent of mitotic cells showed PCS when treated with $0.1 \mu \mathrm{M}$ 348 Hesperadin while only 2\% PCS occurred when treated with DMSO (Supplemental figure 6). There 349 was a dose dependent increase of PCS when cells were treated with Hesperadin. Treatment of cells 350 with ZM, a structurally different Aurora-B kinase inhibitor, also promoted PCS, demonstrating 351 that Aurora-B activity is required for centromeric cohesion (Supplemental figure 6). To rule out 352 the possibility that separase is prematurely activated under our experimental conditions; we treated 353 cells with MG132, a proteasome inhibitor. We observed similar loss of cohesion in the presence 354 or absence of MG132 (Supplemental figure 6).

To circumvent the concern that the CPC's role in cohesion is a consequence of prolonged 356 mitotic arrest we complemented our findings by depleting Aurora-B by shRNA in a HeLa line that 357 stably expressed LAP-CENP-A, visualized mitotic chromosomes by chromosome spreads, and 358 measured the inter-kinetochore distance (Supplemental figure 6). All chromosomes maintained 359 cohesion consistent with the requirement of the CPC to remove arm cohesion. However, there was 360 a $36 \%$ increase of the inter-kinetochore distance on Aurora-B depleted chromosomes, supporting 361 the hypothesis that Aurora-B is required for centromeric cohesion.

362 We determined the epistatic relationship between Aurora-B and Sgo1 in centromeric 363 cohesion regulation. Forced targeting of Sgol to centromeres using a Cenp-B Sgol fusion protein 364 partially rescued Hesperadin-induced PCS (Figure 7H), suggesting Sgo1 is downstream of CPC 365 mediated protection of centromeric cohesion. In contrast, forced targeting of INCENP to 366 centromeres did not rescue Sgo1 depletion induced PCS (Figure 7I), consistent with Aurora-B 367 being upstream of Sgo1. Finally, targeting INCENP to inner centromeres also did not rescue 368 hesperidin-induced PCS (Figure 7H), indicating the kinase activity of Aurora-B is required for 369 protection of centromeric cohesion. These data suggest that R-loops recruit RBMX, which in turn 370 recruits the $\mathrm{CPC}$ to recruit Sgol and maintain centromeric cohesion (Figure 7J). In addition, Figure 
3 and 4 suggest Aurora B also reduces centromeric R-loops, suggesting a self-limiting feedback

372 loop.

Discussion

R-loops are emerging as critical regulators of interphase chromatin, but much less is known about their function in mitosis. Surprisingly, we found that the R-loops were higher in regions of intermediate chromatin density in prophase cells than interphase cells, suggesting that R-loops are formed during chromosome condensation. R-loops decline during prometaphase and metaphase until they reach interphase levels at anaphase. We explored the mechanism that cells use to resolve mitotic R-loops and found that this process was dependent upon Aurora B kinase activity. Purification of the CPC from mitotic chromosomes identified 32 proteins that were also found in purifications of R-loops. We verified that one of these, RBMX, is required to remove mitotic Rloops. Finally, we explored the function of mitotic R-loops and found they localize the CPC to centromeres to maintain sister chromatid cohesion.

We have established that R-loops form during mitosis in distinct locations from those in interphase cells and there are active mechanisms to resolve them. In addition, we show that mitotic R-loops are required for mitotic chromosome cohesion and this is mediated by R-loops recruiting the CPC to inner centromeres. The CPC is both recruited by R-loops and resolves these R-loops demonstrating feedback control. In addition to the CPC, we have identified a set of potential regulators of mitotic R-loops but purifying the CPC from mitotic chromatin. We have confirmed one of these proteins RBMX is both required to recruit the CPC to inner centromeres and resolve R-loops. Importantly, loss of RBMX is also required for centromeric cohesion.

Our data are consistent with a recent paper that suggested that R-loops exist in mitotic 394 centromeres where they recruit the ATR kinase to activate centromeric Aurora B (Kabeche et al., 395 2018). Our findings support this model and extend it by showing that R-loops are required to 396 localize Aurora B to inner centromeres. Another study suggested that the phosphorylation of 397 Histone H3 on Serine 10 is found at R-loops containing chromatin in yeast (Castellano-Pozo et al., 398 2013a). Aurora B is the writer of this histone mark, and our finding that Aurora kinase activity is 399 required to resolve R-loops in human cells suggests that R-loop regulation is a conserved function 400 of the histone H3 S10 phosphorylation. A previous study also showed R-loop association with H3 
401 lysine 9 dimethylation, a marker of condensed chromatin. This is consistent with our 402 demonstration that R-loops are highest in prophase, when chromosomes condense.

403 We employed DRIP-seq assays to identify the genomic positions of R-loops in populations 404 of cells arrested in mitosis and the genomic loci of R-loops regulated by Aurora B. Mitotic R405 loops were depleted from gene bodies, but highly enriched at repetitive DNA, most notably alphasatellite and SAR sequences. Enrichment at alpha-satellite is consistent with roles of Aurora B in centromeric regulation and cohesion. SARs were associated with loop regions of chromatin in older studies (Mirkovitch et al., 1987; Strissel et al., 1996) but their function is still poorly understood; it is also notable that the genomic loci of SAR repeats are within pericentric DNA (Hubley et al., 2016). We identified three SAR binding proteins SAF-A, SAF-AL and SAF-B in purifications of CPC bound to mitotic chromatin. The connection between SARs and the CPC

412 from two independent unbiased methods suggests this to be an important connection. We speculate 413 that R-loops and the CPC act at the base of the loops of condensing chromatin. This is supported 414 by the association of the CPC with condensin and Topo II, which are localized to the base of 415 chromatin loops in mitotic chromosomes. It is also consistent with a recent study that suggested 416 that R-loops template the base of chromatin loops of maize centromeres (Liu et al., 2020).

417 The source of mitotic R-loops is a second area of study suggested by our results. 418 Interestingly, condensin acts at the base of chromosome loops and can generate positive 419 supercoiling (Bazett-Jones et al., 2002; Kimura and Hirano, 1997; Kimura et al., 1999). 420 Topoisomerases are known to work with condensin to relieve topological strain (Baxter et al., 421 2011), and the activity of topoisomerases could expose single-stranded DNA and allow RNAs to 422 hybridize, especially within highly repetitive sequences. R-loops have been reported at sites of 423 negative supercoiling (Stolz et al., 2019), and sites of topoisomerase activity (Drolet et al., 1995; 424 El Hage et al., 2010). R-loops might also be a result of condensing heterochromatic regions as the 425 cell moves from interphase to mitosis. H3 phosphorylation on S10 has been shown to displace 426 Heterochromatin Protein 1 (HP1, Hirota et al., 2005) which binds H3 lysine 9 methylation. We 427 found that R-loops are highest at the nuclear periphery in prophase cells, and that the largest 428 proportion of DRIP peaks existed at repetitive sequences which are marked by H3 lysine 9 429 methylation in interphase.

430 We purified the CPC from mitotic chromatin to gain insight on how it would resolve R431 loops and found a pool of proteins in this proteome that associated with purified R-loops (Cristini 
432 et al., 2018). We initially focused on RBMX because it had been shown to regulate cohesion in a 433 Sgo1-dependent manner (Matsunaga et al., 2012) and our epistasis experiments suggest a pathway 434 whereby R-loops recruit RBMX to recruit Aurora B to resolve R-loops (Figure 7I). We believe 435 that our preparation of proteins associated with the CPC on mitotic chromatin and particularly 436 those that also interact with R-loops will be a rich source of future studies and will help us 437 understand the precise nature of the generation and resolution of R-loops in mitosis.

438 Our work sheds light on a number of questions associated with mitotic R-loops. First, we 439 established that there is a specific population of R-loops that arise and are resolved within the 440 course of mitosis that are distinctly distributed within the genome from interphase R-loops. These 441 R-loops are preferentially enriched within repetitive sequences, including centric and pericentric 442 repeats. We have also identified a number of proteins involved with the regulation of mitotic R443 loops, including Aurora B kinase and a number of other chromatin and RNA regulators. Aurora B 444 kinase has an active role in limiting the formation of repetitive R-loops, and we hypothesize that 445 this is through phosphorylation of substrates found within the pool of R-loop regulators. Although 446 R-loops likely have multiple roles in mitosis, we have identified a pathway linking R-loops to 447 regulation of centromeric cohesion, demonstrating that this regulation is crucial to maintenance of 448 mitotic fidelity and may provide a mechanism for the increase of lagging chromosomes found in 449 cells overexpressing RNaseH1 (Kabeche et al., 2018). Overall, this work links R-loops to major 450 mitotic regulator Aurora B and gives a mechanism for the observation that RNA can regulate 451 Aurora B and centromeres through cis-activity in human cells(Grenfell et al., 2016; Perea-Resa 452 and Blower, 2017).

\section{Materials and Methods}

Table 1. Antibody table

\begin{tabular}{|l|l|l|l|l|l|}
\hline Epitope & Company & Catalogue \# & Western Blot & Immunofluorescence & ChIP/DRIP \\
\hline Flag & Sigma & F7425 & $1: 10,000$ & N/A & N/A \\
\hline HA & Bethyl & A190-108 & $1: 10,000$ & N/A & N/A \\
\hline Aurora B & Bethyl & A300-431A & $1: 5,000$ & $1: 300$ & N/A \\
\hline Survivin & Cell Signaling & 2808 & $1: 10,000$ & N/A & N/A \\
\hline
\end{tabular}




\begin{tabular}{|c|c|c|c|c|c|}
\hline RBMX & Cell Signaling & $14794 S$ & $1: 1,000$ & $1: 300$ & $\mathrm{~N} / \mathrm{A}$ \\
\hline Cyclin-B1 & Santa Cruz & Sc-594 & $1: 1,000$ & N/A & $\mathrm{N} / \mathrm{A}$ \\
\hline Sgo1 & Abcam & Ab58023 & $1: 1,000$ & $1: 100$ & $\mathrm{~N} / \mathrm{A}$ \\
\hline Tubulin & ATCC Hybridoma & DM1a & $1: 10,000$ & $1: 1,000$ & N/A \\
\hline H3 S10-phos & Millipore & $06-570$ & $1: 5,000$ & $1: 1,000$ & N/A \\
\hline SMC3 & $\begin{array}{l}\text { Gift from S Rankin } \\
\text { (OK Medical research } \\
\text { Foundation) }\end{array}$ & N/A & $1: 1,000$ & N/A & N/A \\
\hline $\begin{array}{l}\text { Aurora B } \\
\text { (AIM1) }\end{array}$ & BD Biosciences & 611082 & N/A & $1: 200$ & N/A \\
\hline Aurora B & Abcam & ab2254 & $\mathrm{N} / \mathrm{A}$ & $1: 200$ & $\mathrm{~N} / \mathrm{A}$ \\
\hline $\begin{array}{l}\text { Anti-centromere } \\
\text { antigen (ACA) }\end{array}$ & Antibodies Inc & $15-234-0001$ & N/A & $1: 1,000$ & N/A \\
\hline H2ApT120 & Active Motif & 61195 & $\mathrm{~N} / \mathrm{A}$ & $1: 1,000$ & $\mathrm{~N} / \mathrm{A}$ \\
\hline CENP-A & Abcam & $\begin{array}{l}\text { ab13939-50 } \\
\text { Clone3-19 }\end{array}$ & N/A & $1: 1,000$ & N/A \\
\hline H3pT3 & Millipore & $07-424$ & $\mathrm{~N} / \mathrm{A}$ & $1: 500$ & $\mathrm{~N} / \mathrm{A}$ \\
\hline Aurora-BpT232 & $\begin{array}{l}\text { Rockland Antibodies } \\
\text { and Assays }\end{array}$ & 600-401-677 & N/A & $1: 200$ & N/A \\
\hline Borealin & Stukenberg lab & \#968 & N/A & $1: 200$ & $\mathrm{~N} / \mathrm{A}$ \\
\hline Bub1 & Abcam & ab54893 & $\mathrm{N} / \mathrm{A}$ & $1: 400$ & $\mathrm{~N} / \mathrm{A}$ \\
\hline R-loops & ATCC hybridoma & S9.6 & N/A & $1: 1,000$ & $1: 10$ \\
\hline CENP-T & Foltz lab & N/A & N/A & $1: 1,000$ & $\mathrm{~N} / \mathrm{A}$ \\
\hline mCherry & abcam & Ab183628 & $1: 1000$ & $1: 200$ & N/A \\
\hline GFP & Stukenberg Lab & $\# 786$ & $1: 1000$ & N/A & $1: 10$ \\
\hline$\overline{G F P}$ & abcam & 1218 & $1: 1000$ & $1: 200$ & $\mathrm{~N} / \mathrm{A}$ \\
\hline
\end{tabular}

458 Table 2. Chemical and protein inhibitors

\begin{tabular}{|l|l|l|l|l|l|}
\hline Inhibitor & Company & Catalogue \# & $\begin{array}{l}\text { Concentration } \\
\text { HeLa cells }\end{array}$ & $\begin{array}{l}\text { Concentration } \\
\text { RPE1 cells }\end{array}$ & $\begin{array}{l}\text { Concentration } \\
\text { DLD1 cells }\end{array}$ \\
\hline ZM447439 & Selleck Chem & S1103 & $2 \mu \mathrm{M}$ & $4 \mu \mathrm{M}$ & $2 \mu \mathrm{M}$ \\
\hline
\end{tabular}




\begin{tabular}{|l|l|l|l|l|l|}
\hline AZD1152 & $\begin{array}{l}\text { Cayman } \\
\text { Chemical }\end{array}$ & 13647 & $500 \mathrm{nM}$ & $1 \mu \mathrm{M}$ & $500 \mathrm{nM}$ \\
\hline Hesperadin & Selleck Chem & S1529 & $100-500 \mathrm{nM}$ & N/A & N/A \\
\hline Colcemid & Gibco & 15212012 & $100 \mathrm{ng} / \mathrm{ml}$ & $200 \mathrm{ng} / \mathrm{ml}$ & $100 \mathrm{ng} / \mathrm{ml}$ \\
\hline Nocodazole & Sigma & M1404 & $0.33-3.3 \mu \mathrm{M}$ & N/A & N/A \\
\hline Thymidine & Sigma & T1895 & $2 \mathrm{mM}$ & $4 \mathrm{mM}$ & N/A \\
\hline RNaseH1 & Takara & $2150 \mathrm{~B}$ & N/A & N/A & 40 U/ $10 \mu \mathrm{g}$ DNA \\
\hline
\end{tabular}

460 Table 3. Oligonucleotides

\begin{tabular}{|l|l|l|}
\hline Oligo Name & Sequence 5'-3' & Use \\
\hline RBMX shRNA \#1 & ATCAAGAGGATATAGCGAT & pGIPZ and pTRIPZ shRNA \\
\hline RBMX shRNA \#2 & TCGGGTTGGCAGACAAGAA & pGIPZ and pTRIPZ shRNA \\
\hline Aurora B shRNA & AGCTGCGCAGAGAGATCGA & pGIPZ and pTRIPZ shRNA \\
\hline Sgo1 shRNA & AAGACAACAACAAAATGTT & pGIPZ and pTRIPZ shRNA \\
\hline Control shRNA & TCGCTTGGGCGAGAGTAAG & pGIPZ and pTRIPZ shRNA \\
\hline hRNaseH1-D210N F & $\begin{array}{l}\text { TAAACTGGTTCTGTATACAAACAGTATGTTTA } \\
\text { CGATAAATGG }\end{array}$ & $\begin{array}{l}\text { Human RNaseH1 site- } \\
\text { directed mutagenesis }\end{array}$ \\
\hline hRNaseH1-D210N R & CCATTTATCGTAAACATACTGTTTGTATACAG & $\begin{array}{l}\text { Human RNaseH1 site- } \\
\text { directed mutagenesis }\end{array}$ \\
\hline IL-8 F & AACCAGTTTA & IL-8 locus ChIP \\
\hline IL-8 R & GGGCCATCAGTTGCAAATC & IL-8 locus ChIP \\
\hline$\alpha$-satellite F & TTCCTTCCGGTGGTTTCTTC & $\alpha$-satellite ChIP \\
\hline$\alpha$-satellite R & CGCCATTTGAGGACAATTGC & $\alpha$-satellite ChIP \\
\hline DXZ1 F & CGGGATCACCTTCCCATAAC & X-chromosome HOR DRIP \\
\hline DXZ1 R & GGTGTTGCAAACCTGAACTATC & X-chromosome HOR DRIP \\
\hline H4 F & CGACGACCCATTCGAACGTCT & rDNA DRIP \\
\hline H4 R & CTCTCCCGAATCGAACCCTGA & rDNA DRIP \\
\hline
\end{tabular}


RPE1-T-REx cells were generated from RPE1-hTERT (ATCC) cells using the T-Rex system (Thermo Scientific) plasmid by transfection and selecting for stable integration using Blasticidin. These cells were cultured using DMEM/F12 1:1 (Gibco) supplemented with 10\% 468 (vol/vol) FBS (Gibco), penicillin and streptomycin. HeLa-FRT-T-REx cells were generated using the Flp-in T-REx system (Thermo Scientific) and were a gift from the Dan Foltz lab. HEK-293T cells (ATCC) and HeLa-FRT-T-REx cells were cultured in DMEM (Gibco) supplemented with $10 \%$ (vol/vol) FBS, penicillin and streptomycin. DLD1 cells were a gift from the Michael Guertin lab, and were cultured in RPMI (Gibco) media supplemented with 10\% (vol/vol) FBS, penicillin and streptomycin. All cells were grown in a humidified chamber at $37{ }^{\circ} \mathrm{C}$ in the presence of $5 \%$ $474 \quad \mathrm{CO}_{2}$.

Stable cell lines generation

HeLa-T-REx-RNaseH1 and RNaseH1 ${ }^{\text {D10R, E48R }}$ (2R) were created by transfecting pICERNaseH1-WT-NLS-mCherry and pICE-RNaseH1-D10R-E48R-NLS-mCherry (a gift from Patrick Calsou, Addgene plasmids \#60365 and \#60367 Britton et al., 2014) using Lipofectomine 2000 (Invitrogen) and selecting using $1 \mu \mathrm{g} / \mathrm{ml}$ Puromycin for 2 weeks. Clonal lines were created by plating at very low density and selecting 30 colonies of each and selecting for colonies that were mCherry negative in absence of doxycycline and induced detectable fluorescence within 4 hours of addition of $1 \mu \mathrm{g} / \mathrm{ml}$ doxycycline.

The LAP tag from pIC113 vector (Cheeseman and Desai, 2005) was subcloned into pcDNA5.0/FRT vector (Invitrogen) to make the pcDNA5.0/FRT-LAP-N vector. Full length cDNAs of Aurora-B, Borealin, and Survivin were cloned into pcDNA5.0/FRT-LAP-N vector to make LAP-Aurora-B, LAP-Borealin and LAP-Survivin constructs respectively. These LAP tagged contructs were co-tansfected with pOG44 (Invitrogen) into Flp-In HeLa T-REx cells. Stable lines expressing these constructs were created by selection with hygromycin $(200 \mu \mathrm{g} / \mathrm{ml}$, Invitrogen) for two weeks.

492 pcDNA3.0-HA vector to make HA-tagged Aurora-B, Borealin, INCENP and Survivin 493 respectively. DLAP and DHA destination vectors were made based on pcDNA5.0/FRT-LAP-N and pcDNA3.0- HA vectors respectively. The cDNA of RBMX were obtained from the human 
ORFeome collection (V5.1) and was cloned into DLAP and DHA destination vectors using gateway cloning technology (Invitrogen) to make LAP-RBMX and HA-RBMX. The LAP tag from pIC113 vector (Cheeseman and Desai, 2005) was subcloned into pcDNA5.0/FRT/TO vector (Invitrogen) to make the pcDNA5.0/FRT/TO-LAP-N vector. CB-INCENP-GFP vector is a kind gift from M.A Lampson (Liu et al., 2009). We amplified CENP-B 1-158 (CB) by PCR and clone it into pcDNA5.0/FRT/TO-LAP-N vector using Not I and BamH I sites, which removes sequence encoding S peptide and leaves GFP sequence intact. This generated pcDNA5.0/FRT/TO -CB-GFP vector (CB-GFP). The full length cDNA sequence of Sgol and the cDNA sequence encoding INCENP aa47-aa917 were cloned into pcDNA5.0/FRT/TO-CB-GFP vector to generate the pcDNA5.0/FRT/TO-CB-GFP-Sgo1 (CB-Sgo1) and pcDNA5.0/FRT/TO-CB-GFP-INCENP 47917 (CB-INCENP). The stable lines constitutively expressing LAP-RBMX or inducibly expressing CB-GFP, CB-Sgo1 or CB-INCENP were made by co-transfecting these constructs with pOG44 (Invitrogen) into Flp-In HeLa T-REx cells and selection with hygromycin $(200 \mu \mathrm{g} / \mathrm{ml}$, Invitrogen) for two weeks.

The human lentiviral shRNAmir pGIPZ constructs were obtained from Open Biosystems and grown and purified according to their protocol. The targeting sequences of the shRNAs used in this study are listed in Table 3. To package virus, $1.5 \times 10^{7} \mathrm{HEK}-293 \mathrm{~T}$ cells were co-transfected with $18 \mu \mathrm{g}$ pGIPZ plasmid, $6 \mu \mathrm{g}$ pMD2G plasmid, and $12 \mu \mathrm{g}$ psPAX2 plasmid. Medium were replenished 24 hours after transfection and supernatants containing virus were collected and

514 filtered through $0.2 \mu \mathrm{m}$ filters 48 hours after transfection. Cells were infected with virus in the 515 presence of $8 \mu \mathrm{g} / \mathrm{ml}$ polybrene (Sigma).

To create RPE1-T-REx EGFP, EGFP-RNaseH1, and EGFP-RNaseH1 ${ }^{\text {D201N }}$ cells, EGFPhRNaseH1 or EGFP alone was cloned into pDONR-221 via Gateway cloning (Invitrogen) and 518 then recombined into pLX-304 (Gift from David Root, Addgene plasmid \# 25890 Yang et al., 519 2011). Site-directed mutagenesis on pDONR221-EGFP-hRNaseH1 using primers in Table 3 and 520 then recombined into pLX-304. Virus was packaged as above. Double thymidine synchronized 521 cells were infected with viral supernatant without polybrene upon release from the first thymidine 522 stall and again upon second thymidine stall to achieve $100 \%$ infection and expression in the cell 523 cycle following second thymidine release. 
For immunoprecipitation, HEK-293T Cells were co-transfected with plasmids encoding HAtagged -Aurora-B, -Borealin, -INCENP, -Survivin and Flag-tagged, -RBMX. Forty-eight hours after transfection, cells were synchronized to mitosis with $100 \mathrm{ng} / \mathrm{ml}$ colcemid for 16 hours. Cells were lysed in lysis buffer $(250 \mathrm{mM} \mathrm{NaCl}, 50 \mathrm{mM}$ Tris-HCl, 5mM EDTA, $0.5 \%$ NP-40, $1 \mathrm{mM}$ DTT, 20mM Beta-glycerophosphate, $50 \mathrm{mM} \mathrm{NaF}, 1 \mathrm{mM}$ Sodium orthovanadate, 1x protease inhibitors cocktail (Roche) and sonicated with cell disruptor for 30 cycles with 30 seconds on and 30 seconds off at $4{ }^{\circ} \mathrm{C}$. The whole cell extracts were cleared by centrifugation at $16000 \mathrm{~g}$ for 20 minutes and the supernatants were subjected to immunoprecipitation with EZView anti-flag beads (Sigma) for 4 hours at $4{ }^{\circ} \mathrm{C}$. The beads were washed three times with lysis buffer. The bound proteins were resolved on 6-18\% SDS-PAGE gel and blotted with antibodies as indicated.

\section{Immunofluoresence microscopy}

HeLa T-REx cells were seeded onto coverslips coated with poly-L-Lysine (Sigma) one day before staining. The cells were co-fixed with $2 \%$ paraformaldehyde, PHEM buffer (60 mM Pipes, $25 \mathrm{mM}$ Hepes, $10 \mathrm{mM}$ EGTA, and $4 \mathrm{mM} \mathrm{MgCl} 2, \mathrm{pH}$ 6.9), and 0.5\% Triton-X 100 for 20 minutes at room temperature. Cells stained with RBMX were pre-extracted with $0.5 \%$ Triton-X 100 for 2 minutes prior to fixation as above. After washing with PBS for three times, cells were blocked with $1 \%$ BSA for 30 minutes. Immunostaining was performed with primary antibodies (Table 1) at the indicated dilution for 1 hour at room temperature. After washing three times with PBS, cells were incubated with fluorescent secondary antibodies (Jackson ImmunoResearch). After washing two times with PBS, the cells were counterstained with $0.5 \mu \mathrm{g} / \mathrm{ml}$ DAPI for 5 minutes. After two more washes with PBS, the coverslips were mounted onto slides using ProlongGold Antifade (Invitrogen) and sealed with nail polish. Image acquisition was performed as described previously (Banerjee et al., 2014), or on a Zeiss 880 confocal microscope in the UVA Advanced Microscopy Facility (Figure 1). Images were processed and analyzed using Volocity (V6.3, PerkinElmer). To quantify fluorescence levels at centromeres, we used a volume thresholding algorithm to mark all centromeres on the basis of ACA or CENP-A staining in projected images. To eliminate the size difference of each marked centromere, the sum of the fluorescence intensity was divided by the voxel volume to obtain the value of fluorescence intensity per volume. To quantify fluorescence over chromatin, a volume thresholding algorithm was applied to the DAPI signal and volume normalized. After background subtraction, we calculated the intensity/volume values for each 
channel. These values were normalized against the corresponding ACA or CENP-A

558 intensity/volume. When cells were not stained with a centromere marker (ACA or CENP-A), we marked centromeres based on Bub1, Aurora-B or Sgo1 staining using a volume thresholding

560 algorithm. These values were plotted using Prism (GraphPad) and the statistical significance was 561 determined by the appropriate statistical test for the data, defined by normality and number of comparisons. For Box-and whisker plots, central lines indicate medians and whiskers are from minimum to maximum (range 0-100 percentile). For PCS assay, chromosome spreads were performed where cells were treated with 100ng ml-1 colcemid were trypsinized, harvested and swelled in $75 \mathrm{mM} \mathrm{KCl}$ for $10-15 \mathrm{~min}$ at $37^{\circ} \mathrm{C}$. Subsequently, Cells were fixed with freshly made Carnoy's solution (75\% methanol, 25\% acetic acid) on ice for 30 minutes. After washing with the fixative four times, cells were dropped onto glass slides and dried at room temperature. Slides were stained with DAPI washed briefly with PBS. For spreading HeLa cells expressing LAP-CENP-A and HeLa cells expressing RNaseH1/RNaseH1-2R, mitotic cells were obtained by mitotic shakeoff and swelled in hypotonic buffer $(75 \mathrm{mM} \mathrm{KCl}: 0.8 \%$ NaCitrate: $\mathrm{H} 2 \mathrm{O}$ at 1:1:1) with protease inhibitor cocktail (Roche) at room temperature for 10-15 min. Cells were spun to slides by

572 Cytospin at 1500rpm for $5 \mathrm{~min}$. The chromosome spreads were fixed with 2\% PFA/PBS at room 573 temperature for $20 \mathrm{~min}$, then stained using the above protocol and indicated antibody concentrations. After washing with PBS, DNA was counterstained with DAPI.

\section{ChIP}

577 Chip analysis was performed as previously described. Briefly, cellular proteins and DNA were cross-linked by adding formaldehyde to the growth media to a final concentration of $0.1 \%$. Cells 579 were harvested in ice-cold phosphate-buffered saline and lysed with SDS buffer (50 mM Tris, 10 $\mathrm{mM}$ EDTA, and 1\% w/v SDS). Lysates were sonicated utilizing a Branson sonifier 250 (Branson Ultrasonics, Danbury,CT) and precleared with salmon sperm DNA/protein A-agarose (Upstate 582 Biotechnologies, Lake Placid, NY). Lysates were then tumbled overnight at $4{ }^{\circ} \mathrm{C}$ with salmon 583 sperm DNA/protein A-agarose with anti-GFP or rabbit IgG antibodies. Complexes were 584 precipitated and serially washed three times each with low salt (20 mM Tris, $150 \mathrm{mM} \mathrm{NaCl,} 2 \mathrm{mM}$ 585 EDTA, $0.1 \%(\mathrm{w} / \mathrm{v}) \mathrm{SDS}$, and 1\% (v/v) Triton X-100); high salt (20 mM Tris, 500mM NaCl, $2 \mathrm{mM}$ EDTA, $01 \%(w / v)$ SDS, and 1\% (v/v) Triton X-100); LiCl wash (10 mM Tris, $250 \mathrm{mM} \mathrm{LiCl,} 1$ 
2 mM EDTA). Washed complexes were eluted with freshly prepared elution buffer (1\% SDS and $100 \mathrm{mM} \mathrm{NaHCO} 3$ ), and the $\mathrm{Na}+$ concentration was adjusted to $200 \mathrm{mM}$ by adding $\mathrm{NaCl}$ followed by incubation at $37{ }^{\circ} \mathrm{C}$ to reverse protein/DNA cross-links. DNA was purified utilizing a PCR purification kit (Qiagen). Purified DNA was then amplified across the il8 locus region or centromeric $\alpha$-satellite DNA on chromosome 7, primers available in Table 3.

Proximity ligation assay (PLA)

595 PLA was performed as described (Banerjee et al., 2014).

\section{DRIP/DRIP-seq}

598 DLD1 cells were arrested in colcemid for 24 hours and then treated with either DMSO, AZD-1152 or ZM-447439 at the indicated concentrations (Table 2) for 1 hour. Mitotic shakeoffs were 600 performed to gain a mitotic population. DRIP assays were performed as in Halász et al., 2017. 601 Briefly, cells were fixed using 1\% Formaldehyde for 10 minutes, then quenched with Glycine to a 602 final concentration of $0.5 \mathrm{M}$ at room temperature. Cells were collected, washed twice with PBS, 603 resuspended in lysis buffer (50 mM HEPES-KOH, pH 7.5, 140 mM NaCl, 1 mM EDTA, 1\% 604 Triton X-100, 0.1\% Na-Deoxycholate, $1 \%$ SDS), $1 \mathrm{~mL}$ per $10^{7}$ cells, lysed by being passed through 605 a $20 \mathrm{G}$ needle 10 times, and sonicated 15 cycles of 30s on, 30s off, High setting, Bioruptor. This 606 yielded an average of $300 \mathrm{bp}$ fragment. Sonicated chromatin was digested with Proteinase K to 1 $607 \mu \mathrm{g} / \mathrm{ml}$ at $65{ }^{\circ} \mathrm{C}$ overnight to remove proteins and crosslinks. DNA was precipitated using 1/10 608 volume $3 \mathrm{M} \mathrm{Na}$-acetate and 1 volume isopropanol and incubated for 1 hour at $-80{ }^{\circ} \mathrm{C}$. The DNA 609 pellet was washed, dried, and resuspended in $100 \mu 15 \mathrm{mM}$ Tris- $\mathrm{HCl} \mathrm{pH} \mathrm{8.5.12 \mu g}$ of the resulting 610 DNA was incubated with RNaseH1 buffer +/- RNaseH1 (40 units, Takara) overnight at $37{ }^{\circ} \mathrm{C}$,

611 then $10 \mu \mathrm{g}$ of the reaction was incubated with $5 \mu \mathrm{g}$ of S9.6 hybridoma antibody overnight in IP 612 buffer (50 mM HEPES-KOH pH 7.5, 140 mM NaCl, 5 mM EDTA, $1 \%$ Triton X-100, 0.1\% Na613 Deoxycholate), rotating at $4{ }^{\circ} \mathrm{C} .25 \mu$ pre-blocked Dynabeads Protein A (Thermo Fisher, blocked 614 for 1 hour in PBS/EDTA with $0.5 \%$ BSA) were added to the immunoprecipitation and rotated for

6154 hours at $4{ }^{\circ} \mathrm{C}$. Beads were recovered and washed successively for $30 \mathrm{mins}$ at room temperature 616 each: 2 washes of $1 \mathrm{ml}$ low salt buffer (50 mM HEPES-KOH pH 7.5, $140 \mathrm{mM} \mathrm{NaCl,} 5 \mathrm{mM}$ EDTA, $6171 \%$ Triton X-100, 0.1\% Na-Deoxycholate), 2 washes of $1 \mathrm{ml}$ high salt buffer (50 mM HEPES- 
$\mathrm{KOH} \mathrm{pH}$ 7.5, $500 \mathrm{mM} \mathrm{NaCl}, 5 \mathrm{mM}$ EDTA, 1\% Triton X-100, 0.1\% Na-Deoxycholate), 2 washes

619 of $1 \mathrm{ml} \mathrm{LiCl}$ wash buffer (10 mM Tris-HCl pH 8, $250 \mathrm{mM} \mathrm{LiCl,} 1 \mathrm{mM}$ EDTA, 1\% Triton X-100,

$6200.1 \%$ Na-Deoxycholate, $0.5 \%$ NP-40), and 2 washes of $1 \mathrm{ml} \mathrm{TE} \mathrm{buffer} \mathrm{(10} \mathrm{mM} \mathrm{Tris-HCl} \mathrm{pH} \mathrm{8,} 10$

$621 \mathrm{mM}$ EDTA). Elution was performed in $100 \mu \mathrm{l}$ elution buffer (50 mM Tris-HCl pH 8, $10 \mathrm{mM}$

622 EDTA, $1 \%$ SDS) for 15 minutes at $65^{\circ} \mathrm{C}$, vortexing every 5 minutes. Resulting supernatant DNA

623 was purified using a PCR clean-up kit (Invitrogen), along with $1 \mu \mathrm{g}$ starting DNA from the

624 RNaseH1 reaction. The recovered DNA was analyzed by quantitative real-time PCR using

625 LunaScript qPCR mastermix (NEB) and the ABI StepOnePlus qPCR machine and primers in

626 Table 3. $45 \mathrm{ng}$ of precipitated DNA spiked with $5 \mathrm{ng}$ of fragmented genomic DNA from $S$.

627 cerevisiae (strain MT11, a gift from the David Auble) was used as starting material for the Takara

628 SMARTer ThruPLEX DNA-seq Kit and DNA HT Dual Index Kit. Libraries were sequenced using

629 the Illumina NextSeq 500 at the UVA Genome Analysis and Technology Core using 12-plex

630 multiplexing, mid output 150 round paired end sequencing, resulting in greater than $10 \mathrm{M}$ reads

631 per sample.

632

Bioinformatic Analysis

634 HEK293 reads were obtained from the European Nucleotide Archive (ENA) under

635 accession number GSE68953 for the study (Nadel et al., 2015). These reads were processed

636 identically to the reads derived in this study. Reads were quality thresholded using PRINSEQ

637 (Minimum mean quality $=15$, minimum quality to trim $=20$, minimum length to drop $=100$,

638 maximal $\mathrm{N}$ percentage $=2$ ) and subsampled to $6.5 \mathrm{M}$ reads using seqtk. Sequences were first

639 aligned to SacCer3 genome using BWA-MEM (Li and Durbin, 2009) to determine spike

640 percentage (HEK293 reads used as background alignment for sequence conservation) in order to

641 determine a scaling factor according to library preparation efficiency. These values are listed

642 below in Table 4. Due to an error in de-multiplexing, R2 file of ZM sample had to be reverse

643 complemented to generate FR oriented pairs. Reads were aligned to the human genome (hg38)

644 using BWA-MEM. Given that we expected to observe repetitive sequences in our samples, we

645 did not use repeat-masking but required only one alignment per read pair. Peaks were called

646 using MACS2 (Feng et al., 2012; Zhang et al., 2008), with replicate samples used to refine peaks

647 common to both replicates (FDR 1\%, ZM and AZD were considered replicates in this case). Tag

648 Directories were created using Homer makeTagDirectory (Heinz et al., 2010) and were used to 
generate enrichment graphs using annotatePeak (Heinz et al., 2010) using the peak profile setting. Homer peak annotation was used to generate genome ontology graphs. The most recent GENCODE version (v32, Frankish et al., 2019) was used for annotation of gene bodies, transcription start sites (TSS) and transcription termination sites (TTS). RepeatExplorer Galaxy instance (Novák et al., 2013) was used to generate de novo repeat clusters using compiled input

654 files. The subsampled files were then aligned to the contigs generated using a BLAST-N similarity search (Neumann et al., 2012) to gain a count table, which was then normalized, scaled and repeat experiments were averaged. HOR specific K-mers were obtained from the supplemental information in Miga, 2017. Kmer counts were obtained using the KAT sect function (Mapleson et al., 2017).

Table 4. Spike in quantification

\begin{tabular}{|l|l|l|l|}
\hline Sample & $\begin{array}{l}\text { Reads Mapped and } \\
\text { Paired }\end{array}$ & Corrected & Scaling factor \\
\hline Input 1 & $2.94 \mathrm{M}$ & $2.84 \mathrm{M}$ & 0.211 \\
\hline Input 2 & $2.15 \mathrm{M}$ & $2.05 \mathrm{M}$ & 0.293 \\
\hline HEK293 Input & $0.10 \mathrm{M}$ & 0 & $0.9^{*}$ \\
\hline DMSO 1 & $3.75 \mathrm{M}$ & $3.48 \mathrm{M}$ & 0.172 \\
\hline DMSO 2 & $1.32 \mathrm{M}$ & $1.05 \mathrm{M}$ & 0.571 \\
\hline AZD & $2.07 \mathrm{M}$ & $1.80 \mathrm{M}$ & 0.333 \\
\hline ZM & $1.25 \mathrm{M}$ & $0.98 \mathrm{M}$ & 0.612 \\
\hline DMSO-RNH1 1 & $4.63 \mathrm{M}$ & $4.36 \mathrm{M}$ & 0.138 \\
\hline DMSO-RNH1 2 & $5.52 \mathrm{M}$ & $5.25 \mathrm{M}$ & 0.114 \\
\hline HEK293 DRIP & $0.27 \mathrm{M}$ & 0 & $0.9^{*}$ \\
\hline
\end{tabular}

*Assumed complete efficiency with library preparation

Purification of mitotic chromatin and MNase digestion

Either LAP, LAP-Aurora B, LAP-Survivin or LAP-Borealin expressing HeLa cells 665 (3x109) were arrested with colcemid for 16-18 hours were harvested and mitotic chromosomes were purified as described (Paulson, 1982). Mitotic chromosomes were resuspended in 40ml 
Inhibitors cocktail (EDTA free, Roche), 20mM $\beta$-glycerophosphate,1mM Sodium orthovanadate, $3 \mathrm{mM} \mathrm{CaCl}$, $250 \mathrm{mM} \mathrm{NaCl}$, and 0.1\% Digitonin) and digested with MNase (Roche, 150u ml-1) for 1 hour at room temperature. After digestion extracts were supplemented with $50 \mathrm{mM} \mathrm{NaF}$ and clarified by centrifugation at $12,000 \mathrm{~g}$ for 20 minutes at $4^{\circ} \mathrm{C}$. The supernatants were used as starting materials for LAP purifications that are described in the Figure 1-figure supplement 1.

\section{Multidimensional Protein Identification Technology (MudPIT)}

The elutes from LAP purifications were digested in solution using trypsin. The digested samples were pressure-loaded onto a fused silica capillary desalting column containing $5 \mathrm{~cm}$ of 5 $\mu \mathrm{m}$ Polaris C18-A material (Metachem, Ventura, CA) packed into a 250- $\mu \mathrm{m}$ i.d. capillary with a $2 \mu \mathrm{m}$ filtered union (UpChurch Scientific, Oak Harbor, WA). The desalting column was washed with buffer containing $95 \%$ water, $5 \%$ acetonitrile, and $0.1 \%$ formic acid. After desalting, a 100 $\mu \mathrm{m}$ i.d capillary with a 5 - $\mu \mathrm{m}$ pulled tip packed with $10 \mathrm{~cm} 3 \mu \mathrm{m}$ Aqua C18 material (Phenomenex, Ventura, CA) followed by $3 \mathrm{~cm} 5$ - $\mu \mathrm{m}$ Partisphere strong cation exchanger (Whatman, Clifton, NJ) was attached to the filter union and the entire split-column (desalting column-filter unionanalytical column) was placed in line with an Agilent 1100 quaternary HPLC (Palo Alto, CA) and analyzed using a modified 12-step separation described previously (Washburn et al., 2001). As peptides eluted from the microcapillary column, they were electrosprayed directly into an LTQ 2dimensional ion trap mass spectrometer (ThermoFinnigan, Palo Alto, CA) with the application of a distal $2.4 \mathrm{kV}$ spray voltage. A cycle of one full-scan mass spectrum (400-1400 m/z) followed by 8 data-dependent MS/MS spectra at a 35\% normalized collision energy was repeated continuously throughout each step of the multidimensional separation. Application of mass spectrometer scan functions and HPLC solvent gradients were controlled by the Xcalibur datasystem. MS/MS spectra were analyzed using the following software analysis protocol. Poor quality spectra were removed

692 from the dataset using an automated spectral quality assessment algorithm (Bern et al., 2004). 693 MS/MS spectra remaining after filtering were searched with the SEQUEST ${ }^{\mathrm{TM}}$ algorithm (Eng et 694 al., 1994) against the current version of NCBI Homo sapiens database concatenated to a decoy 695 database in which the sequence for each entry in the original database was reversed (Peng et al., 696 2003). SEQUEST results were assembled and filtered using the DTASelect (version 2.0) program. 697 
All statistical tests were run with the assistance of the Graphpad Prism software. First, statistical outliers were determined and mathematically eliminated using the ROUT method, with

$701 \mathrm{Q}$ value of 1\%. For all measurements, descriptive statistics were then used to determine whether 702 the data conformed to a normal distribution. For the data in which all samples passed a D'Agostino 703 and Pearson test (K2 value measured), data were considered to be normally distributed and a 704 parametric test was applied. These parametric tests were either a student's t-test for comparisons 705 between two samples with similar standard deviations, or Welch's t-test for comparisons between 706 samples with at least 2-fold differing standard deviations, or a one-way ANOVA for comparison 707 of multiple samples. In the case of ANOVA, Dunnet correction for multiple comparison was 708 utilized, and a q statistic was measured for each difference. If at least one sample in a dataset 709 involved non-normally distributed data, non-parametric tests were applied. For comparison 710 between two samples, Mann-Whitney tests were used to compare the ranks of individual data 711 points within the total distribution, a Mann-Whitney U value was collected, and a two-tailed p712 value was determined. For comparison of multiple unpaired samples, a Kruskal-Wallis test was 713 performed to compare ranks of individual data points within the total distribution. Dunn's 714 correction for multiple comparisons was performed on post-test statistics, and Z statistics were 715 used to determine approximate p-values. Two-sided p-values were always determined unless 716 stated within figure legends. If measurements could not be taken for each comparison directly, 717 multiple comparison corrections were applied. Figures show means and ranges of data if normally 718 distributed, medians and ranges of data if not normally distributed.

\section{$721 \quad$ Figure Legends}

722 Figure 1. Aurora B is responsible for removing R-loops from Centromeric Satellite Repeats. DRIP723 seq analysis of mitotic DLD1 cells, stalled in mitosis and treated with vehicle (DMSO), $500 \mathrm{nM}$ 724 AZD-1152, or $2 \mu \mathrm{M}$ ZM-447439 for the last hour of the arrest, compared with asynchronous 725 DRIP-seq from HEK293 cells published in (Nadel et al., 2015). A. Example track of peaks called 726 in vehicle sequence samples, compared with paired RNaseH1-treated samples; replicate data 727 compiled in each. Two DRIP-seq samples per track, measured across 96,139 loci. B. Enrichment 728 of reads at peak loci called in vehicle samples (left, 96,139 loci) or Aurora B inhibited samples 729 (right, 89,803 loci) with replicate data compiled. C. Genomic annotation of all peaks called by the 
same pipeline in asynchronous cells (28,573 loci), vehicle treatment (96,139 loci), and Aurora B inhibited (89,803 loci). D-E. Enrichment of reads across gene bodies, scaled to be a proportion of

732 the gene length in D, and as measured near transcriptional termination sites (TTS) in E. Genes 733 were identified via GENCODE v32. Yellow, Asynchronous cells, Red, Mitotic DMSO treated

734 cells, Green, Mitotic Aurora B inhibited cells. F-G. Analysis of enrichment of reads from Repeat 735 Explorer clusters, after filtering those clusters which had insufficient read counts and those with 736 less than 2-fold enrichment relative to RNaseH1 treated samples. 100 clusters analyzed, 38 737 remained after filtering. Grey lines in F represent 2-fold enrichment. G. Analysis of clusters 738 identified as ALR, 3 clusters measured over 2 DRIP-seq samples; plot shows individual 739 measurements and mean values. H-I. Relative enrichment analysis of higher order repeat specific 740 K-mers derived from Miga, 2017; 2119 measured in all. H. Individual k-mer enrichment log 10741 fold changes in mitotic cells vs asynchronous cells on the $\mathrm{x}$ axis, Aurora B inhibited mitotic cells 742 vs DMSO mitotic cells on the y axis, individual HORs in different colors. Grey lines, 2-fold 743 enrichment lines. I. Distribution of counts of the total k-mer array, points show individual 744 measurements and line represents the mean values. $* * * *, p<0.0001$, calculated by one-way 745 ANOVA.

747 Figure 2. Mitotic R-loops are dynamic and associated with the nuclear periphery during prophase. 748 A. Representative images from randomly cycling RPE1-T-REx cells after indirect 749 immunofluorescence using antibodies against the human centromere (ACA), and R-loops 750 (hybridoma S9.6). Images from one of 5 independent experiments. Scale bar, $7 \mu \mathrm{m}$. B-C. 751 Quantification of S9.6 signal intensity overlapping with ACA (B) and DAPI with the ACA area 752 subtracted (C), divided into interphase and 4 mitotic subsets, prophase, prometaphase, metaphase, 753 and anaphase with 29, 50, 78, 38, and 46 cells measured respectively. Significance values are 754 located in Figure 1-Figure supplement 1C, achieved by Kruskal-Wallis non-parametric ANOVA 755 with post-test. D. Confocal microscopy images of a prophase nucleus. Arrowheads show where 756 the line scan crosses the nuclear periphery. E. Left panel, relative intensity profile of line scan 757 outlined in D. Right panel, 10 individual line scans from different prophase nuclei, scaled and 758 overlaid. F. Scatter plots of intensity correlation between S9.6 and DAPI for a total of 3 nuclei at 759 each phase, thresholded at 3000 a.u. and 5000 a.u. for S9.6 and DAPI respectively where S9.6 760 points were selected by the brightest points in a $0.1 \mu \mathrm{m} 3-\mathrm{D}$ rolling circle. S9.6 intensity was then 
761 subset into low, medium and high (tan, pink, and maroon). Maroon dots are quantified for the

762 distribution of DAPI intensities in G. Significance values achieved by one-way parametric

763 ANOVA with post-test. Interphase: $n=117$; Prophase: $n=137$; Prometaphase: $n=42$ puncta.

Figure 3. Aurora B activity promotes R-loop resolution in mitosis. A. Representative images of RPE1-T-REx cells treated with vehicle (DMSO), $500 \mathrm{nM}$ AZD-1152, or $4 \mu \mathrm{M}$ ZM-447439 for 1 hour. Images are from one of 4 experiments, quantified in B and C as the signal of S9.6 indirect immunofluorescence overlapping with signal of ACA (Centromeric R-loops, B) or DAPI (Chromatin R-loops, C), normalized to ACA signal. Kruskal-Wallis non-parametric ANOVA significance test performed to estimate a p-value. Interphase DMSO: $n=27$ cells; Interphase AZD: $\mathrm{n}=25$ cells; Interphase ZM: $\mathrm{n}=28$ cells; Mitotic DMSO: $\mathrm{n}=97$ cells; Mitotic AZD: $\mathrm{n}=26$ cells;

772 Mitotic ZM: $\mathrm{n}=51$ cells. D. ACA values were compared across samples to justify normalization 773 to ACA, no significant differences were detected by Kruskal-Wallis ANOVA. E-F. DRIP-qPCR 774 results from 3 independent experiments from DLD1 cells arrested in mitosis and treated with 775 vehicle (DMSO), $500 \mathrm{nM}$ AZD-1152, or $2 \mu \mathrm{M}$ ZM-447439 for the last hour of the arrest. DXZ1

776 locus, $\mathrm{X}$-chromosome primary $\alpha$-satellite higher-order repeat array; rDNA assayed at $4 \mathrm{~kb}$ into the 777 rDNA repeat.

Figure 4. R-loop presence is necessary to localize Aurora B. A. Expression of a tet-inducible mCherry-RNaseH1 from E.coli and a catalytically dead mutant with point mutations D10R, E48R (2R) was induced within randomly cycling HeLa-T-REx cells and indirect immunofluorescence

782 for Aurora B was assayed. Aurora B intensity normalized to DAPI intensity was quantified in B, 783 with 10 cells measured in each; mean values and range are shown. Significance was determined 784 by one-way ANOVA compared to WT cells. C-F. RPE1-T-REx cells infected with a constitutive 785 EGFP or EGFP-hRNaseH1 construct, within a double thymidine block and release to allow for 786 peak expression during the first mitosis. Cells were then subjected to indirect immunofluorescence 787 for H2ApT120 and ACA (E-F), or H3pT3 and ACA (G-H). Signal of the histone mark normalized 788 to ACA quantified in F and H, shown as median and range values. Significance values dictated by 789 Mann-Whitney non-parametric tests. 
Figure 5. RBMX associates with the CPC and R-loops. A. MudPiT analysis of LAP-tagged Aurora B, Borealin, and Survivin precipitation many of the same peptides, not observed in the background LAP only precipitation. B. DAVID GO keywords of all proteins precipitated in A, top three are phosphoprotein, ribonucleoprotein, and RNA-binding protein. Light blue, negative log p-value as identified by DAVID; purple, number of proteins associated with each keyword; green, proportion of the total proteins associated with each keyword that also appears in the R-loop interactome published by (citation). C. Co-immunoprecipitation of tagged proteins from HEK293T cells. Flagtagged RBMX or Flag alone was co-expressed with HA-tagged CPC members, and all four CPC members can be observed to be co-immunoprecipitated with RBMX specifically. D. Coimmunoprecipitation of endogenous protein from HeLa-T-REx cells. Immunoprecipitation of endogenous Aurora B, Borealin, and RBMX but not non-specific IgG can be observed to precipitate RBMX and Aurora B. E. Indirect immunofluorescence after extraction of unbound proteins prior to fixation in RPE1-T-REx cells shows RBMX localization to the centromere, as marked by ACA. Scale bar, $1.6 \mu \mathrm{m}$. F. Degradation of R-loops by overexpression of EGFPhRNaseH1 in RPE1-T-REx cells leads to loss of RBMX bound to chromatin. Representative images of prometaphase cells in the left panel. F' Quantification of chromatin bound RBMX in mitotic cells, expressed as a proportion of measured nearby interphase cells as the maximal proportion of RBMX protein that could remain bound to chromatin, which is shown in the right panel. Graphs show mean and range values for the 15 mitotic and 15 paired interphase cells, Pvalue calculated by unpaired two-tailed t-test. G. ChIP-qPCR of LAP, LAP-RBMX, or YFPCENP-A to the $\alpha$-satellite array of chromosome 7 or control locus I18. Values are expressed as fold enrichment of IgG control IP from the same cells at the same locus. Graph shows the results

814 from HeLa-T-REx cells. Borealin indirect immunofluorescence was also performed as a 815 localization control for the CPC.

817 Figure 6. RBMX is necessary to resolve R-loops and localize Aurora B. A-B. shRNA knockdown 818 of RBMX in RPE1-T-REx cells results in loss of Aurora B localization, as well as an increase in 819 prevalence of S9.6 immunofluorescence signal. A. Representative images from one of 3 820 experiments, quantified in B, of the loss of Aurora B immunofluorescence intensity and gain of 821 S9.6 fluorescence intensity. Graphs in B show median and range values for normalized 
822 fluorescence intensity, $\mathrm{n}=22$ cells and 15 cells respectively. P-values estimated by Mann-Whitney 823 non-parametric tests. C-E. loss of Aurora B after shRNA knockdown of RBMX in HeLa-T-REx 824 cells can be rescued by expression of LAP-RBMX. C. Representative images of 825 immunofluorescence of Aurora B and CENP-T from 2 experiments. D. Quantification of 826 centromeric Aurora B, normalized to CENP-T immunofluorescence signal. P-value determined by 827 one-way ANOVA, n=17, 12, 18 respectively. E. Western blot showing RBMX expression after 828 shRNA knockdown and re-expression of LAP-RBMX.

830 Figure 7. R-loops and RBMX recruit Aurora B to recruit Sgo1 and maintain centromeric cohesion. 831 A. Representative images of normal spreads and cells with premature chromatid separation (PCS).

832 B. Quantification of percent PCS in HeLa-T-REx cells overexpressing E. coli RNaseH1 or 833 catalytically dead RNaseH1-2R mutant from 4 replicate experiments, with 10 fields imaged from 834 each cell type in each experiment. C. Quantification of percent PCS in HeLa-T-REx cells 835 expressing shRNAs that are either non-targeting (shCtrl) or against RBMX and a tet-inducible 836 CENP-B DNA binding domain fused to INCENP. 3 replicate experiments. D. RPE1-T-REx cells 837 overexpressing GFP-hRNaseH1 or GFP empty vector, stained using indirect immunofluorescence 838 for Sgo1 and ACA. Quantified in E, p-value determined by unpaired two-tailed t-test. F. Cells in 839 C stained for immunofluorescence of Sgo1 and Aurora B. Quantified in G for Sgo1 (top) and 840 Aurora B (bottom) intensity, normalized to the level of fluorescence in control shRNA cells 841 without CENP-B-INCENP construct expression. P-values determined by one-way ANOVA. H. 842 PCS assay for HeLa-T-REx cells expressing CENP-B DNA binding domain fused with GFP, 843 Sgo1, or INCENP and either treated with vehicle (DMSO), or Aurora B inhibitor Hesperadin at $844100 \mathrm{nM}$ with MG132 to prevent escape from mitotic arrest. 3 replicate experiments. I. PCS assay 845 for HeLa-T-REx cells expressing non-targeting shCtrl or shSgo1, and CENP-B DNA binding 846 domain fused to either GFP or INCENP. 3 replicate experiments. J. Western blot for cells 847 expressing non-targeting shCtrl or shSgo1 and blotted for Sgo1. K. Schematic representation of 848 the results of the epistatic experiments presented in this work.

850 Supplemental Figure 1. R-loops are associated with condensing chromatin. A. Total chromatin 851 intensities of R-loops, quantified by total S9.6 signal over the DAPI stained region, normalized to 852 DAPI. B. Additional images of prophase nuclei with additional line scan tracks from figure 1E 
demarcated. Scale bars, $13 \mu \mathrm{m}$. C. Significance values of S9.6 quantifications from Kruskal-Wallis non-parametric ANOVAs with post-test to estimate approximate p-values, given that data in all cases failed multiple normality tests. Black boxes, $\mathrm{p}<0.0001$; all other values listed within the

856 heatmaps.

Supplemental Figure 2. RNaseH1 overexpression controls R-loop prevalence, Aurora B activation.

A. Western blot showing induction of mCherry-RNaseH1 constructs after 8 hours of doxycycline addition. B. Mitotic spreads of HeLa-T-REx cells overexpressing mCherry-RNaseH1 constructs, with indirect immunofluorescence for ACA, mCherry, and S9.6. C. Quantification of S9.6 normalized to ACA. D. Quantification of total ACA signal, not significantly different in the two conditions. E-H. RPE1-T-REx cells treated as in Figure 1 E-H, with indirect immunofluorescence for ACA and Aurora B pT232 (E-F) or ACA, S9.6, and GFP (G-H). F. Quantification of Aurora B pT232 normalized to ACA. H. Quantification of S9.6 normalized to ACA. representation of constructs expressed in HeLa-T-REx cells. B. Validation of localization of the LAP-tagged proteins. Overlap with indirect immunofluorescence of Borealin in mitotic cells indicates that the proteins localize correctly. C. Schematic representation of purification of proteins. D. DNA fragmentation after Micrococcal Nuclease (MNase) treatment. E. Silver stain gel showing purification of CPC members from LAP-Aurora B purification.

874 Supplemental Figure 4. RBMX is necessary to localize the CPC and CPC localization signals. A.

875 Two different shRNA constructs against RBMX effectively knock down protein levels of RBMX 876 but have no effect on protein levels of CPC members, cohesion, Cyclin B1, or H3S10 877 phosphorylation. B-I. Knockdown of RBMX by the first shRNA in A. in HeLa-T-REx cells leads

878 to loss of B. Borealin immunofluorescence, quantified in C., D. Aurora B pT232 879 immunofluorescence, quantified in E., F. H3pT3 immunofluorescence, quantified in G., and H. 880 H2ApT120 immunofluorescence, quantified in I. J, knockdown of RBMX by the second shRNA 881 confirms loss of Aurora B immunofluorescence, quantified in K. P-values determined by unpaired 882 two-tailed t-test. 
884 Supplemental Figure 5. RBMX is necessary to localize the CPC and CPC localization signals in 885 an Aurora B activity dependent manner. A. Representative images of cells knocking down RBMX 886 using shRNA \#1 and adding back CENP-B DNA binding domain fused to INCENP in a tet887 inducible manner, stained using indirect immunofluorescence for Aurora B and H3pT3. 888 Centromeric Aurora B quantified in top left, centromeric H3pT3 quantified in bottom left. B. 889 Representative images of cells knocking down RBMX using shRNA \#1 and adding back CENP-

890 B DNA binding domain fused to INCENP in a tet-inducible manner, stained using indirect 891 immunofluorescence for Bub1 and H2ApT120. Centromeric Bub1 quantified in top left, 892 centromeric H2ApT120 quantified in bottom left.

894 Supplemental Figure 6. Aurora B controls localization of Sgo1, centromeric cohesion. A. HeLa895 T-REx cells treated with Aurora B inhibitor Hesperadin at $100 \mathrm{nM}$ and stained using indirect 896 immunofluorescence for Aurora B, Sgo1 and ACA. Fluorescence intensity normalized to ACA is 897 quantified in B, p-values determined by unpaired two-tailed t-test. C. PCS assay utilizing two 898 different Aurora B inhibitors, ZM-447439 or Hesperadin, with and without MG132. D. Western

899 blots validating knockdown of Aurora B using an shRNA against Aurora B, relative to non900 targeting shCtrl. E. Interkinetochore distance assay, utilizing HeLa-T-REx cells stably expressing 901 LAP-CENP-A either with shCtrl or shAurora B. Increase in interkinetochore distance quantified 902 in F, p-value determined by unpaired two-tailed t-test.

\section{Acknowledgements}

905 We would like to acknowledge Dr. Sathyan Kizhake Mattada, Dr. Michael Guertin, Dr.

906 Manikarna Dinda, and Dr. David Auble for reagents, Dr. Dan Burke for helpful comments and

907 manuscript review, and Dr. Katherine Pfister, Dr. Ewa Niedzialkowska, Dr. Pawel Janczyk, Tan

908 Truong, and Luke Elderidge for helpful discussions. Funding was provided by the National

909 Institutes of Health grant P41 GM103533 (JY), T32 CA 9109-43 (EM), R01 GM118798 (PTS)

910 and R01 GM124042 (PTS).

911

\section{Competing Interests}

913 We acknowledge no competing interests within this manuscript. 


\section{References}

917 Banerjee, B., Kestner, C.A., and Stukenberg, P.T. (2014). EB1 enables spindle microtubules to

918 regulate centromeric recruitment of Aurora B. J. Cell Biol. 204, 947-963.

919 Baxter, J., Sen, N., Martínez, V.L., De Carandini, M.E.M., Schvartzman, J.B., Diffley, J.F.X., and 920 Aragón, L. (2011). Positive supercoiling of mitotic DNA drives decatenation by topoisomerase II 921 in eukaryotes. Science 331, 1328-1332.

922 Bazett-Jones, D.P., Kimura, K., and Hirano, T. (2002). Efficient supercoiling of DNA by a single 923 condensin complex as revealed by electron spectroscopic imaging. Mol. Cell 9, 1183-1190.

924 Bhatia, V., Barroso, S.I., García-Rubio, M.L., Tumini, E., Herrera-Moyano, E., and Aguilera, A. 925 (2014). BRCA2 prevents R-loop accumulation and associates with TREX-2 mRNA export factor 926 PCID2. Nature 511, 362-365.

927 Biggins, S., and Murray, A.W. (2001). The budding yeast protein kinase Ipl1/Aurora allows the 928 absence of tension to activate the spindle checkpoint. Genes Dev. 15, 3118-3129.

Blower, M.D. (2016). Centromeric Transcription Regulates Aurora-B Localization and Activation.

930 Cell Rep. 15, 1624-1633.

931 Boguslawski, S.J., Smith, D.E., Michalak, M.A., Mickelson, K.E., Yehle, C.O., Patterson, W.L., and 932 Carrico, R.J. (1986). Characterization of monoclonal antibody to DNA.RNA and its application to 933 immunodetection of hybrids. J. Immunol. Methods 89, 123-130.

934 Britton, S., Dernoncourt, E., Delteil, C., Froment, C., Schiltz, O., Salles, B., Frit, P., and Calsou, P. 935 (2014). DNA damage triggers SAF-A and RNA biogenesis factors exclusion from chromatin 936 coupled to R-loops removal. Nucleic Acids Res. 42, 9047-9062.

937 Carmena, M., Wheelock, M., Funabiki, H., and Earnshaw, W.C. (2012). The chromosomal 938 passenger complex (CPC): from easy rider to the godfather of mitosis. Nat. Rev. Mol. Cell Biol. 939 13, 789-803.

940 Castellano-Pozo, M., Santos-Pereira, J.M., Rondón, A.G., Barroso, S., Andújar, E., Pérez-Alegre, 941 M., García-Muse, T., and Aguilera, A. (2013a). R loops are linked to histone H3 S10

942 phosphorylation and chromatin condensation. Mol. Cell 52, 583-590.

943 Castellano-Pozo, M., Santos-Pereira, J.M., Rondón, A.G., Barroso, S., Andújar, E., Pérez-Alegre, 944 M., García-Muse, T., and Aguilera, A. (2013b). R loops are linked to histone H3 S10

945 phosphorylation and chromatin condensation. Mol. Cell 52, 583-590.

946 Chan, F.L., Marshall, O.J., Saffery, R., Kim, B.W., Earle, E., Choo, K.H.A., and Wong, L.H. (2012). 947 Active transcription and essential role of RNA polymerase II at the centromere during mitosis.

948 Proc. Natl. Acad. Sci. U. S. A. 109, 1979-1984. 
949 Cheeseman, I.M., and Desai, A. (2005). A combined approach for the localization and tandem 950 affinity purification of protein complexes from metazoans. Sci. STKE Signal Transduct. Knowl. 951 Environ. 2005, pl1.

952 Cimini, D., Wan, X., Hirel, C.B., and Salmon, E.D. (2006). Aurora kinase promotes turnover of 953 kinetochore microtubules to reduce chromosome segregation errors. Curr. Biol. CB 16, 17119541718.

955 Coelho, P.A., Queiroz-Machado, J., Carmo, A.M., Moutinho-Pereira, S., Maiato, H., and Sunkel, 956 C.E. (2008). Dual role of topoisomerase II in centromere resolution and aurora B activity. PLoS 957 Biol. 6, e207.

958 Costantino, L., and Koshland, D. (2018). Genome-wide Map of R-Loop-Induced Damage Reveals 959 How a Subset of R-Loops Contributes to Genomic Instability. Mol. Cell 71, 487-497.e3.

960 Cristini, A., Groh, M., Kristiansen, M.S., and Gromak, N. (2018). RNA/DNA Hybrid Interactome 961 Identifies DXH9 as a Molecular Player in Transcriptional Termination and R-Loop-Associated 962 DNA Damage. Cell Rep. 23, 1891-1905.

963 Dai, J., Sullivan, B.A., and Higgins, J.M.G. (2006). Regulation of mitotic chromosome cohesion by 964 Haspin and Aurora B. Dev. Cell 11, 741-750.

965 Drolet, M., Phoenix, P., Menzel, R., Massé, E., Liu, L.F., and Crouch, R.J. (1995). Overexpression 966 of RNase $\mathrm{H}$ partially complements the growth defect of an Escherichia coli delta topA mutant: 967 R-loop formation is a major problem in the absence of DNA topoisomerase I. Proc. Natl. Acad. 968 Sci. U. S. A. 92, 3526-3530.

969 El Hage, A., French, S.L., Beyer, A.L., and Tollervey, D. (2010). Loss of Topoisomerase I leads to 970 R-loop-mediated transcriptional blocks during ribosomal RNA synthesis. Genes Dev. 24, 15469711558.

972 Eng, J.K., McCormack, A.L., and Yates, J.R. (1994). An approach to correlate tandem mass 973 spectral data of peptides with amino acid sequences in a protein database. J. Am. Soc. Mass 974 Spectrom. 5, 976-989.

975 Feng, J., Liu, T., Qin, B., Zhang, Y., and Liu, X.S. (2012). Identifying ChIP-seq enrichment using 976 MACS. Nat. Protoc. 7, 1728-1740.

977 Frankish, A., Diekhans, M., Ferreira, A.-M., Johnson, R., Jungreis, I., Loveland, J., Mudge, J.M., 978 Sisu, C., Wright, J., Armstrong, J., et al. (2019). GENCODE reference annotation for the human 979 and mouse genomes. Nucleic Acids Res. 47, D766-D773.

980 Gan, W., Guan, Z., Liu, J., Gui, T., Shen, K., Manley, J.L., and Li, X. (2011). R-loop-mediated 981 genomic instability is caused by impairment of replication fork progression. Genes Dev. 25, 982 2041-2056. 
983 Giménez-Abián, J.F., Sumara, I., Hirota, T., Hauf, S., Gerlich, D., de la Torre, C., Ellenberg, J., and 984 Peters, J.-M. (2004). Regulation of sister chromatid cohesion between chromosome arms. Curr. 985 Biol. CB 14, 1187-1193.

986 Ginno, P.A., Lott, P.L., Christensen, H.C., Korf, I., and Chédin, F. (2012). R-loop formation is a 987 distinctive characteristic of unmethylated human CpG island promoters. Mol. Cell 45, 814-825.

988 Ginno, P.A., Lim, Y.W., Lott, P.L., Korf, I., and Chédin, F. (2013). GC skew at the 5' and 3' ends of 989 human genes links R-loop formation to epigenetic regulation and transcription termination.

990 Genome Res. 23, 1590-1600.

991 Gottesfeld, J.M., and Forbes, D.J. (1997). Mitotic repression of the transcriptional machinery. 992 Trends Biochem. Sci. 22, 197-202.

993 Grenfell, A.W., Heald, R., and Strzelecka, M. (2016). Mitotic noncoding RNA processing 994 promotes kinetochore and spindle assembly in Xenopus. J. Cell Biol. 214, 133-141.

995 Gruneberg, U., Neef, R., Honda, R., Nigg, E.A., and Barr, F.A. (2004). Relocation of Aurora B from 996 centromeres to the central spindle at the metaphase to anaphase transition requires MKIp2. J.

997 Cell Biol. 166, 167-172.

998 Halász, L., Karányi, Z., Boros-Oláh, B., Kuik-Rózsa, T., Sipos, É., Nagy, É., Mosolygó-L, Á., Mázló, 999 A., Rajnavölgyi, É., Halmos, G., et al. (2017). RNA-DNA hybrid (R-loop) immunoprecipitation 1000 mapping: an analytical workflow to evaluate inherent biases. Genome Res. 27, 1063-1073.

1001 Hall, L.L., Carone, D.M., Gomez, A.V., Kolpa, H.J., Byron, M., Mehta, N., Fackelmayer, F.O., and 1002 Lawrence, J.B. (2014). Stable COT-1 repeat RNA is abundant and is associated with euchromatic 1003 interphase chromosomes. Cell 156, 907-919.

1004 Hauf, S., Cole, R.W., LaTerra, S., Zimmer, C., Schnapp, G., Walter, R., Heckel, A., van Meel, J., 1005 Rieder, C.L., and Peters, J.-M. (2003). The small molecule Hesperadin reveals a role for Aurora B 1006 in correcting kinetochore-microtubule attachment and in maintaining the spindle assembly 1007 checkpoint. J. Cell Biol. 161, 281-294.

1008 Heinz, S., Benner, C., Spann, N., Bertolino, E., Lin, Y.C., Laslo, P., Cheng, J.X., Murre, C., Singh, H., 1009 and Glass, C.K. (2010). Simple combinations of lineage-determining transcription factors prime 1010 cis-regulatory elements required for macrophage and B cell identities. Mol. Cell 38, 576-589.

1011 Hindriksen, S., Lens, S.M.A., and Hadders, M.A. (2017). The Ins and Outs of Aurora B Inner 1012 Centromere Localization. Front. Cell Dev. Biol. 5, 112.

1013 Hirota, T., Lipp, J.J., Toh, B.-H., and Peters, J.-M. (2005). Histone H3 serine 10 phosphorylation 1014 by Aurora B causes HP1 dissociation from heterochromatin. Nature 438, 1176-1180.

1015 Hubley, R., Finn, R.D., Clements, J., Eddy, S.R., Jones, T.A., Bao, W., Smit, A.F.A., and Wheeler, 1016 T.J. (2016). The Dfam database of repetitive DNA families. Nucleic Acids Res. 44, D81-89. 
1017 Huen, M.S.Y., Sy, S.M.H., Leung, K.M., Ching, Y.-P., Tipoe, G.L., Man, C., Dong, S., and Chen, J. 1018 (2010). SON is a spliceosome-associated factor required for mitotic progression. Cell Cycle 1019 Georget. Tex 9, 2679-2685.

1020 Ideue, T., Cho, Y., Nishimura, K., and Tani, T. (2014). Involvement of satellite I noncoding RNA in 1021 regulation of chromosome segregation. Genes Cells Devoted Mol. Cell. Mech. 19, 528-538.

1022 Jambhekar, A., Emerman, A.B., Schweidenback, C.T.H., and Blower, M.D. (2014). RNA stimulates 1023 Aurora B kinase activity during mitosis. PloS One 9, e100748.

1024 Jeyaprakash, A.A., Klein, U.R., Lindner, D., Ebert, J., Nigg, E.A., and Conti, E. (2007). Structure of 1025 a Survivin-Borealin-INCENP core complex reveals how chromosomal passengers travel together. 1026 Cell 131, 271-285.

1027 Jiang, Y., Liu, M., Spencer, C.A., and Price, D.H. (2004). Involvement of transcription termination 1028 factor 2 in mitotic repression of transcription elongation. Mol. Cell 14, 375-385.

1029 Kabeche, L., Nguyen, H.D., Buisson, R., and Zou, L. (2018). A mitosis-specific and R loop-driven 1030 ATR pathway promotes faithful chromosome segregation. Science 359, 108-114.

1031 Kallio, M.J., McCleland, M.L., Stukenberg, P.T., and Gorbsky, G.J. (2002). Inhibition of aurora B 1032 kinase blocks chromosome segregation, overrides the spindle checkpoint, and perturbs 1033 microtubule dynamics in mitosis. Curr. Biol. CB 12, 900-905.

1034 Kang, J., Chaudhary, J., Dong, H., Kim, S., Brautigam, C.A., and Yu, H. (2011). Mitotic centromeric 1035 targeting of HP1 and its binding to Sgo1 are dispensable for sister-chromatid cohesion in human 1036 cells. Mol. Biol. Cell 22, 1181-1190.

1037 Karamysheva, Z., Díaz-Martínez, L.A., Warrington, R., and Yu, H. (2015). Graded requirement for 1038 the spliceosome in cell cycle progression. Cell Cycle Georget. Tex 14, 1873-1883.

1039 Kimura, K., and Hirano, T. (1997). ATP-dependent positive supercoiling of DNA by 135 1040 condensin: a biochemical implication for chromosome condensation. Cell 90, 625-634.

1041 Kimura, K., Rybenkov, V.V., Crisona, N.J., Hirano, T., and Cozzarelli, N.R. (1999). 13S condensin 1042 actively reconfigures DNA by introducing global positive writhe: implications for chromosome 1043 condensation. Cell 98, 239-248.

1044 Kitajima, T.S., Sakuno, T., Ishiguro, K., lemura, S., Natsume, T., Kawashima, S.A., and Watanabe, 1045 Y. (2006). Shugoshin collaborates with protein phosphatase $2 A$ to protect cohesin. Nature 441, 1046 46-52.

1047 Klein, U.R., Nigg, E.A., and Gruneberg, U. (2006). Centromere targeting of the chromosomal 1048 passenger complex requires a ternary subcomplex of Borealin, Survivin, and the N-terminal 1049 domain of INCENP. Mol. Biol. Cell 17, 2547-2558. 
1050 Knowlton, A.L., Lan, W., and Stukenberg, P.T. (2006). Aurora B is enriched at merotelic

1051 attachment sites, where it regulates MCAK. Curr. Biol. CB 16, 1705-1710.

1052 van der Lelij, P., Stocsits, R.R., Ladurner, R., Petzold, G., Kreidl, E., Koch, B., Schmitz, J., 1053 Neumann, B., Ellenberg, J., and Peters, J.-M. (2014). SNW1 enables sister chromatid cohesion 1054 by mediating the splicing of sororin and APC2 pre-mRNAs. EMBO J. 33, 2643-2658.

1055 Li, H., and Durbin, R. (2009). Fast and accurate short read alignment with Burrows-Wheeler 1056 transform. Bioinforma. Oxf. Engl. 25, 1754-1760.

1057 Liu, D., Vader, G., Vromans, M.J.M., Lampson, M.A., and Lens, S.M.A. (2009). Sensing 1058 chromosome bi-orientation by spatial separation of aurora $B$ kinase from kinetochore 1059 substrates. Science 323, 1350-1353.

1060 Liu, H., Qu, Q., Warrington, R., Rice, A., Cheng, N., and Yu, H. (2015). Mitotic Transcription 1061 Installs Sgo1 at Centromeres to Coordinate Chromosome Segregation. Mol. Cell 59, 426-436.

1062 Liu, Y., Su, H., Zhang, J., Liu, Y., Feng, C., and Han, F. (2020). Back-spliced RNA from 1063 retrotransposon binds to centromere and regulates centromeric chromatin loops in maize. PLoS 1064 Biol. 18, e3000582.

1065 Losada, A., Hirano, M., and Hirano, T. (2002). Cohesin release is required for sister chromatid 1066 resolution, but not for condensin-mediated compaction, at the onset of mitosis. Genes Dev. 16, 1067 3004-3016.

1068 Losada, A., Yokochi, T., and Hirano, T. (2005). Functional contribution of Pds5 to cohesin1069 mediated cohesion in human cells and Xenopus egg extracts. J. Cell Sci. 118, 2133-2141.

1070 Mapleson, D., Garcia Accinelli, G., Kettleborough, G., Wright, J., and Clavijo, B.J. (2017). KAT: a 1071 K-mer analysis toolkit to quality control NGS datasets and genome assemblies. Bioinforma. Oxf. 1072 Engl. 33, 574-576.

1073 Matsunaga, S., Takata, H., Morimoto, A., Hayashihara, K., Higashi, T., Akatsuchi, K., Mizusawa, 1074 E., Yamakawa, M., Ashida, M., Matsunaga, T.M., et al. (2012). RBMX: a regulator for 1075 maintenance and centromeric protection of sister chromatid cohesion. Cell Rep. 1, 299-308.

1076 McNulty, S.M., Sullivan, L.L., and Sullivan, B.A. (2017). Human Centromeres Produce 1077 Chromosome-Specific and Array-Specific Alpha Satellite Transcripts that Are Complexed with 1078 CENP-A and CENP-C. Dev. Cell 42, 226-240.e6.

1079 Meppelink, A., Kabeche, L., Vromans, M.J.M., Compton, D.A., and Lens, S.M.A. (2015).

1080 Shugoshin-1 balances Aurora B kinase activity via PP2A to promote chromosome bi-orientation. 1081 Cell Rep. 11, 508-515.

1082 Miga, K.H. (2017). Chromosome-Specific Centromere Sequences Provide an Estimate of the 1083 Ancestral Chromosome 2 Fusion Event in Hominin Genomes. J. Hered. 108, 45-52. 
1084 Mirkovitch, J., Gasser, S.M., and Laemmli, U.K. (1987). Relation of chromosome structure and 1085 gene expression. Philos. Trans. R. Soc. Lond. B. Biol. Sci. 317, 563-574.

1086 Morrison, C., Henzing, A.J., Jensen, O.N., Osheroff, N., Dodson, H., Kandels-Lewis, S.E., Adams, 1087 R.R., and Earnshaw, W.C. (2002). Proteomic analysis of human metaphase chromosomes 1088 reveals topoisomerase II alpha as an Aurora B substrate. Nucleic Acids Res. 30, 5318-5327.

1089 Nadel, J., Athanasiadou, R., Lemetre, C., Wijetunga, N.A., Ó Broin, P., Sato, H., Zhang, Z., 1090 Jeddeloh, J., Montagna, C., Golden, A., et al. (2015). RNA:DNA hybrids in the human genome 1091 have distinctive nucleotide characteristics, chromatin composition, and transcriptional 1092 relationships. Epigenetics Chromatin 8, 46.

1093 Nakama, M., Kawakami, K., Kajitani, T., Urano, T., and Murakami, Y. (2012). DNA-RNA hybrid 1094 formation mediates RNAi-directed heterochromatin formation. Genes Cells Devoted Mol. Cell. 1095 Mech. 17, 218-233.

1096 Naumova, N., Imakaev, M., Fudenberg, G., Zhan, Y., Lajoie, B.R., Mirny, L.A., and Dekker, J. 1097 (2013). Organization of the mitotic chromosome. Science 342, 948-953.

1098 Neumann, P., Navrátilová, A., Schroeder-Reiter, E., Koblížková, A., Steinbauerová, V., 1099 Chocholová, E., Novák, P., Wanner, G., and Macas, J. (2012). Stretching the rules: monocentric 1100 chromosomes with multiple centromere domains. PLoS Genet. 8, e1002777.

1101 Nishimura, K., Cho, Y., Tokunaga, K., Nakao, M., Tani, T., and Ideue, T. (2019). DEAH box RNA 1102 helicase DHX38 associates with satellite I noncoding RNA involved in chromosome segregation. 1103 Genes Cells Devoted Mol. Cell. Mech. 24, 585-590.

1104 Nishiyama, T., Sykora, M.M., Huis in 't Veld, P.J., Mechtler, K., and Peters, J.-M. (2013). Aurora B 1105 and Cdk1 mediate Wapl activation and release of acetylated cohesin from chromosomes by 1106 phosphorylating Sororin. Proc. Natl. Acad. Sci. U. S. A. 110, 13404-13409.

1107 Novák, P., Neumann, P., and Macas, J. (2010). Graph-based clustering and characterization of 1108 repetitive sequences in next-generation sequencing data. BMC Bioinformatics 11, 378.

1109 Novák, P., Neumann, P., Pech, J., Steinhaisl, J., and Macas, J. (2013). RepeatExplorer: a Galaxy1110 based web server for genome-wide characterization of eukaryotic repetitive elements from 1111 next-generation sequence reads. Bioinforma. Oxf. Engl. 29, 792-793.

1112 Nozawa, R.-S., Nagao, K., Masuda, H.-T., Iwasaki, O., Hirota, T., Nozaki, N., Kimura, H., and 1113 Obuse, C. (2010). Human POGZ modulates dissociation of HP1alpha from mitotic chromosome 1114 arms through Aurora B activation. Nat. Cell Biol. 12, 719-727.

1115 Ohle, C., Tesorero, R., Schermann, G., Dobrev, N., Sinning, I., and Fischer, T. (2016). Transient 1116 RNA-DNA Hybrids Are Required for Efficient Double-Strand Break Repair. Cell 167, 10011117 1013.e7. 
1118 Parsons, G.G., and Spencer, C.A. (1997). Mitotic repression of RNA polymerase II transcription is 1119 accompanied by release of transcription elongation complexes. Mol. Cell. Biol. 17, 5791-5802.

1120 Paulson, J.R. (1982). Isolation of chromosome clusters from metaphase-arrested HeLa cells.

1121 Chromosoma 85, 571-581.

1122 Peng, J., Elias, J.E., Thoreen, C.C., Licklider, L.J., and Gygi, S.P. (2003). Evaluation of

1123 multidimensional chromatography coupled with tandem mass spectrometry (LC/LC-MS/MS) for 1124 large-scale protein analysis: the yeast proteome. J. Proteome Res. 2, 43-50.

1125 Perea-Resa, C., and Blower, M.D. (2017). Satellite Transcripts Locally Promote Centromere 1126 Formation. Dev. Cell 42, 201-202.

1127 Perea-Resa, C., Bury, L., Cheeseman, I.M., and Blower, M.D. (2020). Cohesin Removal 1128 Reprograms Gene Expression upon Mitotic Entry. Mol. Cell 78, 127-140.e7.

1129 Petsalaki, E., Akoumianaki, T., Black, E.J., Gillespie, D.A.F., and Zachos, G. (2011).

1130 Phosphorylation at serine 331 is required for Aurora B activation. J. Cell Biol. 195, 449-466.

1131 Prescott, D.M., and Bender, M.A. (1962). Synthesis of RNA and protein during mitosis in 1132 mammalian tissue culture cells. Exp. Cell Res. 26, 260-268.

1133 Resnick, T.D., Satinover, D.L., Maclsaac, F., Stukenberg, P.T., Earnshaw, W.C., Orr-Weaver, T.L., 1134 and Carmena, M. (2006). INCENP and Aurora B promote meiotic sister chromatid cohesion 1135 through localization of the Shugoshin MEI-S332 in Drosophila. Dev. Cell 11, 57-68.

1136 Sacristan, C., and Kops, G.J.P.L. (2015). Joined at the hip: kinetochores, microtubules, and 1137 spindle assembly checkpoint signaling. Trends Cell Biol. 25, 21-28.

1138 Salimian, K.J., Ballister, E.R., Smoak, E.M., Wood, S., Panchenko, T., Lampson, M.A., and Black, 1139 B.E. (2011). Feedback control in sensing chromosome biorientation by the Aurora B kinase. 1140 Curr. Biol. CB 21, 1158-1165.

1141 Santaguida, S., Vernieri, C., Villa, F., Ciliberto, A., and Musacchio, A. (2011). Evidence that 1142 Aurora $B$ is implicated in spindle checkpoint signalling independently of error correction. EMBO 1143 J. 30, 1508-1519.

1144 Skourti-Stathaki, K., Kamieniarz-Gdula, K., and Proudfoot, N.J. (2014). R-loops induce repressive 1145 chromatin marks over mammalian gene terminators. Nature 516, 436-439.

1146 Stolz, R., Sulthana, S., Hartono, S.R., Malig, M., Benham, C.J., and Chedin, F. (2019). Interplay 1147 between DNA sequence and negative superhelicity drives R-loop structures. Proc. Natl. Acad. 1148 Sci. U. S. A. 116, 6260-6269.

1149 Strissel, P.L., Espinosa, R., Rowley, J.D., and Swift, H. (1996). Scaffold attachment regions in 1150 centromere-associated DNA. Chromosoma 105, 122-133. 
1151 Stukenberg, P.T., and Burke, D.J. (2015). Connecting the microtubule attachment status of each 1152 kinetochore to cell cycle arrest through the spindle assembly checkpoint. Chromosoma 124, 1153 463-480.

1154 Sundaramoorthy, S., Vázquez-Novelle, M.D., Lekomtsev, S., Howell, M., and Petronczki, M. 1155 (2014). Functional genomics identifies a requirement of pre-mRNA splicing factors for sister 1156 chromatid cohesion. EMBO J. 33, 2623-2642.

1157 Tang, Z., Shu, H., Qi, W., Mahmood, N.A., Mumby, M.C., and Yu, H. (2006). PP2A is required for 1158 centromeric localization of Sgo1 and proper chromosome segregation. Dev. Cell 10, 575-585.

1159 Tanno, Y., Kitajima, T.S., Honda, T., Ando, Y., Ishiguro, K.-I., and Watanabe, Y. (2010).

1160 Phosphorylation of mammalian Sgo2 by Aurora B recruits PP2A and MCAK to centromeres.

1161 Genes Dev. 24, 2169-2179.

1162 Taylor, J.H. (1960). Nucleic acid synthesis in relation to the cell division cycle. Ann. N. Y. Acad. 1163 Sci. 90, 409-421.

1164 van der Waal, M.S., Saurin, A.T., Vromans, M.J.M., Vleugel, M., Wurzenberger, C., Gerlich, D.W., 1165 Medema, R.H., Kops, G.J.P.L., and Lens, S.M.A. (2012). Mps1 promotes rapid centromere 1166 accumulation of Aurora B. EMBO Rep. 13, 847-854.

1167 Wahba, L., Amon, J.D., Koshland, D., and Vuica-Ross, M. (2011). RNase H and multiple RNA 1168 biogenesis factors cooperate to prevent RNA:DNA hybrids from generating genome instability. 1169 Mol. Cell 44, 978-988.

1170 Washburn, M.P., Wolters, D., and Yates, J.R. (2001). Large-scale analysis of the yeast proteome 1171 by multidimensional protein identification technology. Nat. Biotechnol. 19, 242-247.

1172 Welburn, J.P.I., Vleugel, M., Liu, D., Yates, J.R., Lampson, M.A., Fukagawa, T., and Cheeseman, 1173 I.M. (2010). Aurora B phosphorylates spatially distinct targets to differentially regulate the 1174 kinetochore-microtubule interface. Mol. Cell 38, 383-392.

1175 Willard, H.F. (1985). Chromosome-specific organization of human alpha satellite DNA. Am. J. 1176 Hum. Genet. 37, 524-532.

1177 Yang, X., Boehm, J.S., Yang, X., Salehi-Ashtiani, K., Hao, T., Shen, Y., Lubonja, R., Thomas, S.R., 1178 Alkan, O., Bhimdi, T., et al. (2011). A public genome-scale lentiviral expression library of human 1179 ORFs. Nat. Methods 8, 659-661.

1180 Yasuhara, T., Kato, R., Hagiwara, Y., Shiotani, B., Yamauchi, M., Nakada, S., Shibata, A., and 1181 Miyagawa, K. (2018). Human Rad52 Promotes XPG-Mediated R-loop Processing to Initiate 1182 Transcription-Associated Homologous Recombination Repair. Cell 175, 558-570.e11. 
bioRxiv preprint doi: https://doi.org/10.1101/2021.01.14.426738; this version posted January 15, 2021. The copyright holder for this preprint (which was not certified by peer review) is the author/funder. All rights reserved. No reuse allowed without permission.

1183 Zhang, Y., Liu, T., Meyer, C.A., Eeckhoute, J., Johnson, D.S., Bernstein, B.E., Nusbaum, C., Myers, 1184 R.M., Brown, M., Li, W., et al. (2008). Model-based analysis of ChIP-Seq (MACS). Genome Biol. 11859 9, R137.

1186

1187 
A Rxiv preprint doi: https:/doi.org/10.1101/2021.01.14.426738; this version posted January 15,2021 . The copyright holder for this preprint Mitotic Dhich so 0 peaks

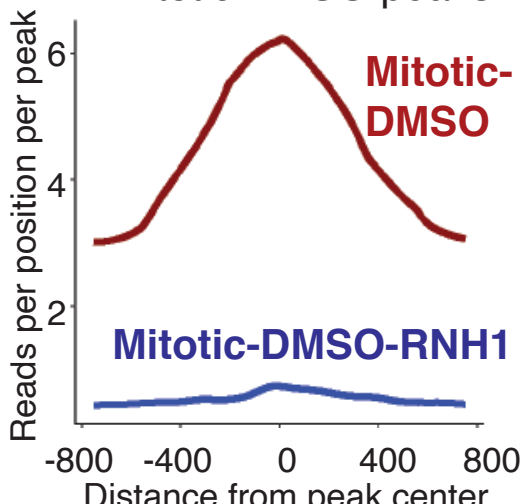

B
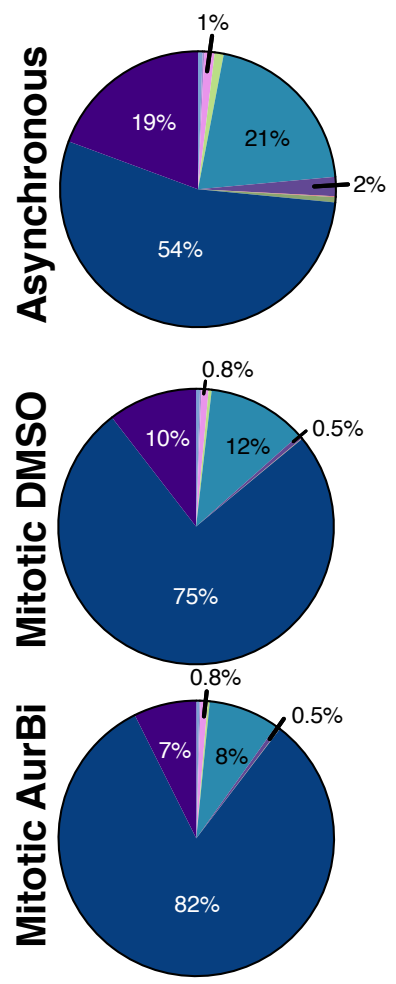

H

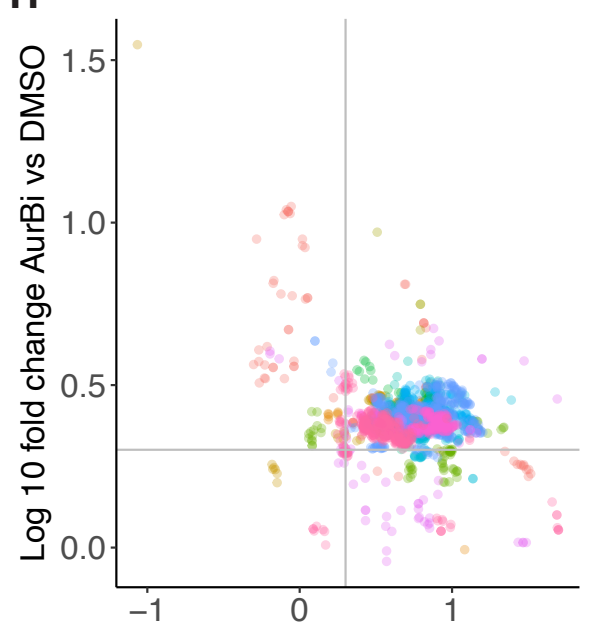

D11Z1

D12Z3

D13Z1

D14Z9

D17Z1

D18Z1

D1Z7

D2Z1

D3Z1

D4Z1

D6Z1

D7Z1

D7Z2

D8Z2

DXZ1

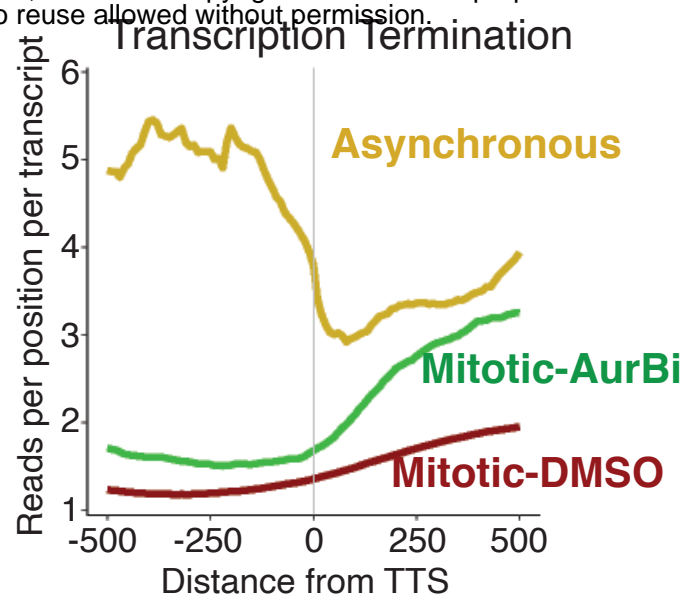

Proportion of Gene Distance

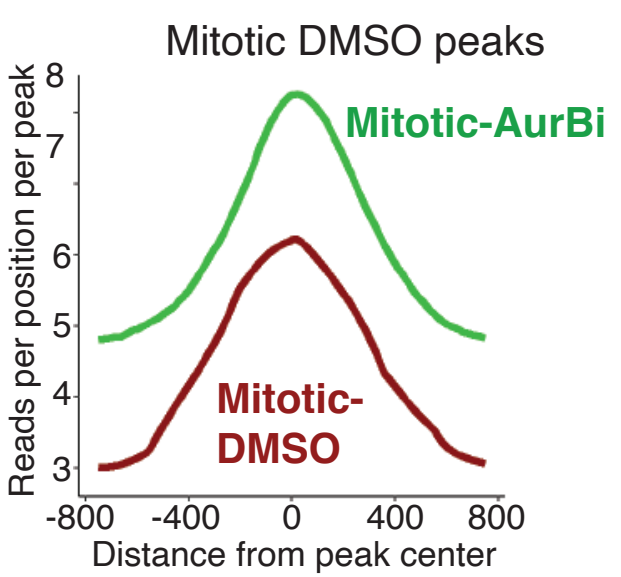

F Repeat Explorer Clusters

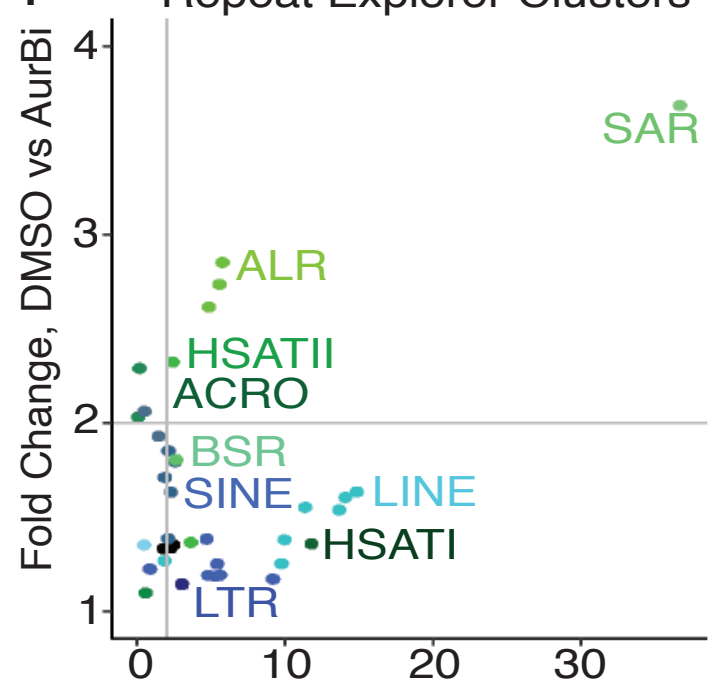

Fold Change, mitotic vs asynchronous

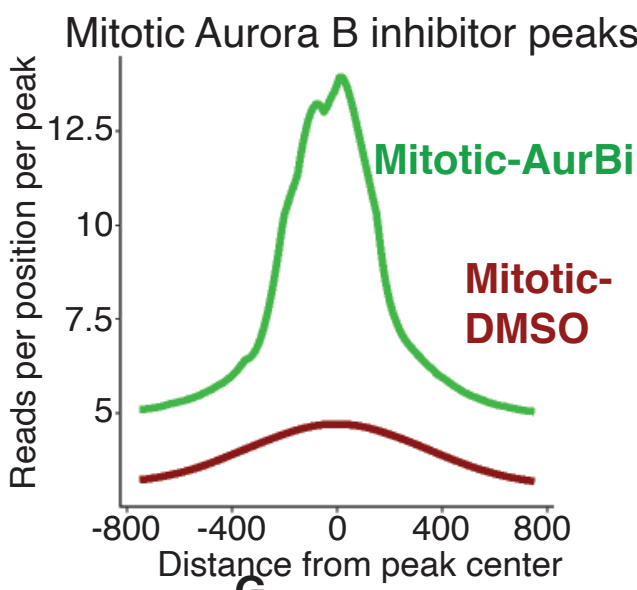

G

Log 10 fold change Mitotic vs Asynchronous

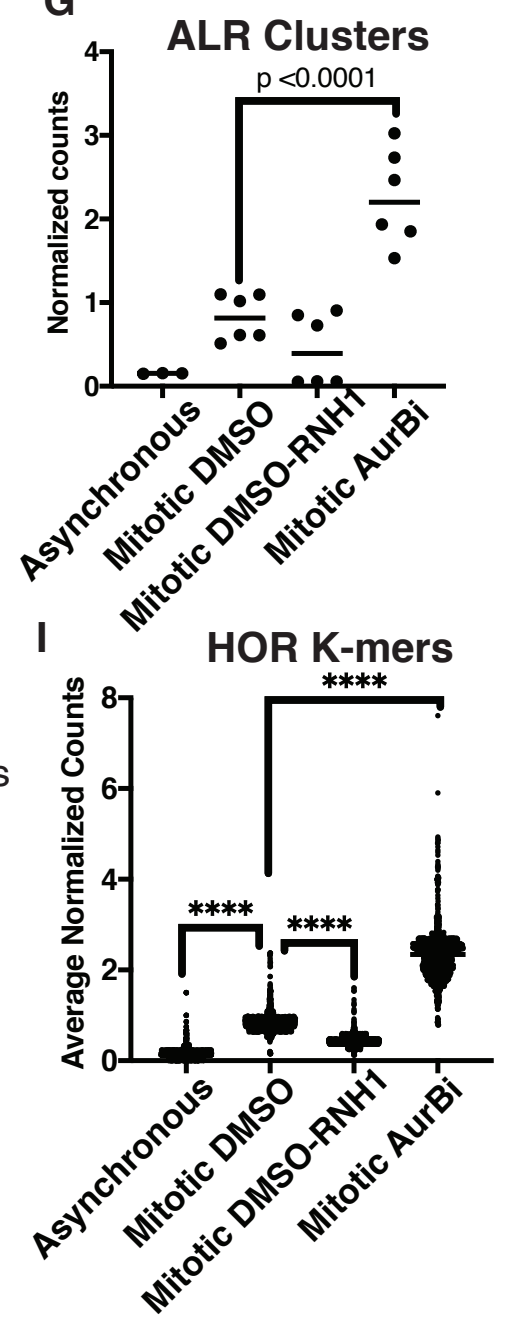

Figure 1.Aurora B is responsible for removing R-loops from Centromeric Satellite Repeats. 


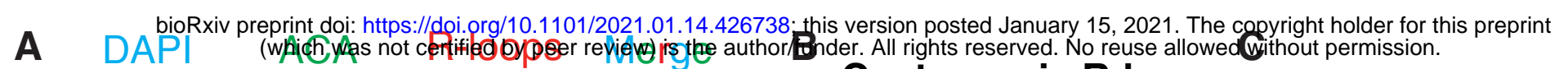

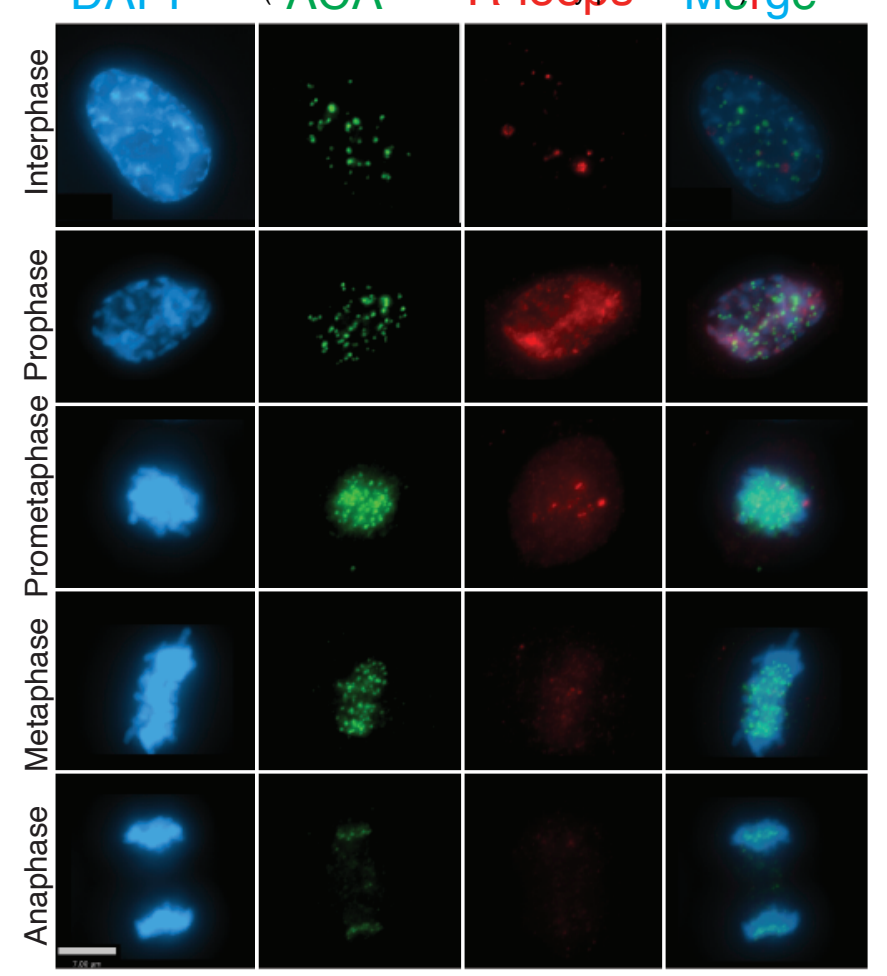

D
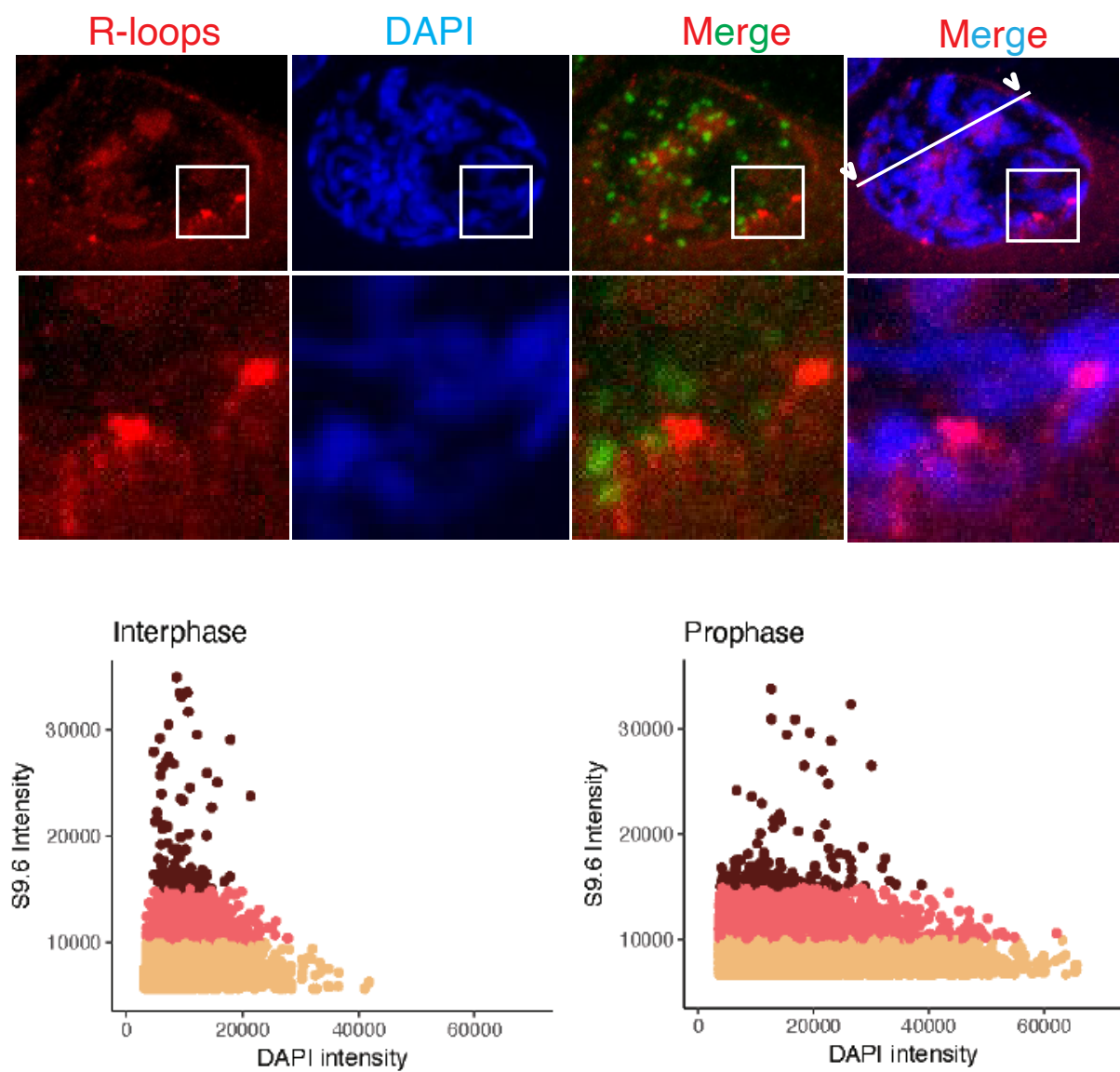

Centromeric R-loops

Arm R-loops
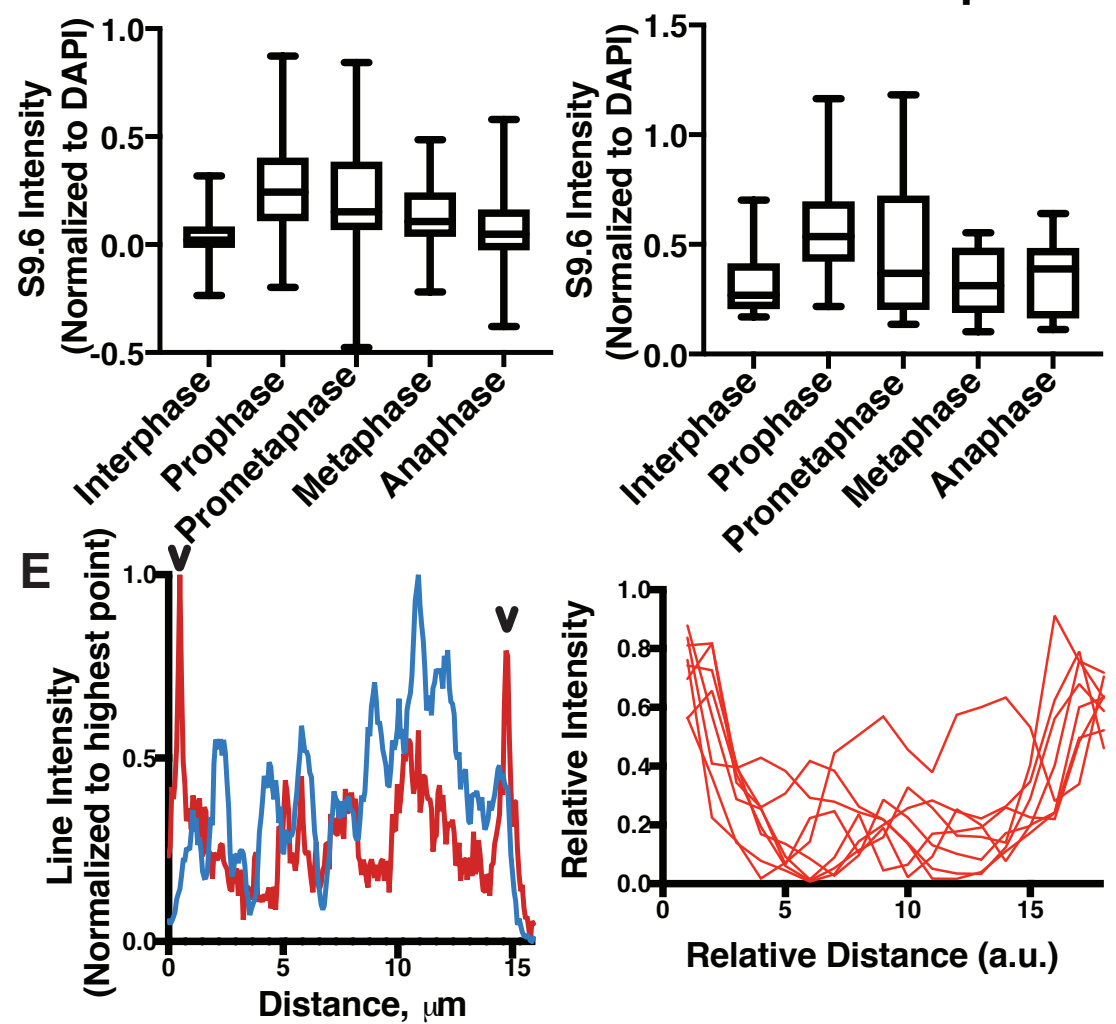

G

R-loop Puncta

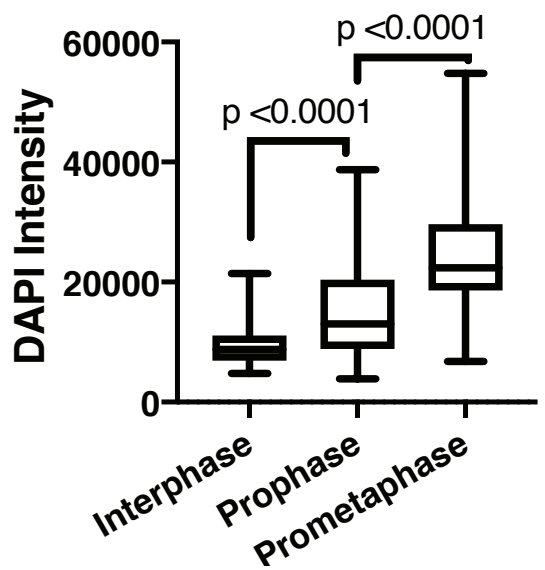

Prometaphase

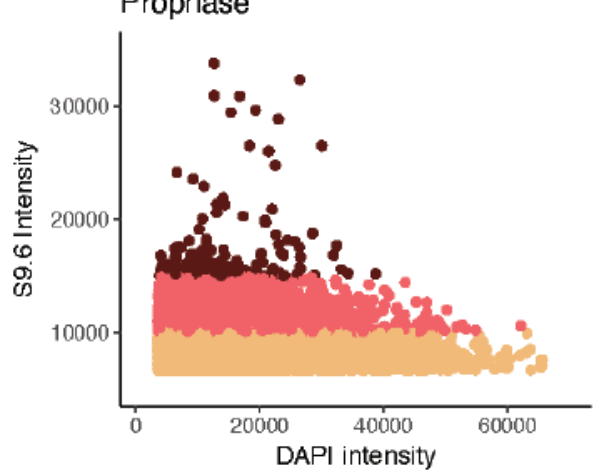

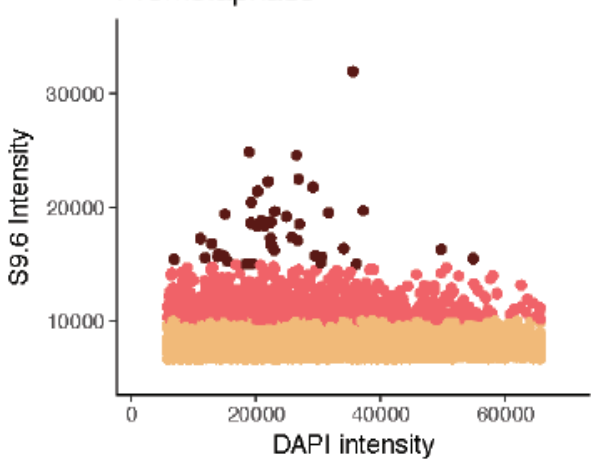

Figure 2. Mitotic R-loops are dynamic and associated with the nuclear periphery during prophase. 
bioRxiv preprint doi: https://doi.org/10.1101/2021.01.14.426738; this version posted January 15, 2021. The copyright holder for this preprint

A (which was not certified by peer review) is the author/funger. All rights reserved. No reuse allowed without permission.
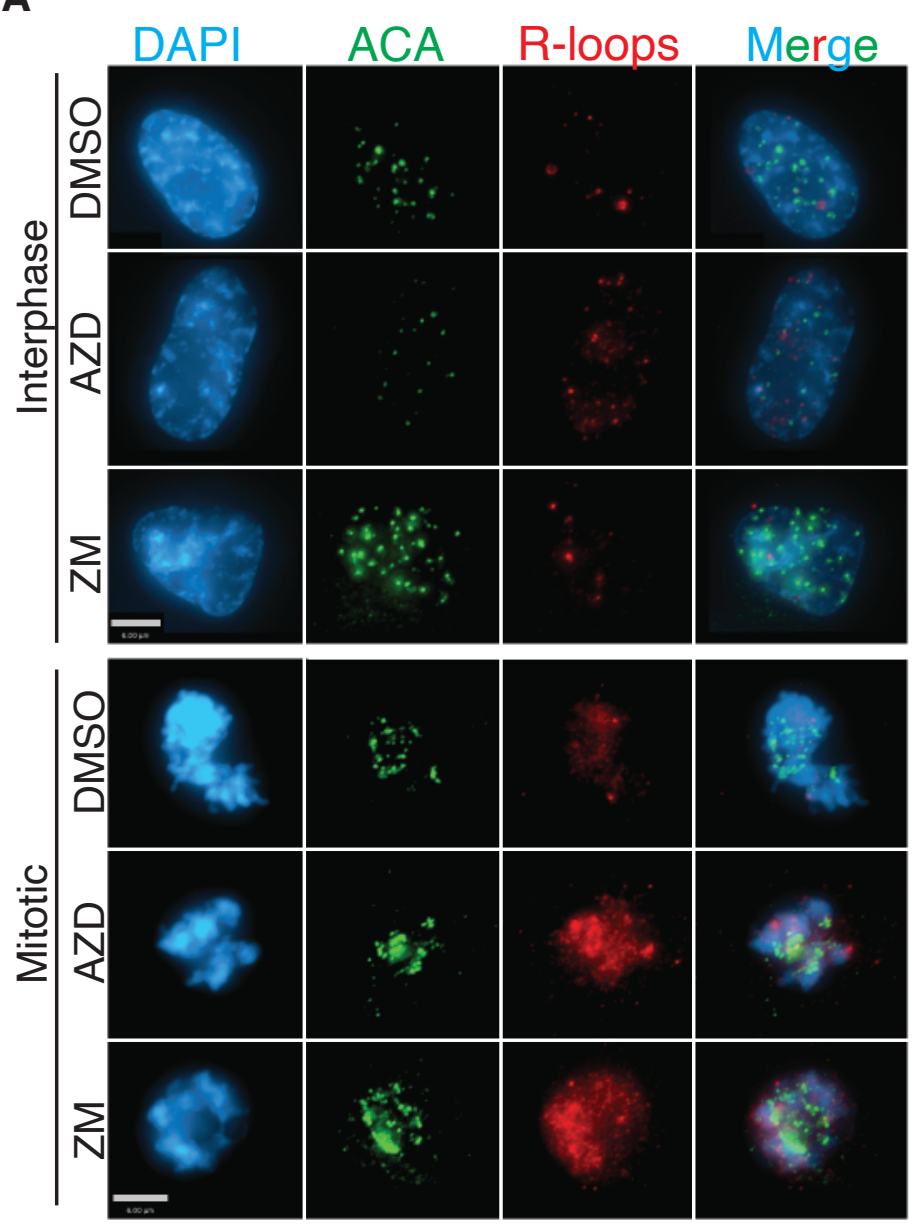

E

DRIP-qPCR DXZ1

$\mathbf{F}$

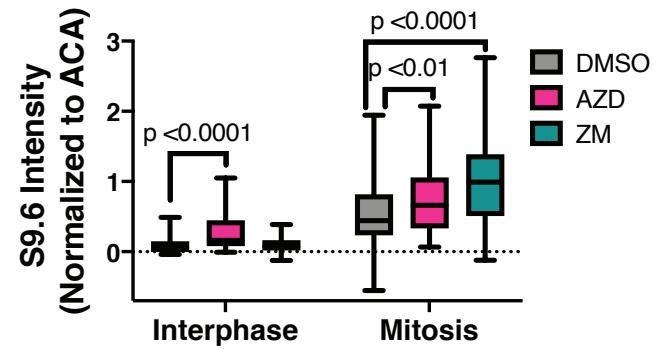

C

Chromatin R-loops

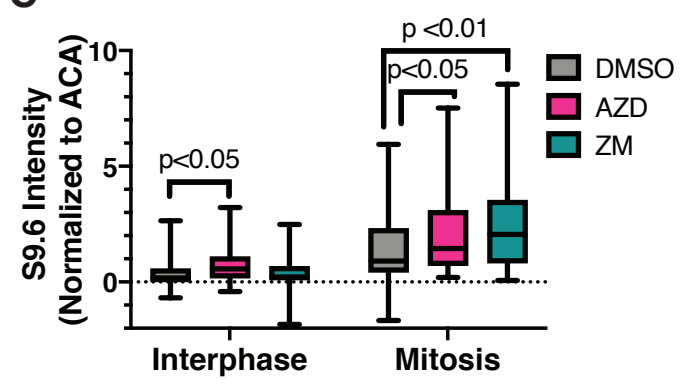

D

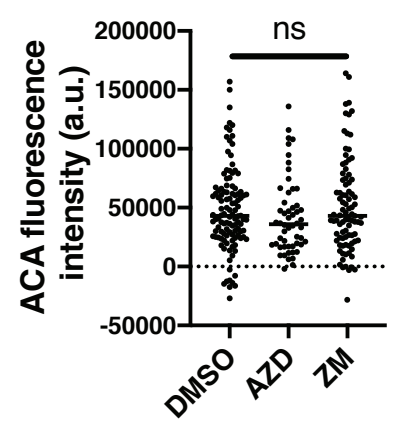

DRIP-qPCR rDNA
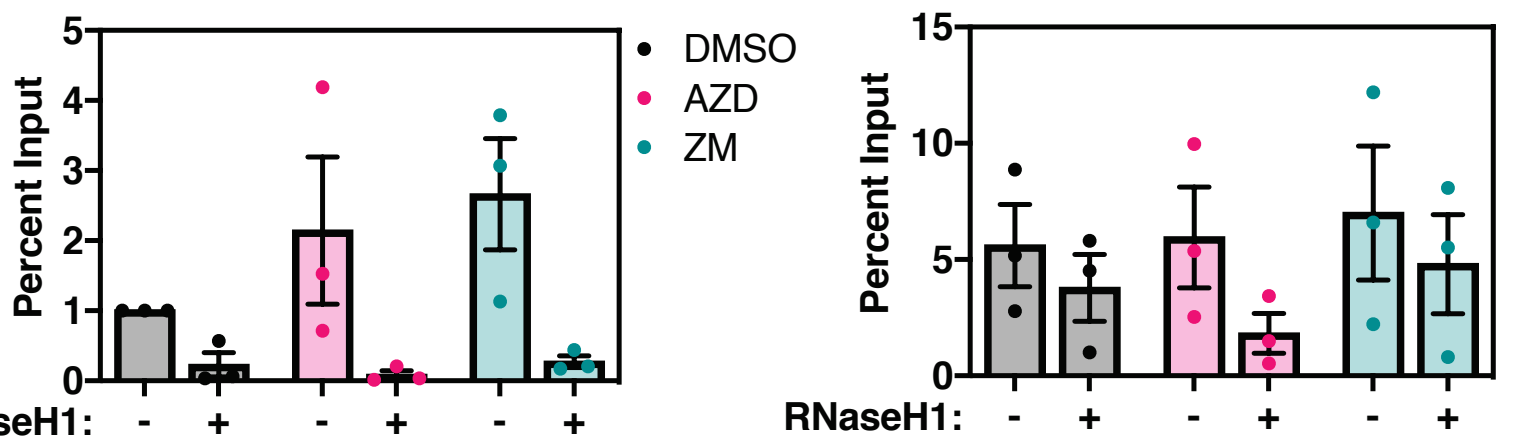

Figure 3. Aurora B activity promotes R-loop resolution in mitosis. 
bioRxiv preprint doi: https://doi.org/10.1101/2021.01.14.426738; this version posted January 15, 2021. The copyright holder for this preprint

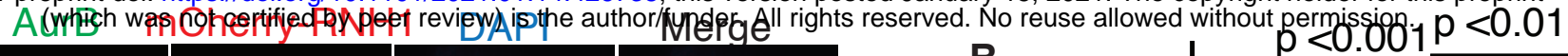

A

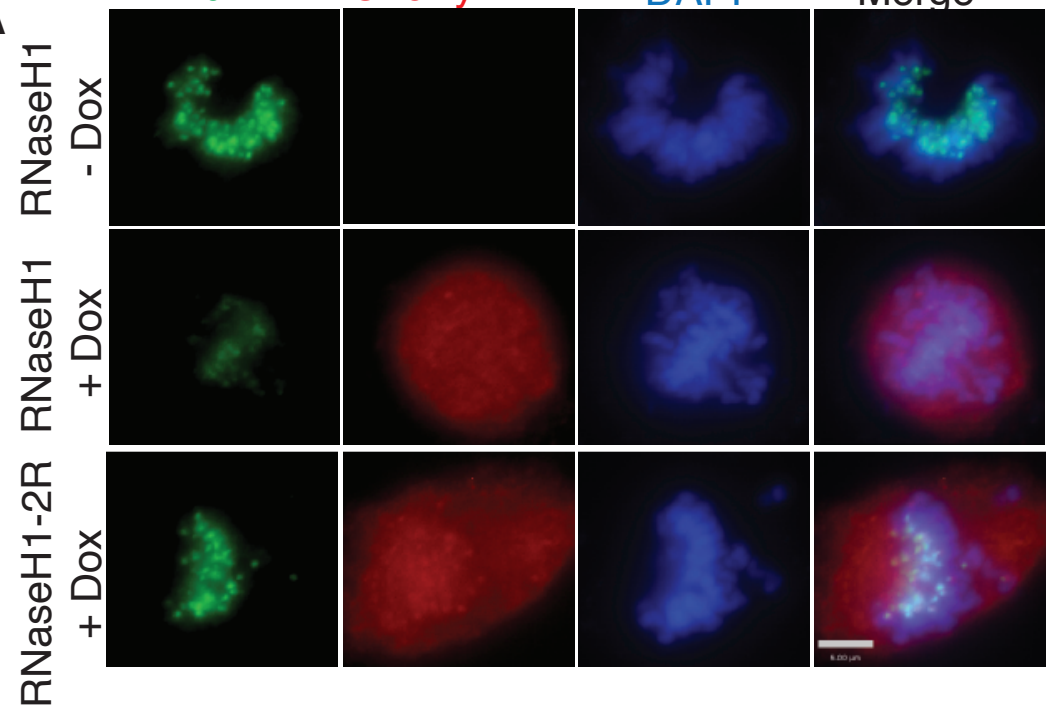

C

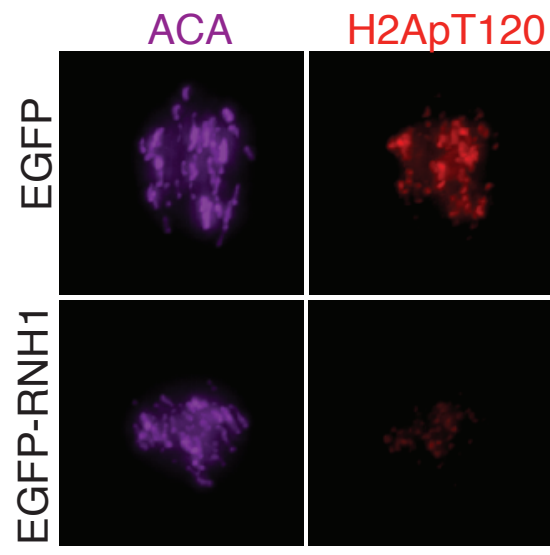

E

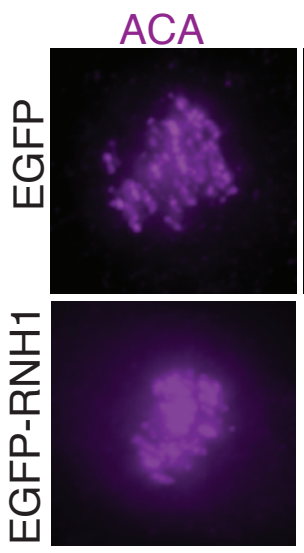

B

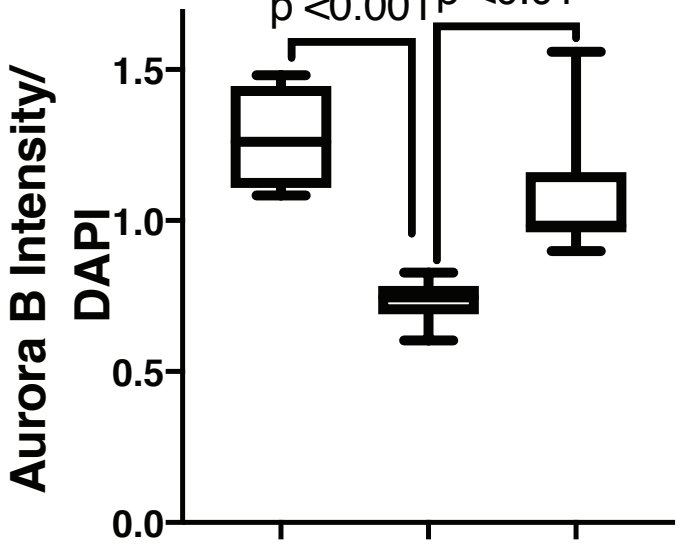

RNaseH1: WT WT $2 R$

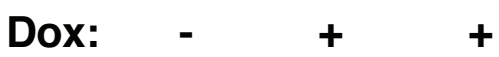

D 4

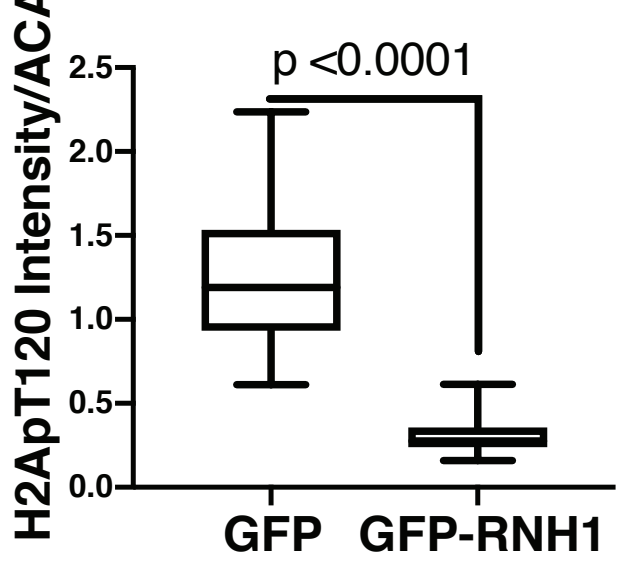

F

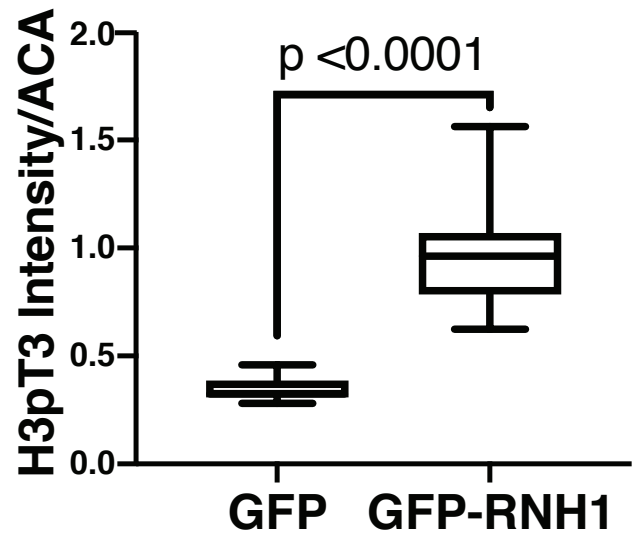

Figure 4. R-loop presence is necessary to localize AuroraB. 


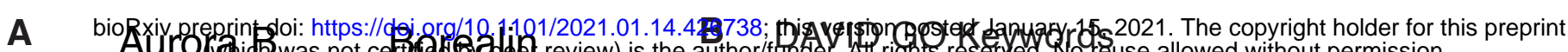

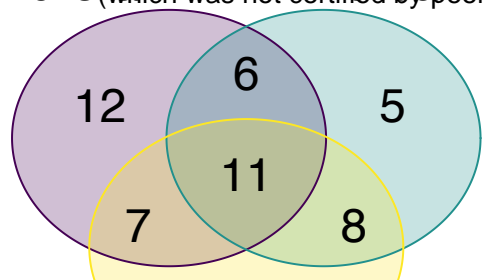

62

C

D
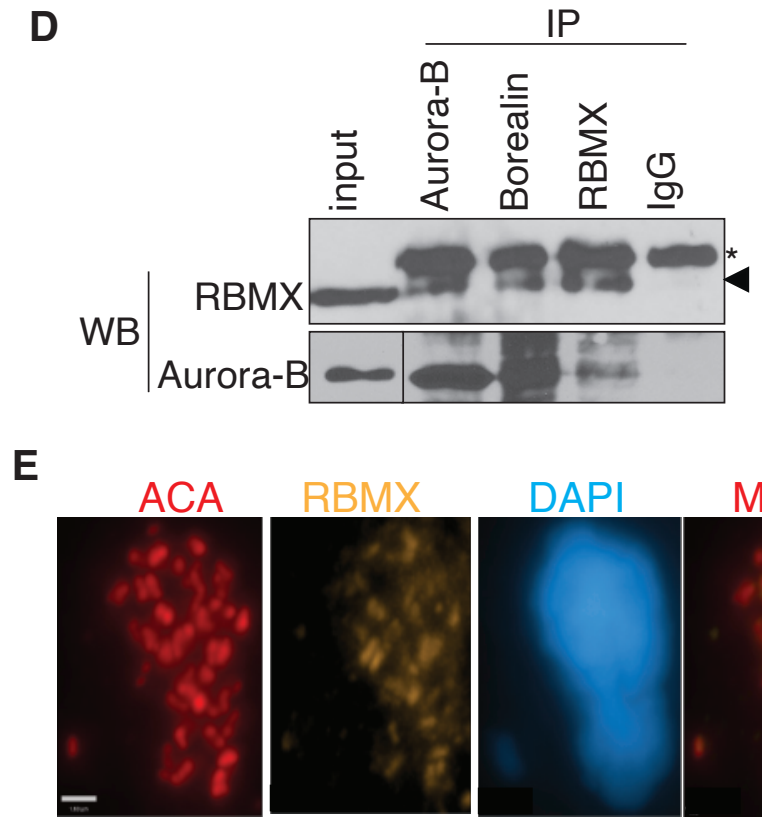

F

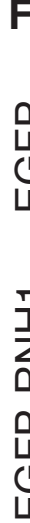

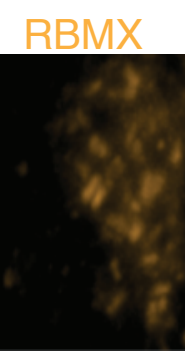

DAPI

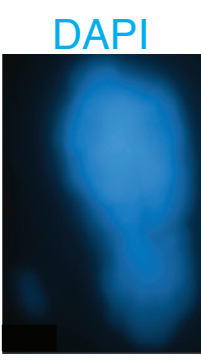

RBMX
Merge

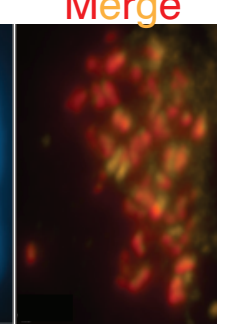

Merge
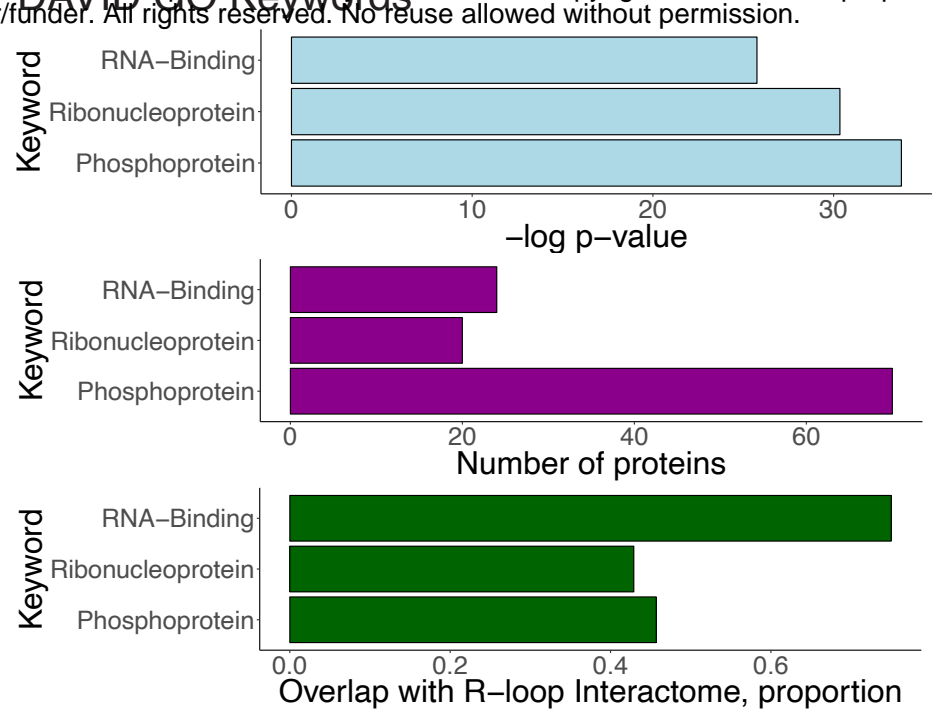

G

H

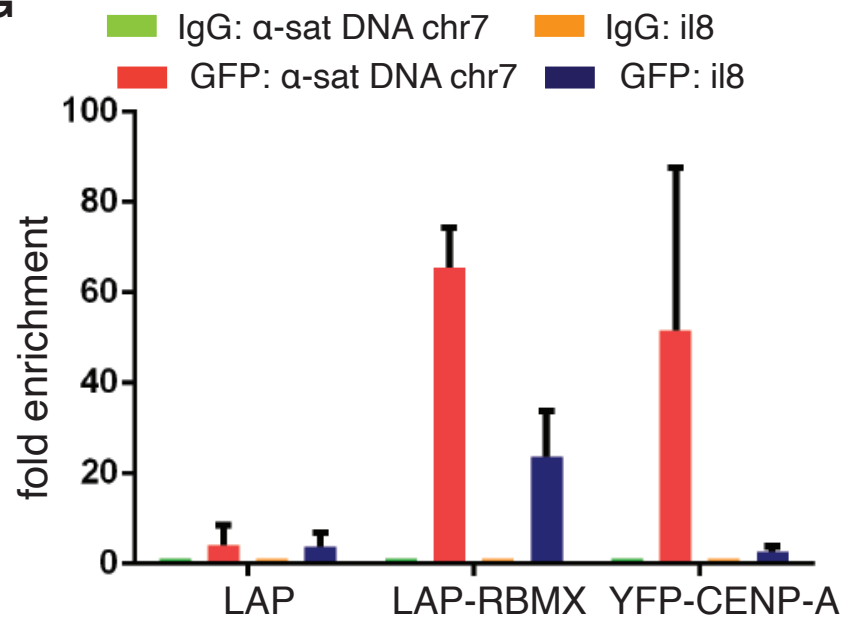

PLA

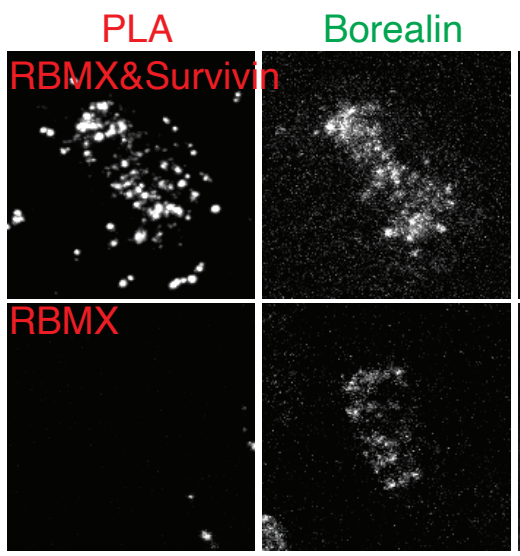

F' RBMX RNaseH OE

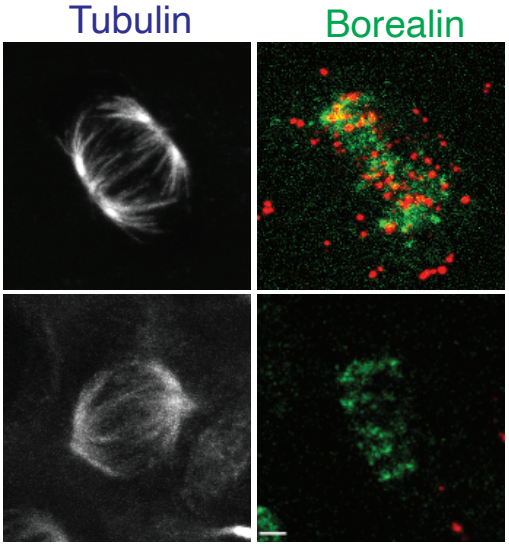

Interphase RBMX signal
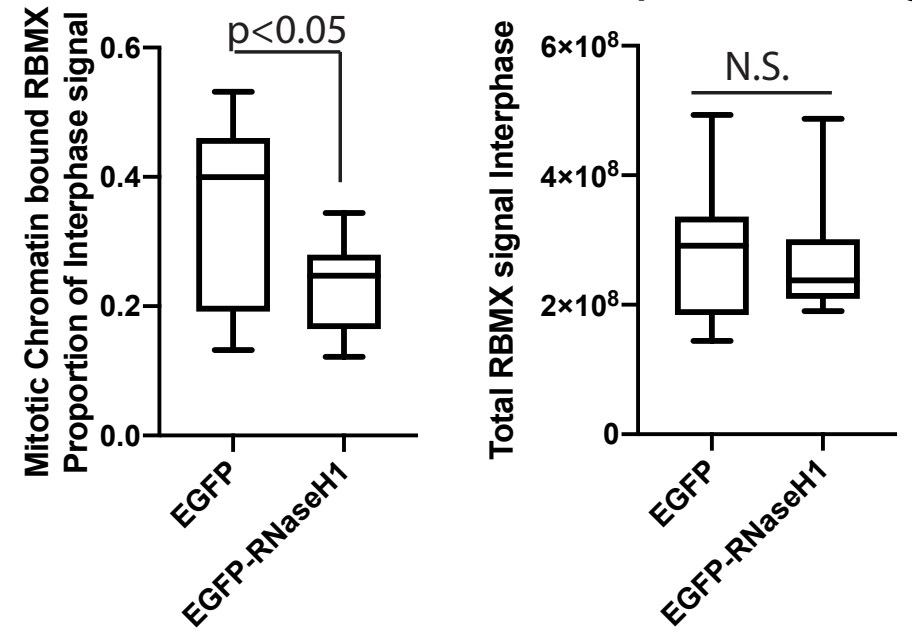

Figure 5. RBMX associates with the CPC and R-loops. 
bioRxiv preprint doi: https://doi.org/10.1101/2021.01.14.426738; this version posted January 15, 2021. The copyright holder for tps $\Varangle Q \mathbb{Q} @ 01$

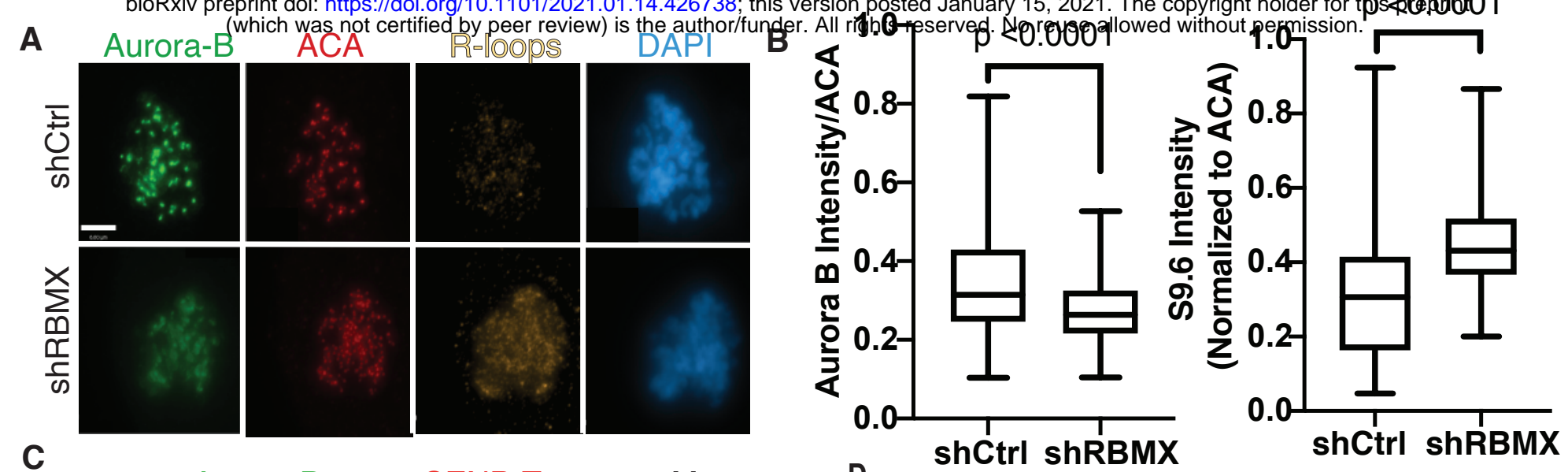

C

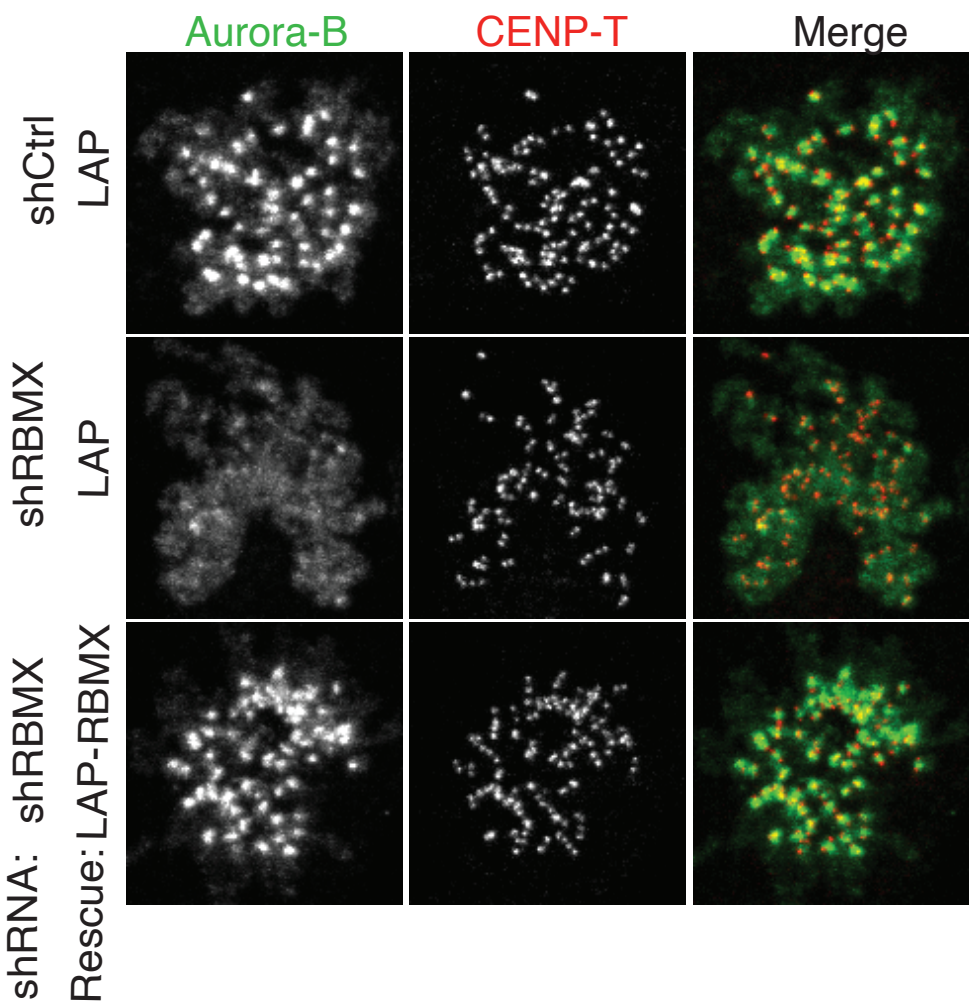

D

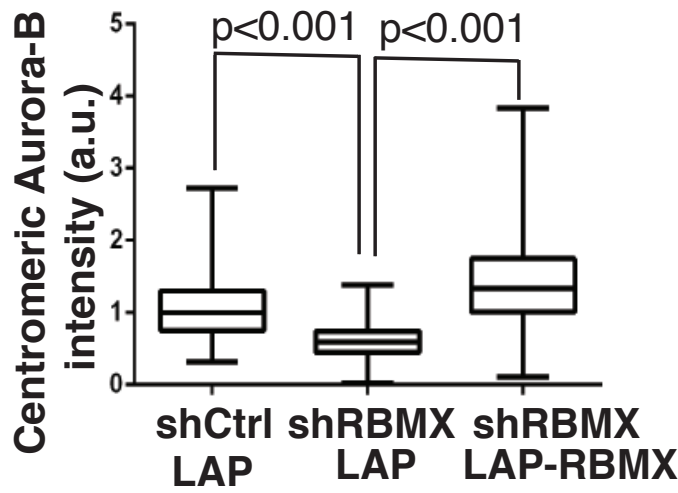

E

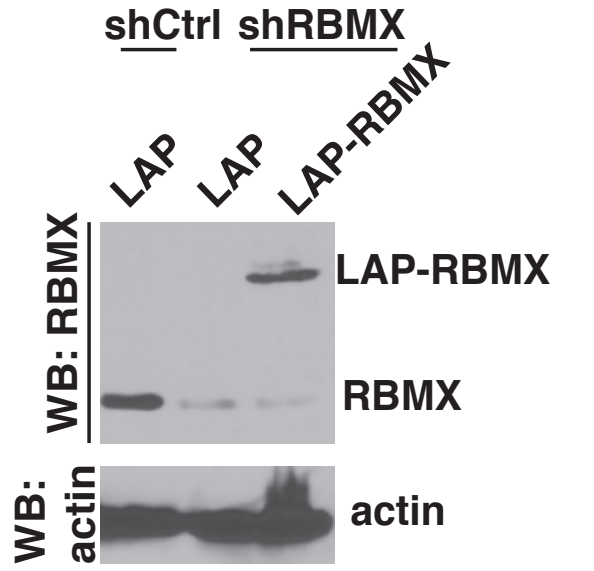

Figure 6. RBMX is necessary to resolve R-loops and localize Aurora B. 
A bioRxiv preprint doi: https://doi.org/10.1101/2021.01.14.42638; this version posted January 15,2021 . The copyright holder for this preprint
(which was not certified by peer review) is a
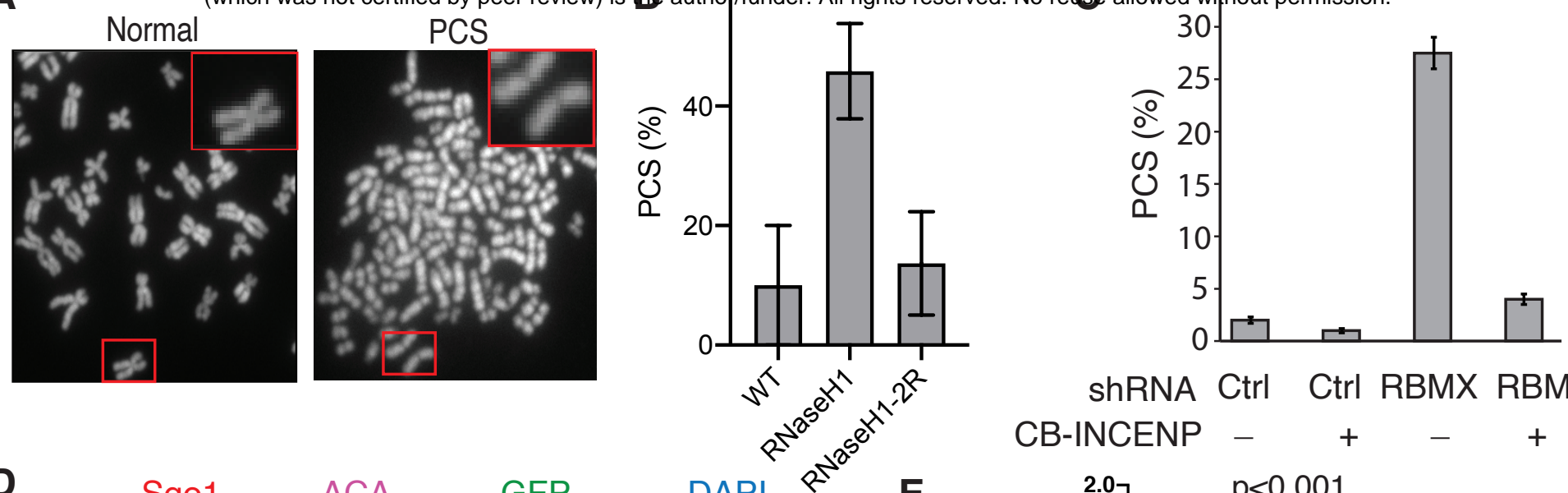
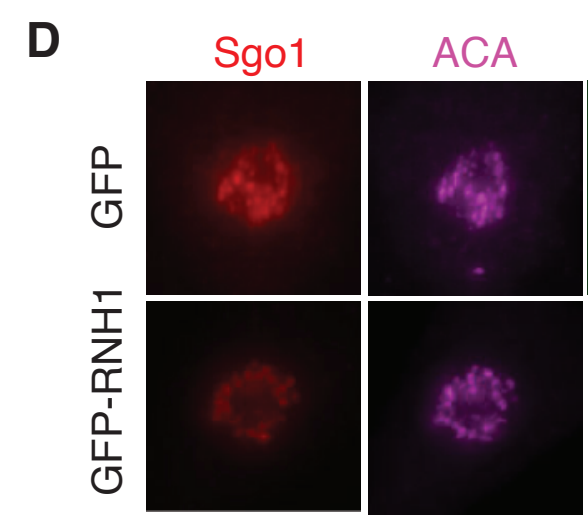

GFP

$\mathbf{F}$

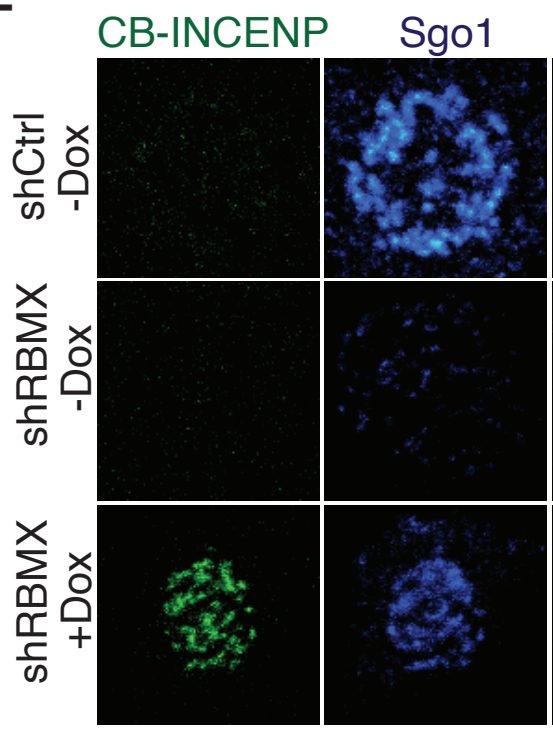

Aurora-B
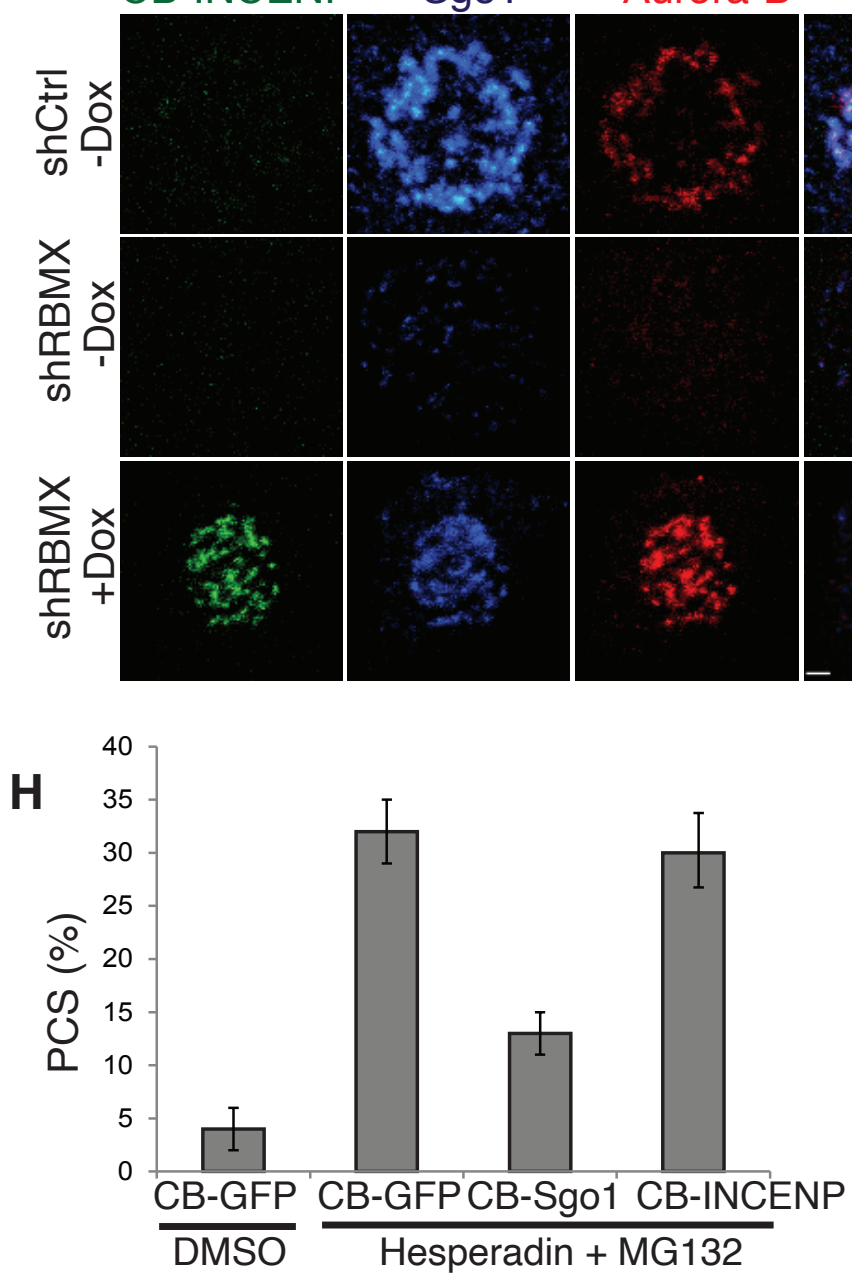

DAPI

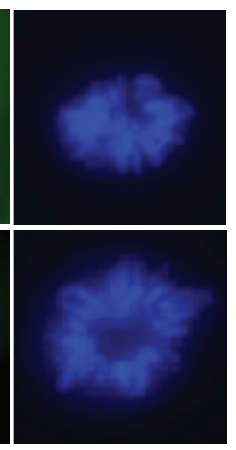

Merge
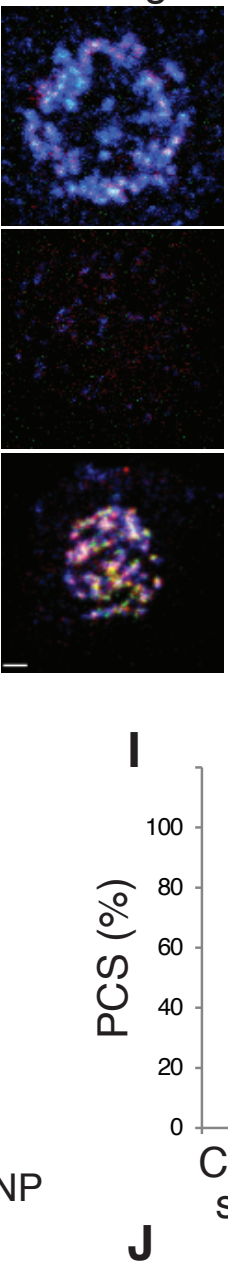

$E$

shRNA Ctrl Ctrl RBMX RBMX CB-INCENP $-t_{-} \quad-\quad+$

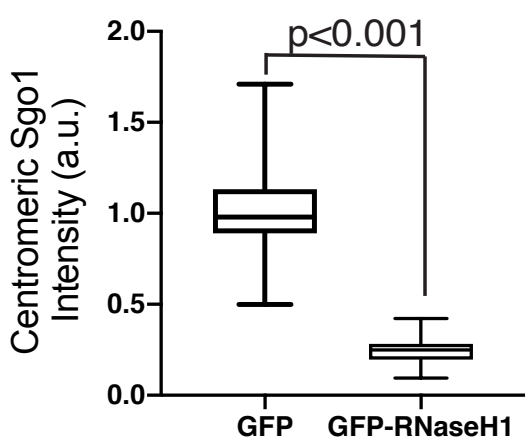

G

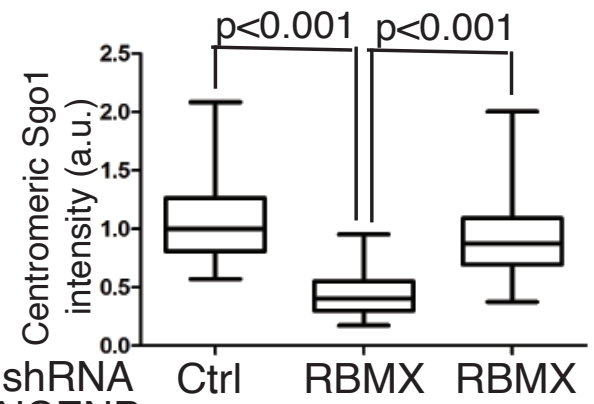
CB-INCENP

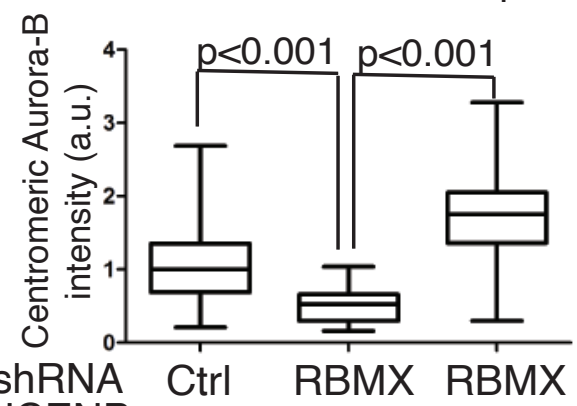

CB-INCENP
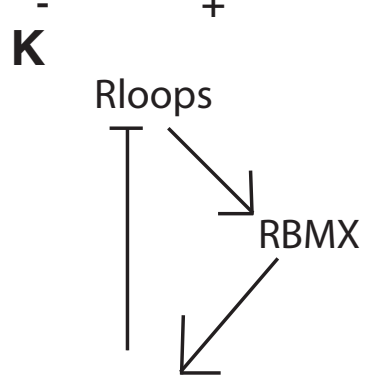

Aurora B

CB-GFP CB-GFP CB-INCENP shCtrl shSgo1 shSgo1

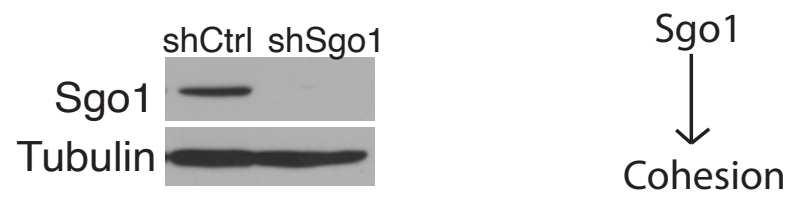


bioRxiv preprint doi: $h$ ttps://doi.org/10.1101/2021.01 14.426738; this version posted January 15, 2021. The copyright holder for this preprint

A

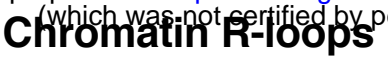
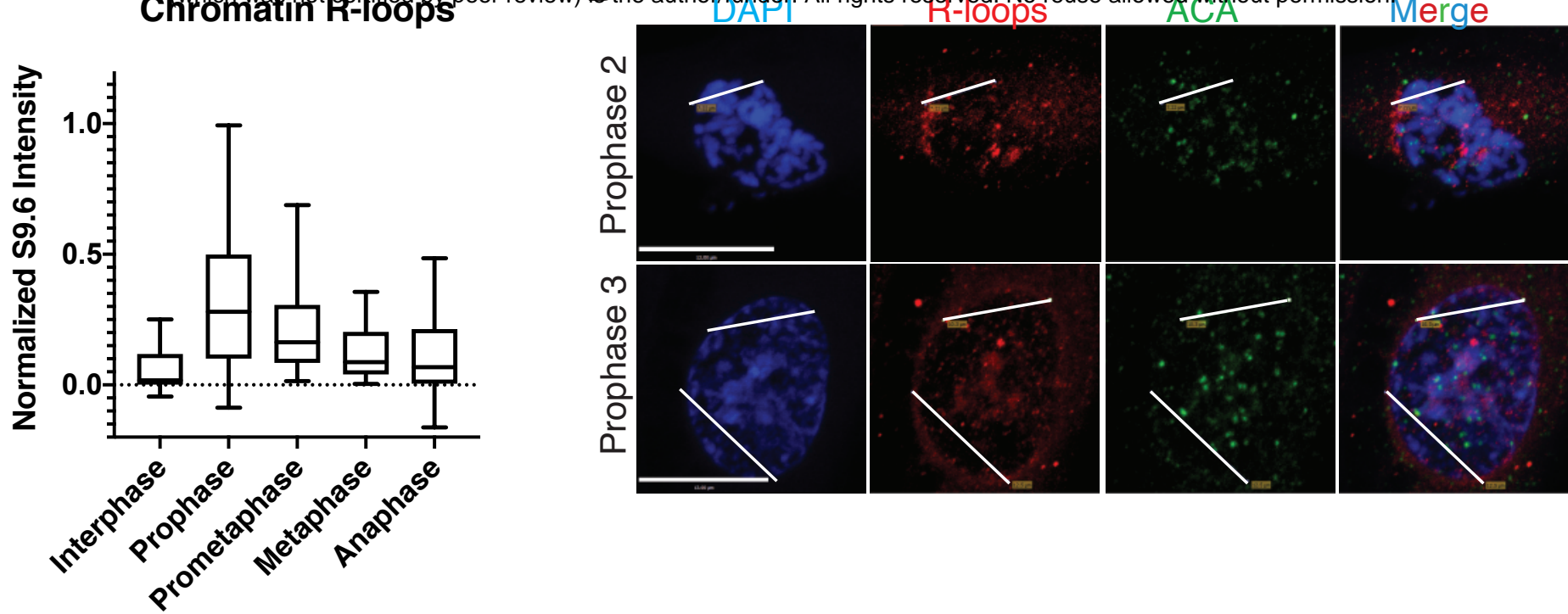

C

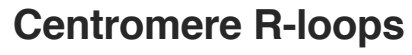

Chromatin R-loops
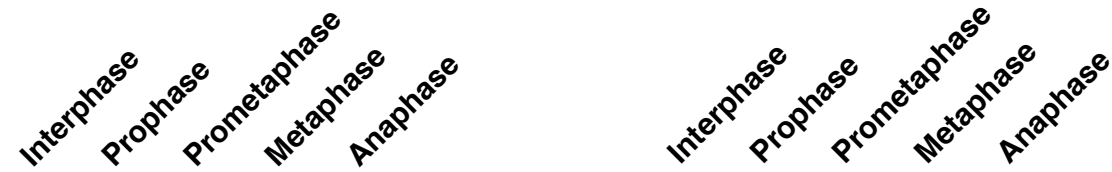

\section{Arm R-loops}
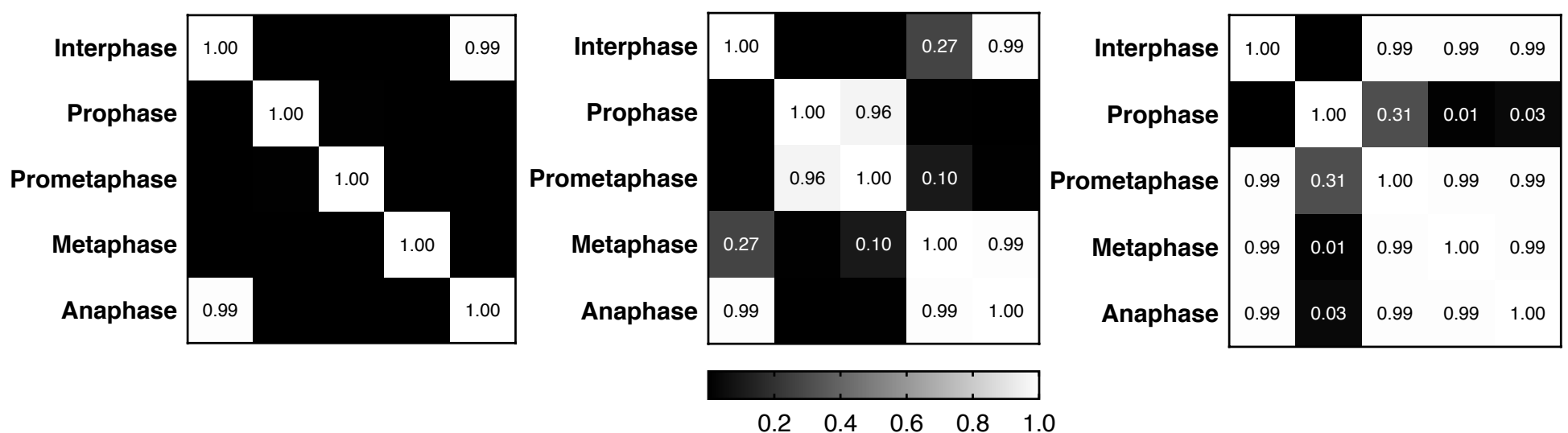

Supplemental figure 1. R-loops are associated with condensing chromatin. 
bioRxiv preprint doi: https://doi.org/10.1101/2021.01.14.426738; this version posted January 15, 2021. The copyright holder for this preprint (which was not certified by peer review) is the author/Qnder. QhipometiphAlloopsallo

A

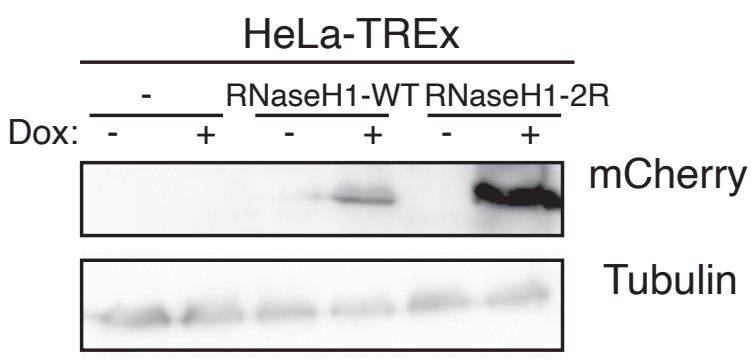

B

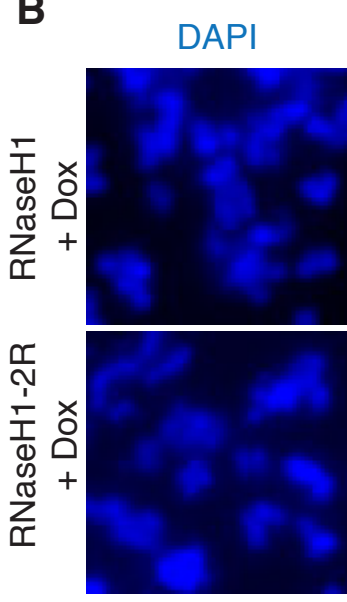

E

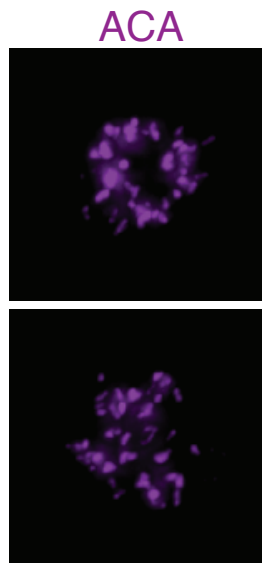

G

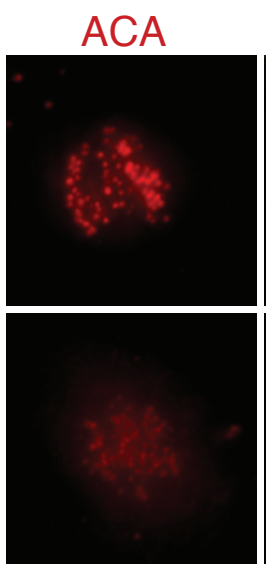

ACA

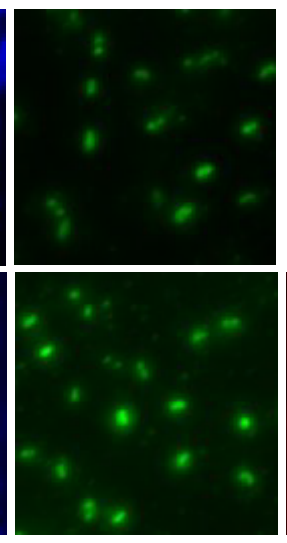

AurB pT232
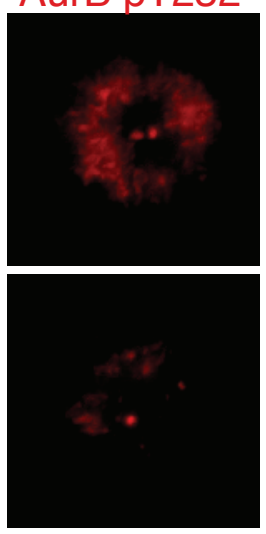

R-loops
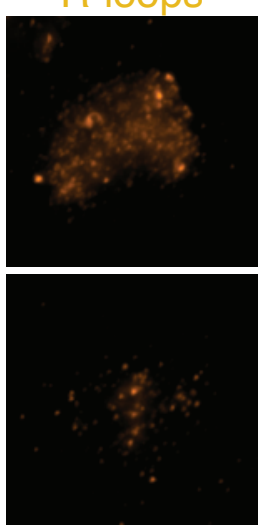

mCherry

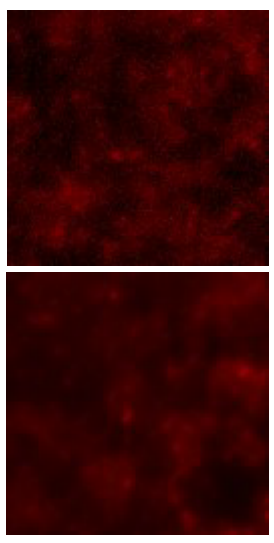

GFP

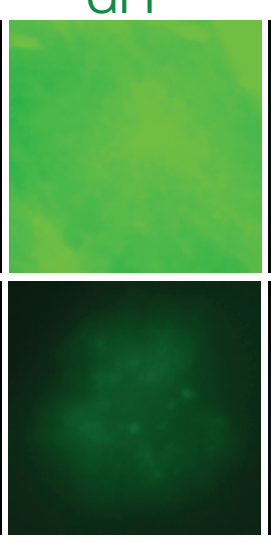

GFP

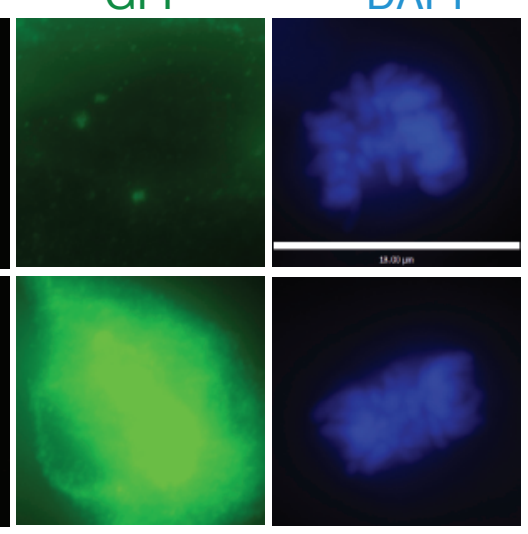

R-loops

DAPI
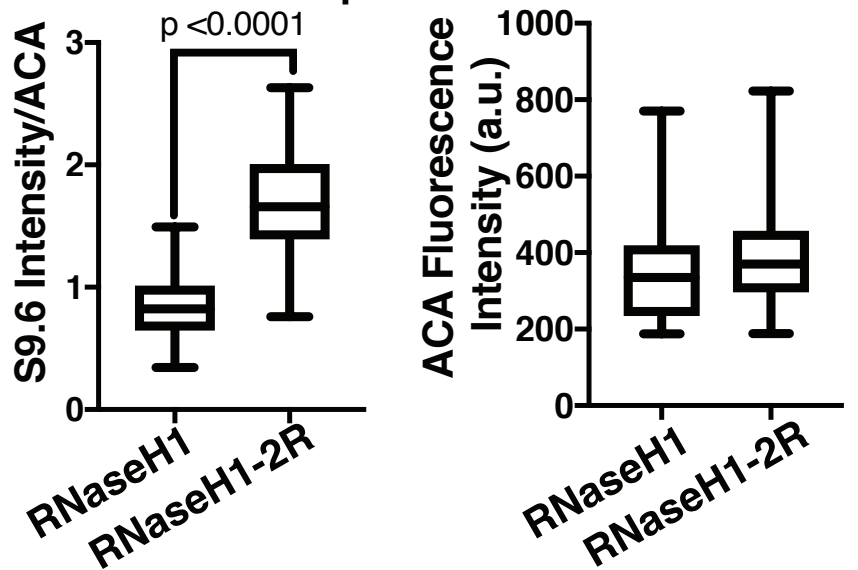

Merge

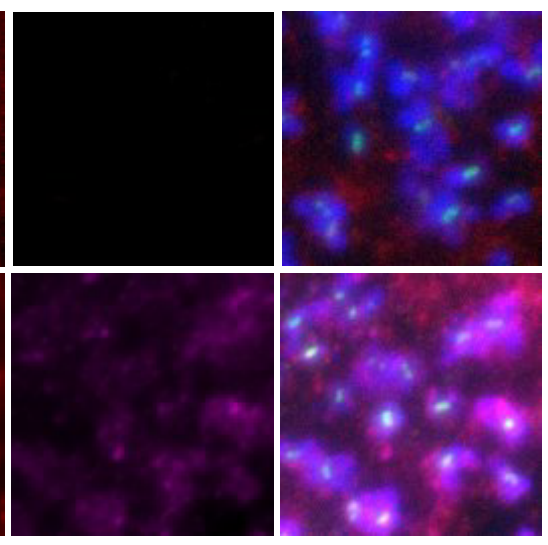

$\mathbf{F}$

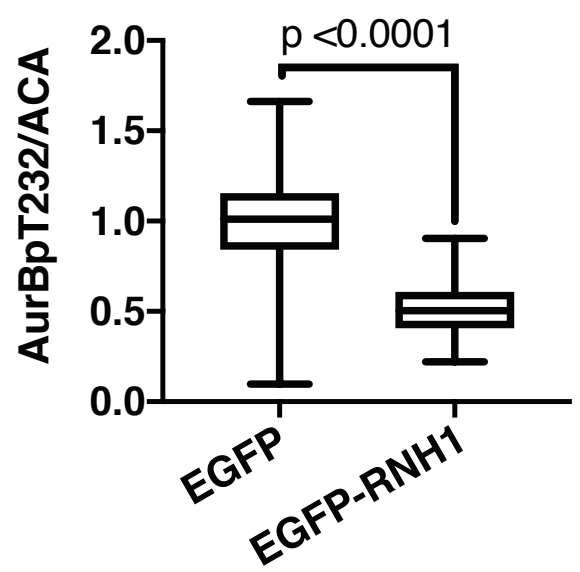

H
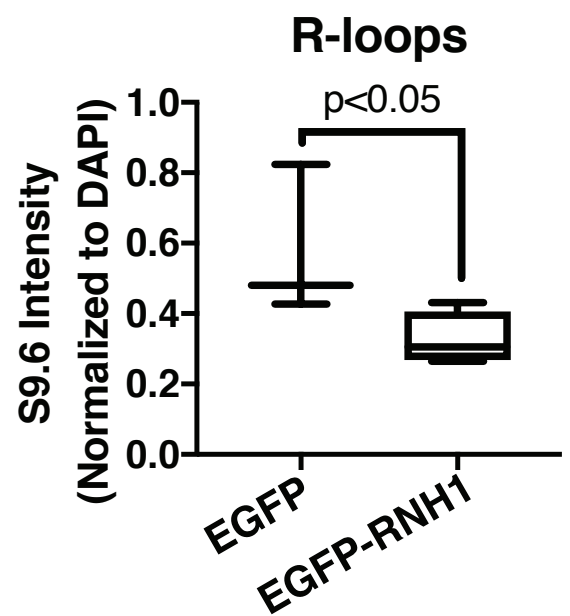

Supplemental figure 2. RNaseH1 overexpression controls R-loop prevalence, Aurora B activation 
bioRxiv preprint doi: https://doi.org/10.1101/2021.01.14.426738; this version posted January 15, 2021. The copyright holder for this preprint (which was not certified by peer review) is the author/funder. All rights reserved. No reuse allowed without permission.

A

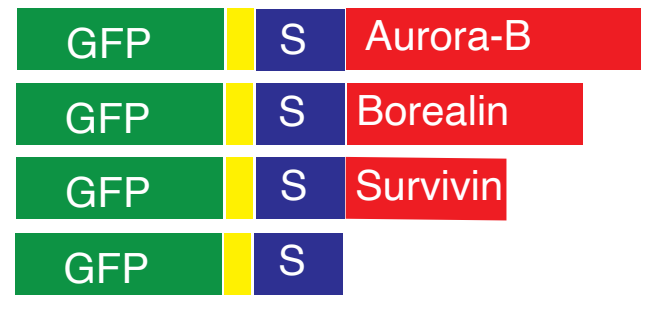

C

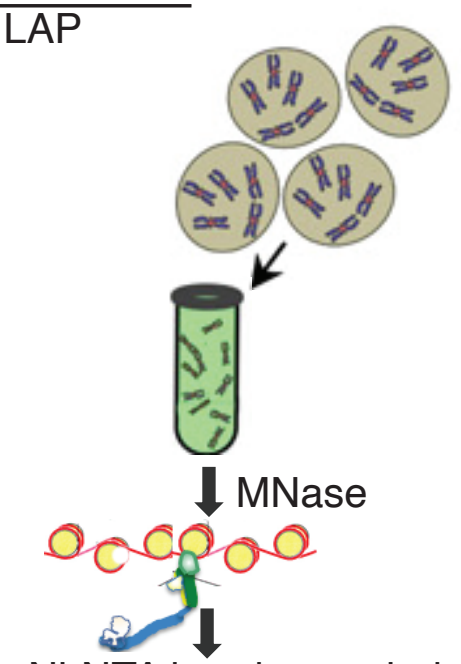

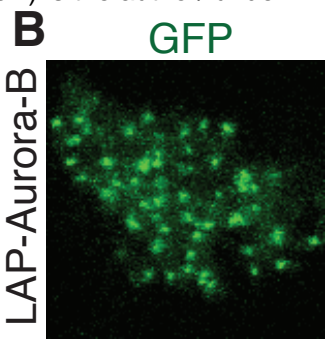
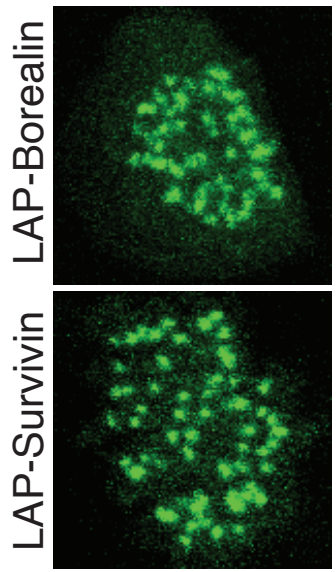

Borealin
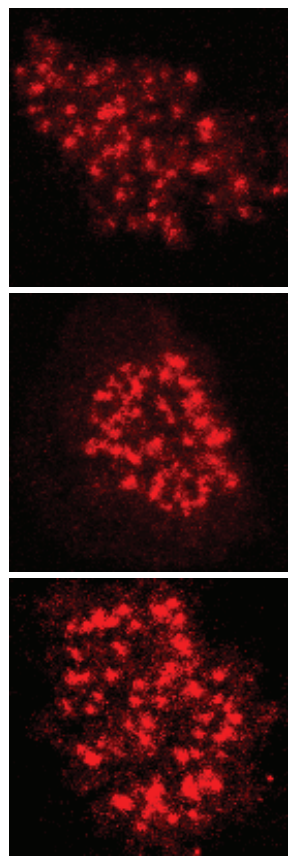

CENP-A
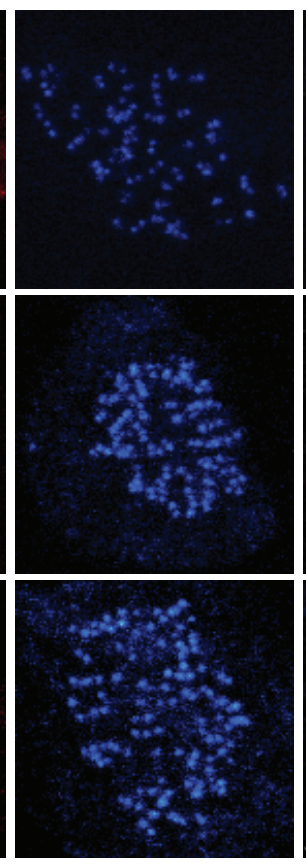

Merge
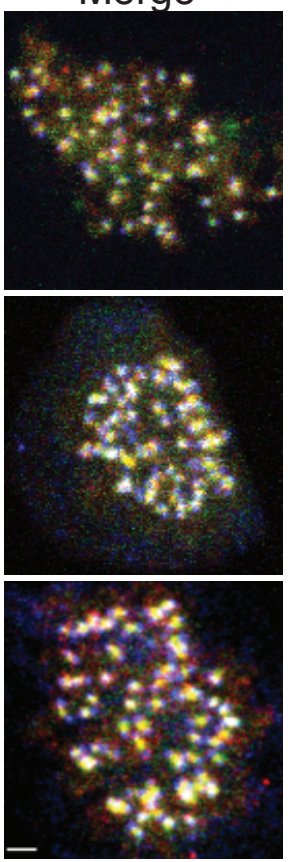

Purify with Ni-NTA beads coupled with GBP

Elute with imidazole

Repurify with S-protein beads

$\downarrow$ Elute with Urea MudPIT
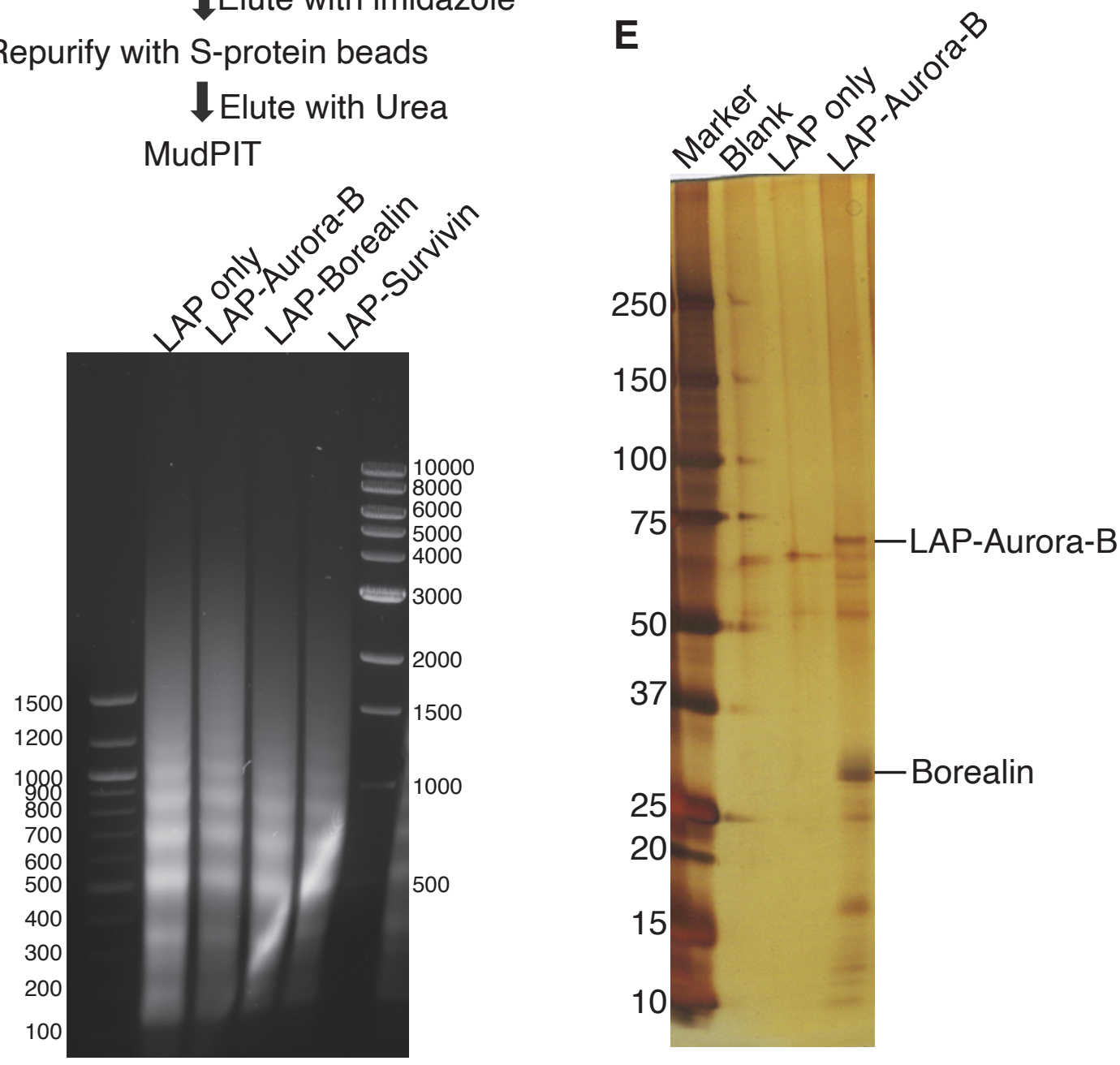

Supplemental figure 3. Validation of MudPiT analysis of CPC members. 


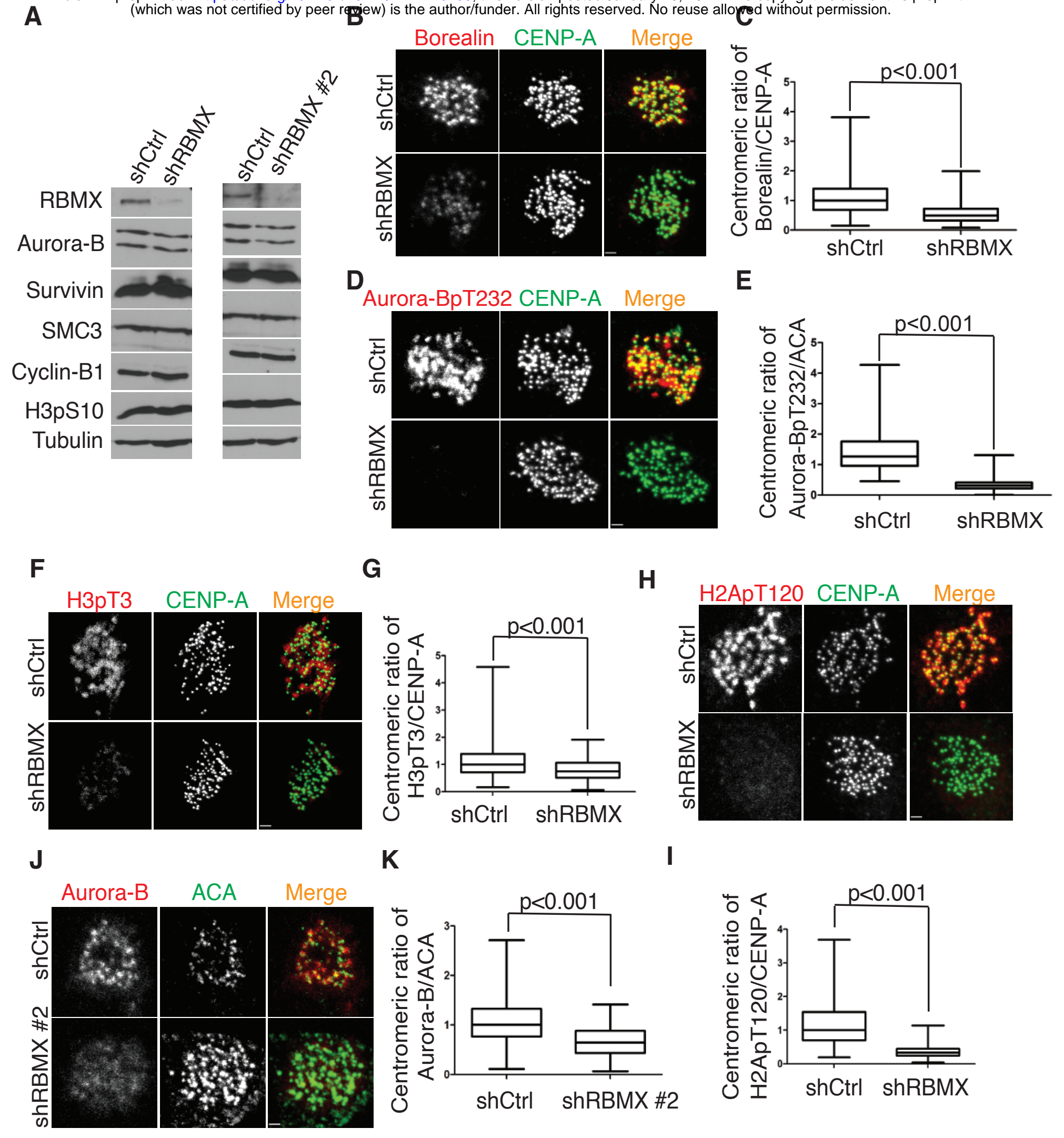
ced without permission.

Supplemental figure 4. RBMX is necessary to localize the CPC and CPC localization signals. 

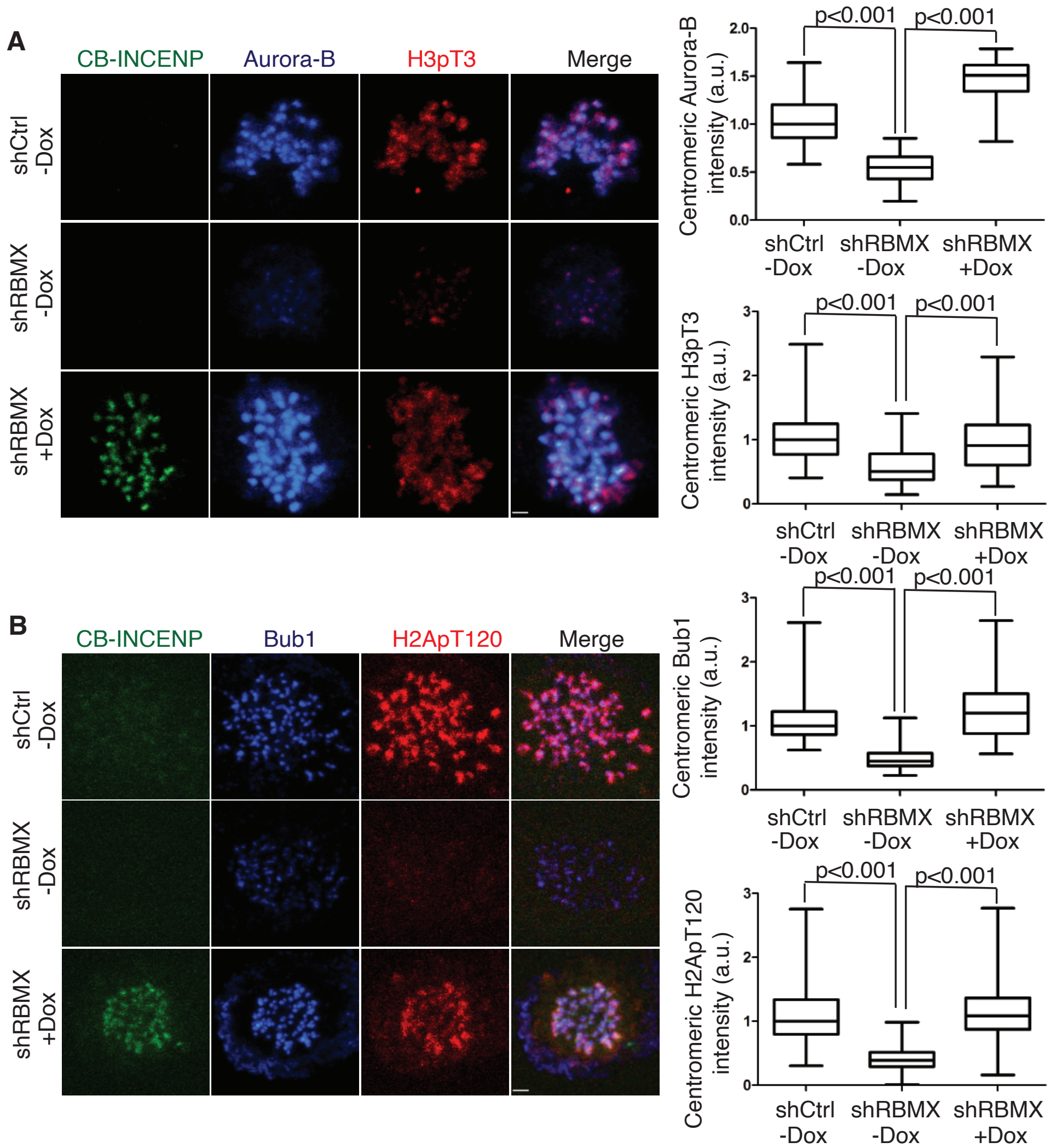

Supplemental figure 5. RBMX is necessary to localize the CPC and CPC localization signals in an Aurora B activity dependent manner. 
A bioRxiv preprint doi: $h$ ttps://doi.org/10.1101/2021.01.14.4 738 ; this version posted January 15, 2021. The copyright holder for this preprint
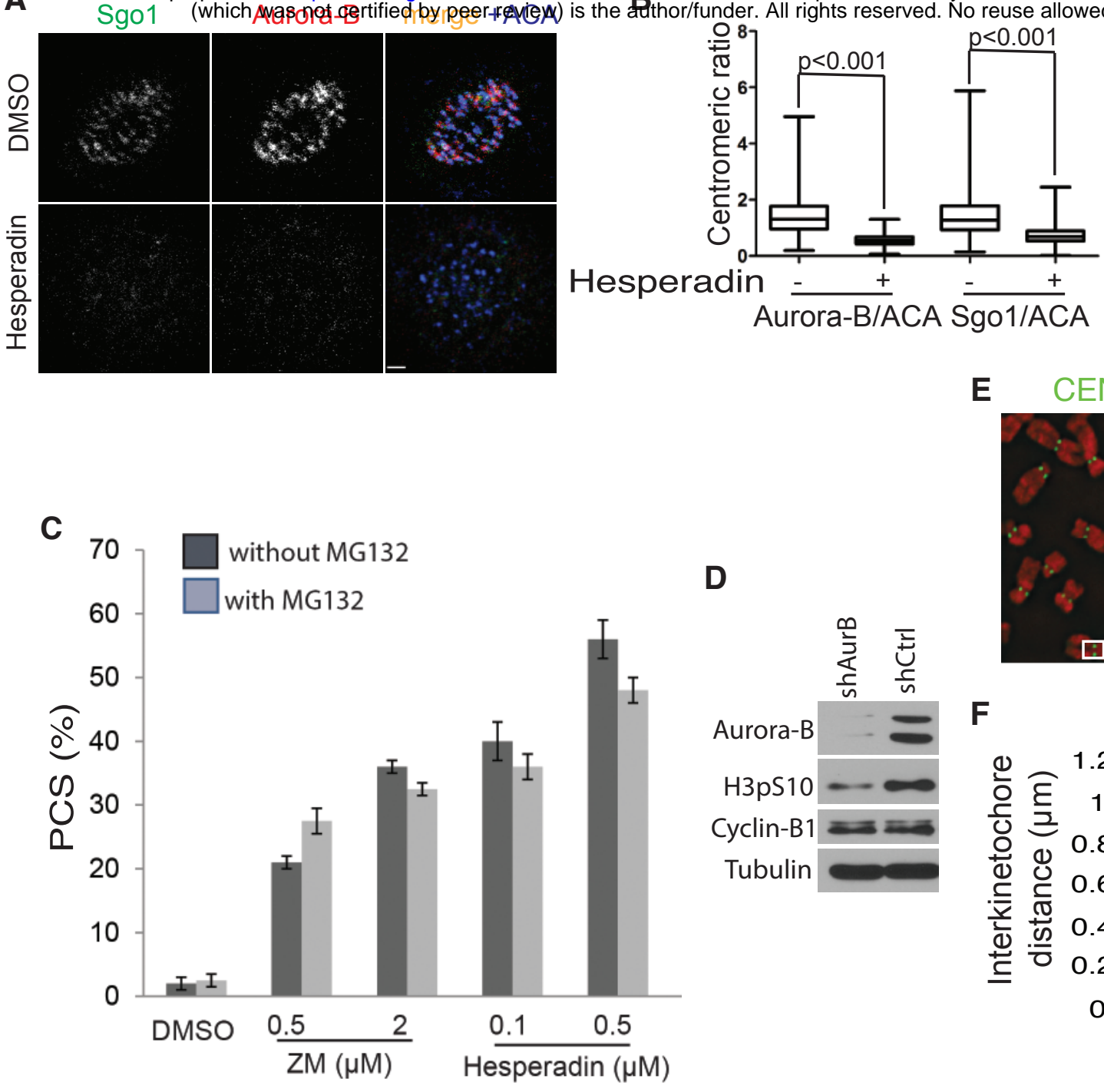

D

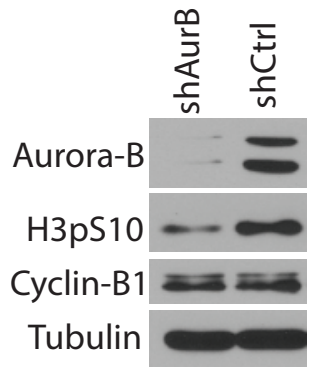

E CENP-A/DAPI

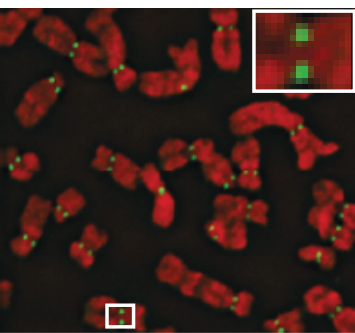

$F$

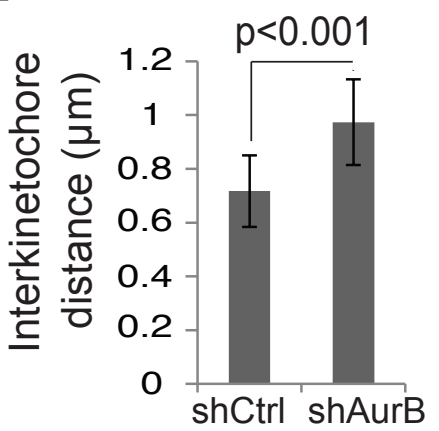

Supplemental figure 6. Aurora B controls localization of Sgo1, centromeric cohesion 